\title{
Geotechnical properties of compacted biosolids for monofill design, As-Samra, Jordan
}

Brendan C. O'Kelly PhD, FTCD, CEng, CEnv, MICE

Associate Professor, Department of Civil, Structural and Environmental Engineering, Trinity College Dublin, Dublin, Ireland

(corresponding author: bokelly@tcd.ie)

\author{
Nicolas K. Oettle PhD, PE, GE \\ Senior Geotechnical Engineer, AECOM, San Jose, CA, USA \\ Jose A. Ramos PE \\ Senior Geotechnical Engineer, AECOM, Chelmsford, MA, USA
}

This paper presents the results of a comprehensive geotechnical laboratory testing for the assessment and design of a proposed biosolid monofill facility at the As-Samra Waste Water Treatment Plant (WWTP) in Jordan. Previous landfill operations for biosolid materials typically involved co-disposal or lagooning of the dewatered biosolid slurry. However, it is proposed that the solar-dried As-Samra WWTP biosolid material will be placed in a new monofill facility at the site. This approach is suited to the As-Samra desert climate, since the material's water content can be readily reduced to between 60 and $100 \%$ in evaporation lagoons. New insights were gained on the strength and compressibility of the non-inundated and saturated compacted biosolid materials, including their (a) very low normalised undrained strength ratio and effective angle of shearing resistance values for the saturated normally consolidated states of 0.14 and $15^{\circ}$, respectively; (b) very high strain rate dependency of strength; and (c) extremely low permeability coefficient values on the order of $10^{-12} \mathrm{~m} / \mathrm{s}$ for compaction at approximately $100 \%$ water content. The paper concludes with recommendations on the appropriate water content range for compaction of the material in the proposed monofill and the selection of design strength values for geotechnical stability analysis.

\section{Notation}

$A, B$ pore pressure coefficients

$A_{\mathrm{f}} \quad$ pore pressure coefficient $A$ at failure

$C_{\mathrm{c}} \quad$ compression index

$C_{\mathrm{R}} \quad$ compression ratio (in terms of strain)

$C_{\mathrm{r}} \quad$ recompression index

$C_{\alpha} \quad$ secondary compression coefficient (in terms of strain)

$C_{\alpha \mathrm{e}} \quad$ secondary compression coefficient (in terms of void ratio)

$c^{\prime} \quad$ cohesion intercept (effective stress)

$c_{\text {DSS }}^{\prime} \quad$ cohesion intercept from direct simple shear testing

$c_{\mathrm{TC}}^{\prime} \quad$ cohesion intercept from triaxial compression testing

$c_{\mathrm{TE}}^{\prime} \quad$ cohesion intercept from triaxial extension testing

$c_{\mathrm{v}} \quad$ coefficient of consolidation

$D_{10} \quad$ effective grain size

$d \quad$ specimen diameter

e void ratio

$e_{\mathrm{f}} \quad$ final void ratio

$e_{\mathrm{i}} \quad$ initial void ratio

G shear modulus

$I_{\mathrm{P}} \quad$ plasticity index

$k_{\mathrm{v}} \quad$ permeability coefficient for vertical flow condition

$M_{\mathrm{TC}} \quad$ gradient of triaxial compression failure line in $p^{\prime}-q^{\prime}$ space

$M_{\mathrm{TE}} \quad$ gradient of triaxial extension failure line in $p^{\prime}-q^{\prime}$ space

$m \quad$ at-rest rebound parameter

$m_{\mathrm{v}} \quad$ coefficient of volume compressibility

$N \quad$ loss on ignition

$n \quad$ number of experimental measurements

$p^{\prime} \quad$ mean effective stress

$q^{\prime} \quad$ deviatoric stress

$q_{\mathrm{f}}^{\prime} \quad$ peak deviatoric stress
$R^{2} \quad$ coefficient of determination

$R_{\mathrm{R}} \quad$ recompression ratio (in terms of strain)

$S_{\mathrm{c}} \quad$ solids content

$S_{\mathrm{r}} \quad$ degree of saturation

$S_{\mathrm{uLV}} \quad$ laboratory vane strength

$s_{\text {uTC }} \quad$ undrained shear strength in triaxial compression

$t \quad$ stage duration (time period)

$u_{\mathrm{b}} \quad$ back pressure

$u_{\mathrm{e}} \quad$ excess pore water pressure

$w \quad$ gravimetric water content

$w_{\mathrm{f}} \quad$ water content during shearing stage

$w_{\mathrm{i}} \quad$ initial water content

$w_{\mathrm{L}} \quad$ liquid limit

$w_{\text {opt }} \quad$ optimum water content for compaction

$w_{\mathrm{P}} \quad$ plastic limit

$w_{\mathrm{S}} \quad$ shrinkage limit

$\gamma \quad$ shear strain

$\dot{\gamma} \quad$ shear strain rate

$\gamma_{d} \quad$ dry unit weight

$\varepsilon_{\mathrm{a}} \quad$ axial (vertical) strain

$\dot{\varepsilon}_{\mathrm{a}} \quad$ axial strain rate

$\varepsilon_{\mathrm{v}} \quad$ volumetric strain

$\dot{\theta}$ angular rotation rate

$\rho_{\mathrm{s}} \quad$ particle density

$\rho_{\mathrm{w}} \quad$ density of water

$\sigma \quad$ standard deviation

$\sigma_{\mathrm{c}} \quad$ cell pressure

$\sigma_{\mathrm{s}} \quad$ swelling pressure

$\sigma_{\mathrm{v}} \quad$ applied vertical stress

$\sigma_{\mathrm{c}}^{\prime} \quad$ effective cell pressure 
$\sigma_{\mathrm{ci}}^{\prime} \quad$ effective cell pressure at start of shearing stage

$\sigma_{\max }^{\prime}$ pre-consolidation pressure

$\sigma_{\mathrm{v}}^{\prime} \quad$ effective vertical stress

$\sigma_{\mathrm{vc}}^{\prime} \quad$ pre-shear vertical consolidation stress

$\tau_{\text {DSS }} \quad$ shear resistance in direct simple shear

$\tau_{\mathrm{fDSS}}$ shear strength for direct simple shear condition

$\tau_{\text {f TC }}$ shear strength for triaxial compression condition

$\tau_{\mathrm{fTE}} \quad$ shear strength for triaxial extension condition

$\tau_{\mathrm{TC}} \quad$ shear resistance in triaxial compression

$\phi^{\prime} \quad$ effective angle of shearing resistance

$\phi_{\mathrm{cv}}^{\prime} \quad$ critical state angle of shearing resistance

$\phi_{\mathrm{DS}}^{\prime} \quad$ effective angle of shearing resistance from direct shear testing

$\phi_{\text {DSS }}^{\prime} \quad$ effective angle of shearing resistance from direct simple shear testing

$\phi_{\mathrm{NC}}^{\prime} \quad$ effective angle of shearing resistance for normally consolidated state

$\phi_{\mathrm{TC}}^{\prime} \quad$ effective angle of shearing resistance from triaxial compression testing

$\phi_{\mathrm{TE}}^{\prime} \quad$ effective angle of shearing resistance from triaxial extension testing

$\phi_{\mathrm{u}} \quad$ undrained angle of shearing resistance (total stress)

\section{Introduction}

Biosolid (sewage sludge) material is the residue by-product of wastewater treatment processes. This manufactured soil is a difficult, challenging and unconventional geomaterial with an extremely high water content; high organic content; very high compression, swelling and shrinkage potentials and extremely low permeability coefficient values, with a propensity to degrade and produce copious amounts of biogas (Arulrajah et al., 2011, 2013; Aydilek et al., 2000; Chen et al., 2014; Diliūnas et al., 2010; Disfani et al., 2015; Kayser et al., 2011; Klein and Sarsby, 2000; Koenig et al., 1996; Lin et al., 2013, 2014; Lo et al., 2002; O'Kelly, 2006a, 2008a, 2013a, 2013b, 2016a, 2016b, 2016c, 2018a, 2018b; Sarsby, 2005; Stone et al., 1998; Zhan et al., 2014).

The background to the present investigation was to facilitate the development of a large biosolid disposal facility at the site of the As-Samra Waste Water Treatment Plant (WWTP), located in the Hashemite Kingdom of Jordan, for the purposes of providing an environmentally sensitive and protective means for the disposal and management of the biosolid material produced from this treatment plant for a targeted minimum 20-year period. The As-Samra WWTP is one of the biggest WWTPs in the region, presently serving a population of approximately $2 \cdot 27$ million people, mainly in Amman and Zarqa, Jordan. At the As-Samra WWTP facility, the biosolid residues produced by the anaerobic digestion process are dewatered by the application of mechanical pressure within a belt filter press device. The caked solids are then stored and allowed to solar dry in lined lagoons for approximately 2-3 months in order to reduce the gravimetric water content value $(w$, in per cent) to approximately $100 \%$ (the value of the solids content $\left(S_{\mathrm{c}}\right.$ in per cent), normally used in environmental engineering, can be determined from the water content value as
$\left.S_{\mathrm{c}}=100 /[1+(w / 100)]\right)$. As-Samra has a desert climate, characterised by very hot summers and mild winters (mean annual maximum and minimum air temperatures of 25.8 and $13.9^{\circ} \mathrm{C}$, respectively, with an average annual rainfall of $0.123 \mathrm{~m} /$ year (based on 2009-2013 data)). Solar drying can be continued for longer periods in the evaporation lagoons to reduce the water content value further if necessary.

Various disposal options are available to WWTP operators, including the beneficial reuse of the biosolid materials as agricultural fertilisers, for composting, in forestry and for soil redevelopment in mine reclamation, as structural fill materials (e.g. for road embankment construction), as daily cover for landfills or their general disposal in landfills. Biosolid materials disposed of in landfills are often intermixed with typical municipal solid waste (MSW) streams (Koenig and Kay, 1995; Koenig et al., 1996; Lo et al., 2002; Loll, 1991). For these co-disposal landfills, the design for geotechnical stability regularly adopts typical shear strength values and design procedures employed for MSW landfills (Bray et al., 2009; Kavazanjian et al., 1995). Large quantities of dewatered biosolid materials have also been disposed of in single-purpose disposal pits (Lin et al., 2014; Zhan et al., 2014) and lagoons (Aydilek et al., 2000; Klein and Sarsby, 2000), although appropriate design shear strength values for geotechnical stability are often difficult to estimate for these scenarios on account of the complex nature of the materials' behaviour. For instance, high values of the peak effective angle of shearing resistance $\left(\phi^{\prime}\right)$ have been reported for saturated, compacted (e.g. $37 \cdot 2$ and $22 \cdot 3-30 \cdot 3^{\circ}$ in the papers by Arulrajah et al. (2011) and Chen et al. (2014), respectively) and consolidated biosolid materials (e.g. $32^{\circ}$ in the paper of O'Kelly (2006a)), with analogies often drawn to the geomechanical behaviour of (fibrous) peats to explain these high laboratorymeasured values. However, as described by O'Kelly (2013b, 2016b), such analogies are often not helpful for understanding the geomechanical behaviours of biosolid and sewage sludge materials; furthermore, these high $\phi^{\prime}$ values reported for saturated, compacted and consolidated biosolid materials are unrealistic in practice and should not be relied on for geotechnical design.

In many countries, on-site or off-site soil conditioning techniques using additives, such as cement or lime, have been commonly used to improve the shear strength of biosolid stockpiles and lagoon deposits sufficiently and expeditiously (O'Kelly, 2016b). Of these additives, lime is most frequently employed, but because of its high associated cost and main usage for biochemical stabilisation rather than solidification, alternative materials (e.g. fly ash, lime kiln dust, Bauxsol and smelter slag) have been investigated for strength enhancement purposes (Disfani et al., 2015; Kayser et al., 2011; Lin et al., 2013). As a potentially more efficient disposal strategy, O'Kelly (2004) presented the feasibility and anticipated performance of single-purpose landfill (monofill) operations in which the biosolid materials are placed in layers near their optimum water contents for compaction, with these layers individually compacted to maximise the operational life of each monofill site. The design, construction and long-term 
performance aspects of such monofills were subsequently described in the papers by O'Kelly (2005a, 2016a, 2016b).

After exploring the various options available, it was concluded that a monofill would provide the most appropriate disposal route for the biosolid material produced at the As-Samra WWTP, particularly given that its water content can be readily reduced to between 60 and $100 \%$ by solar drying of the caked material in the on-site lagoons. Although a number of researchers have investigated the shear strength properties of biosolid materials produced at different WWTPs located around the world (including Arulrajah et al. (2011, 2013), Chen et al. (2014), Diliūnas et al. (2010), Kayser et al. (2011), Koenig and Bari (2001), Lin et al. (2013), Lo et al. (2002), O'Kelly (2004, 2005a, 2005b, 2006a, 2013a, 2013b, 2016a, 2016b, 2018b), Sarsby (2005); Stone et al. (1998) and Zhan et al. (2014)), nevertheless it remains notoriously difficult to estimate appropriate shear strength values from the available literature for performing stability evaluations of compacted biosolid monofills. Principal reasons include $(a)$ the compositions of the wastewater streams can vary significantly from one geographic location to another and $(b)$ a variety of pretreatment processes are employed at the WWTPs, along with different chemical mixing and residue dewatering options, such that from a geotechnical standpoint, the biosolid materials produced can have very different (a wide range of) water and organic contents, and hence geomechanical properties and behaviour (O'Kelly, 2016b). In other words, the values of the geotechnical properties reported for biosolid materials are generally WWTP specific. There is also a lack of documented field shear strength data for biosolid monofills. Further, compared with inorganic soils, biosolid materials have a propensity to degrade, often producing copious amounts of biogas, and their strain rate dependency of strength is substantially greater (O'Kelly, 2016b). These contribute to the uncertainty in assigning design values of the shear strength parameters for the proposed biosolid monofill facility at the As-Samra WWTP. There is also a dearth of documented design experience and field performance records for biosolid landfills presented in the literature.

In order to remedy these shortcomings and to facilitate the geotechnical design of the proposed biosolid monofill at the AsSamra WWTP facility, this paper presents the results and interpretation of a comprehensive programme of geotechnical laboratory testing performed on compacted As-Samra WWTP biosolid specimens. The work programme included soil index, compaction, shear strength, compression and permeability testing, with the objective of determining the pertinent and representative material property values that would allow assessments of the slope stability and long-term performance of the proposed anticipated $30 \mathrm{~m}$ high biosolid monofill facility. The following were of particular interest

- optimum water content for compaction

- dependence of the mobilised strength on the compaction water content, different sequences of specimen saturation and consolidation, the stress path followed and the strain rate applied during the shearing stage

- rate of increase in undrained shear strength with reducing water content

- degree of strength anisotropy for compacted specimens

- effective-stress strength parameter $\left(c^{\prime}, \phi^{\prime}\right)$ values for the compacted material and their stress level dependence.

Further, the compression, creep and permeability properties of the compacted biosolid material were investigated for both inundated and non-inundated conditions. Additionally, unconsolidated undrained (UU) triaxial compression (TC) and consolidatedisotropic undrained compression (CIUC) triaxial testing customarily reported in previous investigations for biosolid materials, more sophisticated consolidated-isotropic drained compression (CIDC) and consolidated-isotropic undrained extension (CIUE) triaxial testing, along with consolidated-undrained direct simple shear (CU DSS) tests were also performed as part of the present research. CIDC and CIUE triaxial and CU DSS test results have not been reported previously for biosolid materials. Further, the authors provide their experiences in overcoming various laboratory testing issues (e.g. the pros and cons of using different test-specimen sizes and consolidation period durations for the CIUC triaxial and $\mathrm{CU}$ DSS tests were investigated). The paper concludes with recommendations on the water content range for the placement and compaction of the solar-dried As-Samra biosolid material in the proposed biosolid monofill facility, along with design shear strength values (with due consideration of how biogas production, creep etc. play a role in their selection) for performing geotechnical stability assessments.

Apart from the measurement of the total volatile solids, chemical content and composition tests were not performed as part of the present investigation. Typical chemical content and composition data for biosolid and sewage sludge materials were reported by Metcalf \& Eddy, Inc. (2004) and O'Kelly (2018a). Specific examples of the biosolid materials produced from the Eastern and Western WWTPs (Melbourne, Australia) and the Mangere WWTP (Auckland, New Zealand) are presented by Arulrajah et al. (2011, 2013), Kayser (2012) and Ukwatta et al. (2016), including the results of X-ray fluorescence and X-ray diffraction analyses performed for the determination of their chemical composition and mineralogy. Microstructure results from computerised tomography and scanning electron microscopy testing are reported for the Mangere and Tullamore (County Offaly, Ireland) WWTP biosolid materials in the papers by Kayser et al. (2011) and O'Kelly (2005c), respectively. They indicate that these biosolid materials were composed of small quantities of grit and organic fibres in a matrix of clay- and silt-sized particles, with a dispersed gaseous phase (occluded gas-filled voids). Finally, Wan (1998), Kayser (2012) and O'Kelly (2018a) describe the average proportions of the total protein, carbohydrate, and oil and grease (lipids) factions in the solid phase of different biosolid materials, which can be determined using the modified Lowry, colorimetric determination and Soxhlet extraction methods, respectively. For instance, Kayser (2012) reported that the average 
proportions of the total proteins, carbohydrates and lipids in the solid phase of the Mangere WWTP biosolid material (a digested primary and secondary sludge with $N=66-70 \%$; where $N$ is the percentage loss in dry mass on ignition) were $18 \cdot 5,9 \cdot 1$ and $4 \cdot 2 \%$, respectively, with standard deviations of $2 \cdot 1,1 \cdot 4$ and $0 \cdot 9 \%$, respectively. Broadly similar concentrations of typically $18 \%(15-20 \%)$ for the total protein fraction, $10 \%(8-15 \%)$ for the total carbohydrate fraction and $18 \%(5-20 \%)$ for the total lipid fraction were reported for digested primary sludge by Metcalf \& Eddy, Inc. (2004).

\section{Experimental material and methods}

Bulk samples of the dewatered biosolid material $(w=350 \%)$ from the As-Samra WWTP were delivered to a commercial geotechnical laboratory in the USA for testing. At the laboratory, the biosolid material was thoroughly mixed, allowed to air-dry to approximately $100 \%$ water content and again thoroughly mixed prior to the preparation of multiple specimens for strength, compressibility and permeability testing.

\section{Physiochemical and compaction testing}

To allow a general comparison of the geotechnical behaviour of the As-Samra WWTP biosolid material with other biosolid materials reported in the literature, the first round of laboratory testing included the Atterberg limit tests (ASTM, 2010a), sieve and sedimentation tests (ASTM, 2007a), the shrinkage limit test by the wax method (ASTM, 2008), the particle density $\left(\rho_{\mathrm{s}}\right)$ test using method A of ASTM (2014a), the loss on ignition test employing an ignition temperature of $440^{\circ} \mathrm{C}$ (ASTM, 2014b), the $\mathrm{pH}$ test (ASTM, 2013a) and the standard Proctor (SP) (ASTM, 2012a) and modified Proctor (MP) (ASTM, 2012b) compaction tests. Loss on ignition tests were also performed on the sampled biosolid material at the As-Samra WWTP facility in order to establish and quantify the level of any decomposition that occurred during the transportation of the material from the treatment plant to the geotechnical laboratory. For the particle density tests, kerosene was used instead of distilled water as the fluid in the density bottles (see the papers of O'Kelly (2005b, 2018a)). For the $\mathrm{pH}$ testing, the $\mathrm{pH}$ values of the biosolid samples in distilled water and in calcium chloride were measured using a $\mathrm{pH}$ meter. The water content was determined at the standard oven-drying temperature of $110 \pm 5^{\circ} \mathrm{C}$ (ASTM, 2010b), which is acceptable for routine water content determinations on biosolid materials (O'Kelly, 2014; O'Kelly and Li, 2018; O'Kelly and Sivakumar, 2014; USEPA, 2001). Similarly, from experimental investigations of the oven-drying characteristics of the Tullamore WWTP biosolid material $(N=70 \%)$ over the temperature range of $60-150^{\circ} \mathrm{C}$, O'Kelly (2005d) deduced that $86^{\circ} \mathrm{C}$ was the correct oven-drying temperature for water content determinations on this material, but that the error arising from using an oven-drying temperature of $105-110^{\circ} \mathrm{C}$ was acceptable for routine water content determinations.

\section{Strength, compression and permeability testing \\ Specimen preparation}

Shear strength, oedometer and permeability testing was performed on specimens prepared by compacting equal-height layers of the biosolid material at target water contents of 60 and $100 \%$ using tamping tools - that is, at the limits of the anticipated water content range achievable for solar drying of the biosolid material over an approximately 2-3 month period in the on-site lagoons before its placement in the proposed monofill facility. With the anticipated field compaction effort corresponding to that produced using large landfill compactors, a target compaction effort level was devised for the preparation of the laboratory test specimens - that is, for water content values on the dry side of (or near) the optimum water content for compaction $\left(w_{\text {opt }}\right)$, the targeted dry unit weight $\left(\gamma_{\mathrm{d}}\right)$ values for the test specimens were determined as $95 \%$ of the MP compacted $\gamma_{\mathrm{d}}$ values. Wet side of the $w_{\mathrm{opt}}$ value, the targeted $\gamma_{\mathrm{d}}$ values were midway between the SP and MP $\gamma_{\mathrm{d}}$ values corresponding to the particular water content value under investigation.

\section{Undrained shear strength}

The undrained shear strength was determined using the laboratory vane (LV) and UU TC tests in accordance with ASTM (2003, 2013b). For the three LV tests performed, a $12.7 \mathrm{~mm}$ tall by $12.7 \mathrm{~mm}$ wide cruciform vane used was inserted into the compacted test specimens and then torqued to produce an angular rotation rate $(\dot{\theta})$ of between 60 and $90 \%$ min (ASTM, 2013b), mobilising the peak vane strength value over the cylindrical shear failure surface. For the six UU triaxial tests performed, the $51 \mathrm{~mm}$ dia. $\times 102 \mathrm{~mm}$ long compacted specimens investigated were subjected to cell pressures of 75,150 or $300 \mathrm{kPa}$ (simulating the range of confinement stresses expected in the anticipated approximately $30 \mathrm{~m}$ high biosolid monofill facility) and then compressed at an axial strain rate $\left(\dot{\varepsilon}_{\mathrm{a}}\right)$ of $60 \% / \mathrm{h}$, without measurement of the pore water pressure (suction) response. In addition to the water contents of 60 and $100 \%$, compacted specimens prepared at water content values of 80 and $66 \%$ were also tested in UU TC, employing a representative cell pressure of $150 \mathrm{kPa}$, in order to evaluate the rate of strength gain with reducing water content. The compacted LV and UU triaxial specimens were not saturated prior to shearing in order to simulate the short-term conditions - that is, during the placement and compaction of the material in the proposed monofill facility and for some short period thereafter.

Isotropically consolidated triaxial undrained compression and extension tests

Six CIUC triaxial tests, with measurement of the pore water pressure response during the compression stage, were performed in accordance with ASTM (2011a) on 36 and $51 \mathrm{~mm}$ dia. biosolid specimens prepared by compaction at a target water content of $100 \%$ and then set up in the triaxial apparatus for the two-way vertical combined with radial (i.e. all around) drainage conditions during the triaxial saturation and consolidation stages. These test specimens were subjected to target effective cell pressures $\left(\sigma_{\mathrm{ci}}^{\prime}\right)$ of 75,150 and $300 \mathrm{kPa}$, achieved using applied back pressure $\left(u_{\mathrm{b}}\right)$ values exceeding $445 \mathrm{kPa}$. The purpose of these tests was to investigate the saturated material's effective-stress strength properties, as well as the effect of different shearing rates on the mobilised strength, with the undrained compression stage for the 36 and $51 \mathrm{~mm}$ dia. specimens performed at

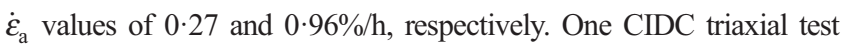
(performed in accordance with ASTM (2011b)) and one CIUE 
triaxial test were also performed on $51 \mathrm{~mm}$ dia. compacted specimens prepared at $100 \%$ water content. These test specimens were set up in the triaxial apparatus to allow all-around specimen drainage also, targeting a $\sigma_{\mathrm{ci}}^{\prime}$ value of $150 \mathrm{kPa}$. All of the triaxial tests described in this section included a saturation stage, using the approach of sequential cell and back-pressure increments.

\section{Consolidated-undrained direct simple shear}

The CU DSS tests were performed in accordance with ASTM (2007b) on $63.5 \mathrm{~mm}$ dia. $\times 25.4 \mathrm{~mm}$ high specimens prepared by compacting the biosolid material at target water contents of 60 and $100 \%$. For these tests, the specimens were set up in the apparatus to allow two-way vertical drainage to occur during the consolidation stage. Prior to the consolidation stage, the test specimens were inundated with water, but they were not back-pressure saturated. The DSS test programme began with the incremental consolidation of a test specimen (prepared at $100 \%$ water content) over a $24 \mathrm{~h}$ period to target a vertical effective stress $\left(\sigma_{\mathrm{vc}}^{\prime}\right)$ value of $150 \mathrm{kPa}$, after which the specimen was sheared undrained at a shear strain rate $(\dot{\gamma})$ of $5 \% / \mathrm{h}$ while keeping its height constant. From the analysis of these experimental results, it transpired that a longer consolidation period and slower $\dot{\gamma}$ values were required. Hence, subsequent CU DSS tests were performed on two sets of three test specimens compacted at approximately 60 and $100 \%$ water contents, targeting $\sigma_{\mathrm{vc}}^{\prime}$ values of 75,150 and $300 \mathrm{kPa}$ for each specimen set, but with the consolidation period exceeding $4.5 \mathrm{~d}$ and the undrained shearing stage performed at a significantly slower $\dot{\gamma}$ of $0 \cdot 22 \% / \mathrm{h}$.

\section{Oedometer testing}

Oedometer load-unload-reload testing was performed in accordance with ASTM (2011c) on four $63.5 \mathrm{~mm}$ dia. $\times 25.4 \mathrm{~mm}$ high compacted biosolid specimens. Oedometer specimens 1 and 2 were prepared at target water contents of 60 and $100 \%$, respectively, with the testing performed with no water placed in the consolidation cell (i.e. non-inundated condition) in order to investigate the onedimensional (1D) consolidation and swelling characteristics of the compacted biosolid material without access to free water. In other words, these two tests were aimed at investigating the field scenario of the compacted biosolid material for the desert climate at the proposed As-Samra WWTP monofill facility, with the capping layer and surface water control system in place. Plastic covers were placed on the consolidation cells for these two tests to mitigate against air-drying of the non-inundated specimens over the course of the long-duration tests. Oedometer specimens 3 and 4 were prepared at a target water content of $100 \%$, and they were both inundated with water at the start of the oedometer tests in order to simulate the field scenario where the compacted biosolid material in the proposed monofill had become submerged (waterlogged) due to inadequate drainage systems.

For oedometer specimens 1, 2 and 3, the load stages were typically of $24 \mathrm{~h}$ duration and employed a stress increment (decrement) ratio of unity. For the first load stage, the swelling pressure was determined as the value of the applied vertical stress that produced zero net strain of the test specimen at the end of this stage, the duration of which was extended to $3 \mathrm{~d}$ for the non-inundated specimen 2 and inundated specimen 3 in order to achieve near-equilibrium states. For the inundated oedometer specimen 4, the applied stress was incremented from initially 50 to $100 \mathrm{kPa}$ and then to $150 \mathrm{kPa}$ being maintained at the latter value for an extended period of $42 \mathrm{~d}$ in order to investigate the long-term compression behaviour.

\section{Permeameter test}

Previous laboratory permeability investigations for dewatered and compacted biosolid and sewage sludge materials have generally employed 1D consolidation testing to estimate the permeability coefficient value indirectly, with the direct measurement approach using permeameter apparatus rarely undertaken on account of their extremely low permeability coefficient values, and hence excessively long test durations (O'Kelly, 2016c). However, as described in the papers by O'Kelly (2005c, 2006a, 2008a, 2016b, 2016c), there are various issues and challenges in applying standard, curve-fitting techniques developed for inorganic soil in the analysis of the specimen strain against time data gathered from 1D consolidation testing of biosolid and sewage sludge materials. Hence, for the present investigation, the flexible-wall permeameter apparatus was used in accordance with ASTM (2010c) to measure the coefficient of permeability $\left(k_{\mathrm{v}}\right)$ value for the vertical flow of degassed distilled water through a $50.8 \mathrm{~mm}$ dia. $\times 50.8 \mathrm{~mm}$ high saturated biosolid test specimen that had been prepared by compaction at $110 \%$ water content producing $\gamma_{\mathrm{d}}=5.40 \mathrm{kN} / \mathrm{m}^{3}, e_{\mathrm{i}}=2.05$ and $S_{\mathrm{r}}=90 \%$; where $e_{\mathrm{i}}$ and $S_{\mathrm{r}}$ (in per cent) are the initial void ratio and degree of saturation, respectively. This constant-gradient permeability test was performed at an ambient temperature of $20^{\circ} \mathrm{C}$ using an applied cell pressure of $620 \mathrm{kPa}$ and inlet and outlet pressure values of 559 and $531 \mathrm{kPa}$, respectively, with the permeation stage itself continued over a $2 \cdot 5$ month period.

\section{Experimental results and analyses}

\section{Physiochemical properties and soil classification}

The As-Samra WWTP biosolid material tested had a Casagrande liquid limit $\left(w_{\mathrm{L}}\right)$ value of $458 \%$, a plastic limit $\left(w_{\mathrm{P}}\right)$ value of $68 \%$, a plasticity index $\left(I_{\mathrm{P}}\right)$ value of $390 \%$, a shrinkage limit $\left(w_{\mathrm{S}}\right)$ value of $5 \%$, a $\rho_{\mathrm{s}}$ value of $1.68 \mathrm{Mg} / \mathrm{m}^{3}$, an $N$ value of $62.6 \%$ and a $\mathrm{pH}$ range of $7 \cdot 8-7 \cdot 9$. The results of the sieve and sedimentation testing (see Figure 1) indicated that $84 \%$ (dry mass basis) of the biosolid material passed the number $200(0.075 \mathrm{~mm})$ test sieve, with $13 \%$ of the biosolid material colloidal (i.e. $<2 \mu \mathrm{m}$ ) in size and an estimated effective grain size $\left(D_{10}\right)$ of approximately $1 \mu \mathrm{m}$.

Based on these experimental measurements, the As-Samra WWTP biosolid material was classified as organic clay of extremely high plasticity, which is typical of other dewatered biosolid and sewage sludge materials (O'Kelly, 2016b). The $N$ value measured for the sampled biosolid material at the As-Samra WWTP facility ranged $63 \cdot 0-64 \cdot 8 \%$, compared to $62 \cdot 6 \%$ measured for the same material tested at the geotechnical laboratory in the USA. This indicated that an insignificant amount of biodegradation had occurred during the transportation of the 
Geotechnical properties of compacted biosolids for monofill design, As-Samra, Jordan

'Kelly, Oettle and Ramos

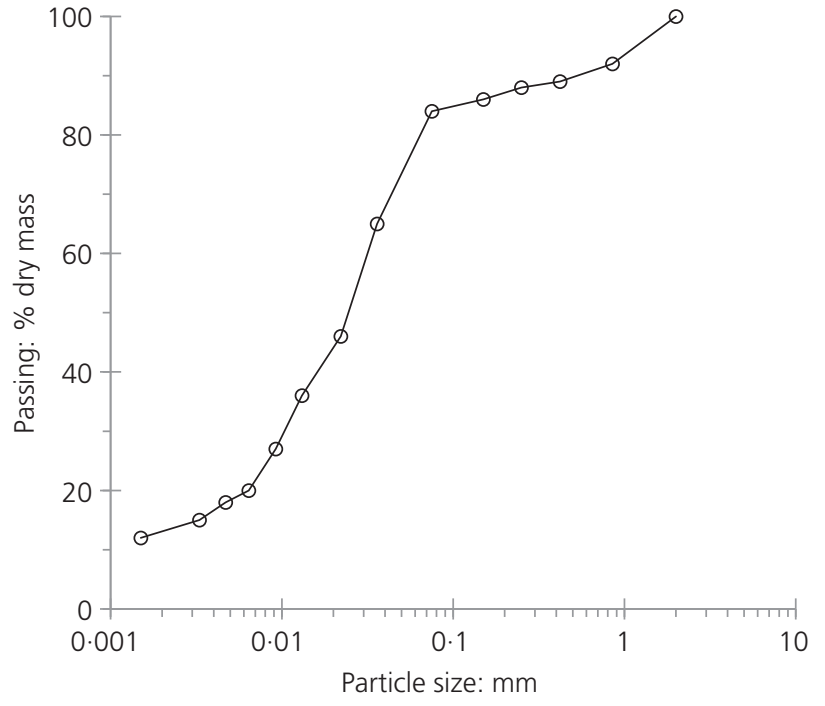

Figure 1. Particle-size distribution of As-Samra WWTP biosolid material

test material and its subsequent air-drying in the geotechnical laboratory to reduce the water content from initially approximately $350 \%$ to targeted values between approximately 60 and $110 \%$ before preparing the various compacted specimens for strength, compression and permeability testing.

The presented experimental results for the As-Samra WWTP biosolid material are similar to those reported in the literature for other dewatered biosolid materials, which are comprehensively reviewed in the paper by O'Kelly (2016b). For instance, values of $w_{\mathrm{L}}=315 \%, w_{\mathrm{P}}=55 \%, I_{\mathrm{P}}=260 \%, w_{\mathrm{S}}=10 \%, \rho_{\mathrm{s}}=1.55 \mathrm{Mg} / \mathrm{m}^{3}$,
$N=70 \%$ and $\mathrm{pH}=8.0$ were reported by O'Kelly (2006a) for dewatered Tullamore WWTP biosolid material. Values of $w_{\mathrm{L}}=$ $666 \%, w_{\mathrm{P}}=105 \%, I_{\mathrm{P}}=561 \%, \rho_{\mathrm{s}}=1.62 \mathrm{Mg} / \mathrm{m}^{3}, N=66-70 \%$ and $\mathrm{pH}=8.3$ were reported by Kayser et al. (2011) for dewatered Mangere WWTP biosolid material.

\section{Compaction properties}

The compaction test results for the As-Samra WWTP biosolid material (see Figure 2) indicated $w_{\text {opt }}$ values of 83 and $59 \%$ for SP- and MP-compaction efforts, respectively, with corresponding maximum $\gamma_{\mathrm{d}}$ values of 5.8 and $6.7 \mathrm{kN} / \mathrm{m}^{3}$. These values compare favourably with $w_{\mathrm{opt}}$ and $\gamma_{\mathrm{d}}$ values of $85 \%$ and $5.5 \mathrm{kN} / \mathrm{m}^{3}$ (O'Kelly, 2006a) for SP compaction of the Tullamore WWTP biosolid material (see also Figure 2(b)) and $51-53 \%$ and $7 \cdot 8-8 \cdot 0 \mathrm{kN} / \mathrm{m}^{3}$ for aged biosolid material $(N=35 \cdot 4-38 \cdot 5 \%)$ from the Melbourne Western WWTP (Arulrajah et al., 2011).

Based on the experimental results presented for the As-Samra WWTP biosolid material, the targeted dry unit weight for the strength, compression and permeability test specimens compacted on the dry side of (or near) the identified MP $w_{\text {opt }}$ value was determined as $95 \%$ of the associated MP $\gamma_{\mathrm{d}}$ value (e.g. $6 \cdot 3 \mathrm{kN} / \mathrm{m}^{3}$ for $w \approx 60 \%$ ). Referring to Figure 2(b), for test specimens with water contents on the wet side of (or near) the identified SP $w_{\text {opt }}$ value, the targeted dry unit weight was midway between the associated $\gamma_{\mathrm{d}}$ values for SP and MP compaction (e.g. $5 \cdot 6 \mathrm{kN} / \mathrm{m}^{3}$ for $w \approx 100 \%$ ).

\section{Shear strength}

\section{Laboratory vane}

The three LV tests performed on specimens compacted at $w=100 \%$ to produce $\gamma_{\mathrm{d}}=5.6 \mathrm{kN} / \mathrm{m}^{3}$ mobilised undrained vane strength $\left(s_{\mathrm{uLV}}\right)$ values of $35.0,37.5$ and $42.5 \mathrm{kPa}$ (i.e. a mean $s_{\mathrm{uLV}}$ value of $38.3 \mathrm{kPa}$, with $\sigma=3.8 \mathrm{kPa}$, where $\sigma$ is the standard deviation).

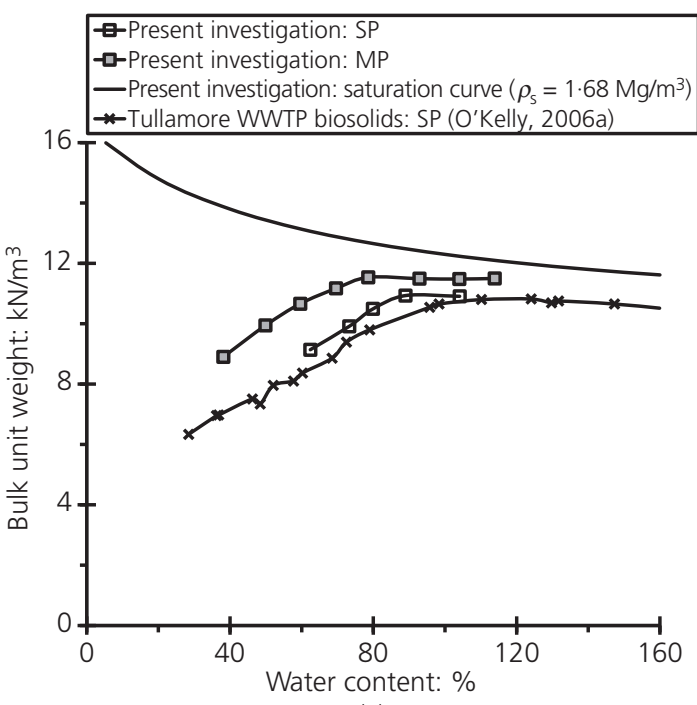

(a)

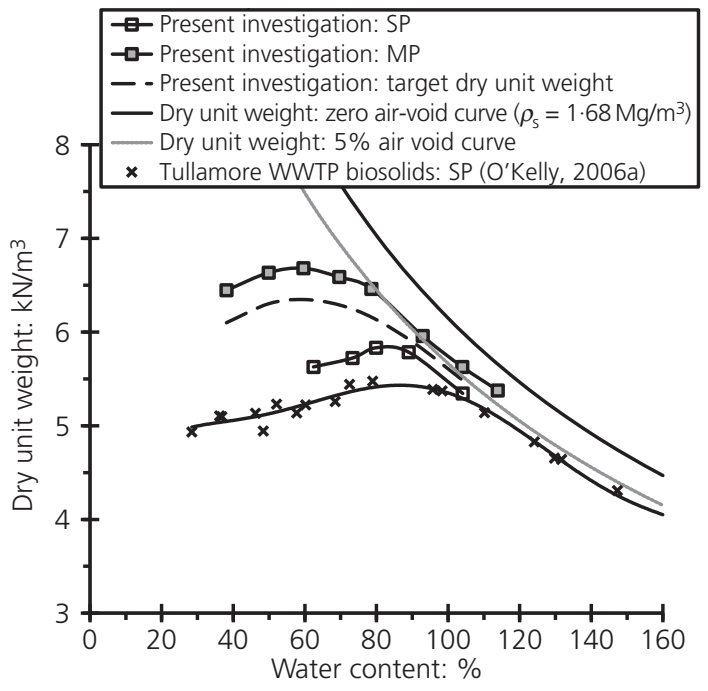

(b)

Figure 2. Compaction test results for As-Samra WWTP biosolid material: (a) bulk unit weight; (b) dry unit weight 


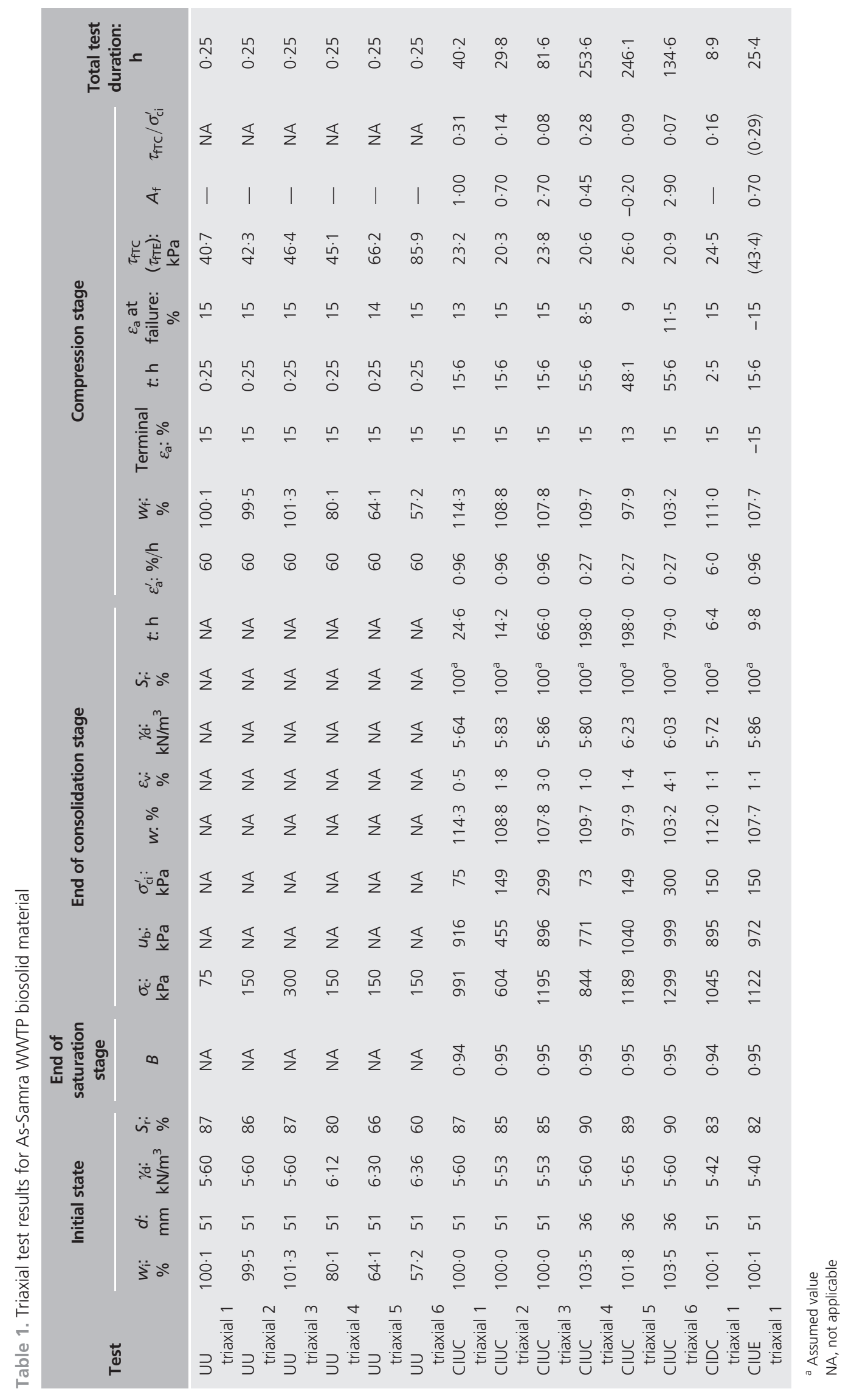


Table 2. CU DSS results for As-Samra WWTP biosolid material

\begin{tabular}{|c|c|c|c|c|c|c|c|c|c|c|c|c|c|c|c|}
\hline \multirow{2}{*}{ Test } & \multicolumn{3}{|c|}{ Initial state } & \multicolumn{4}{|c|}{$\begin{array}{c}\text { End of } \\
\text { consolidation stage }\end{array}$} & \multicolumn{7}{|c|}{ Shearing stage } & \multirow{2}{*}{$\begin{array}{l}\text { Total test } \\
\text { duration: } \mathrm{h}\end{array}$} \\
\hline & $\begin{array}{l}W_{\mathrm{i}}: \\
\%\end{array}$ & $\begin{array}{c}\gamma_{\mathrm{d}}: \\
\mathrm{kN} / \mathrm{m}^{3}\end{array}$ & $\begin{array}{l}S_{r}: \\
\%\end{array}$ & $\begin{array}{l}W_{f}: \\
\%\end{array}$ & $\sigma_{\mathrm{vc}}^{\prime}: \mathrm{kPa}$ & $\begin{array}{l}\varepsilon_{\mathrm{v}}: \\
\%\end{array}$ & $t: \mathrm{h}$ & $\begin{array}{l}\dot{\gamma}: \\
\% / h\end{array}$ & $\begin{array}{c}\text { Terminal } \\
\gamma: \%\end{array}$ & $t: \mathrm{h}$ & $\begin{array}{c}\gamma \text { at } \\
\text { failure: } \%\end{array}$ & $\begin{array}{c}\tau_{\text {f DSs: }}: \\
\mathrm{kPa}\end{array}$ & $A_{\mathrm{f}}$ & $\tau_{\mathrm{fDSS}} / \sigma_{\mathrm{vc}}^{\prime}$ & \\
\hline CU DSS 1 & $100 \cdot 1$ & $5 \cdot 68$ & 88 & $99 \cdot 2$ & 150 & $2 \cdot 0$ & 24 & 5.00 & $22 \cdot 1$ & $4 \cdot 4$ & 22 & $42 \cdot 5$ & $0 \cdot 2$ & 0.28 & $28 \cdot 4$ \\
\hline CU DSS 2 & $106 \cdot 7$ & $5 \cdot 51$ & 90 & $96 \cdot 5$ & 75 & 1.6 & 112 & 0.22 & $22 \cdot 1$ & 100 & 22 & $36 \cdot 9$ & -0.5 & 0.49 & $212 \cdot 0$ \\
\hline CU DSS 3 & $103 \cdot 5$ & $5 \cdot 59$ & 89 & 88.0 & 150 & $2 \cdot 4$ & 175 & 0.22 & $22 \cdot 1$ & 100 & 22 & $46 \cdot 0$ & -0.8 & 0.31 & $275 \cdot 0$ \\
\hline CU DSS 4 & $103 \cdot 5$ & $5 \cdot 59$ & 89 & $107 \cdot 7$ & 300 & $2 \cdot 7$ & 142 & 0.22 & $21 \cdot 8$ & 99 & 22 & $34 \cdot 3$ & $2 \cdot 4$ & $0 \cdot 11$ & $241 \cdot 0$ \\
\hline CU DSS 5 & $66 \cdot 8$ & 6.05 & 65 & $97 \cdot 2$ & 75 & $3 \cdot 1$ & 101 & 0.22 & $22 \cdot 0$ & 100 & 22 & $24 \cdot 8$ & $0 \cdot 3$ & 0.33 & $201 \cdot 0$ \\
\hline CU DSS 6 & $62 \cdot 8$ & $6 \cdot 19$ & 63 & $104 \cdot 6$ & 150 & 1.7 & 116 & 0.22 & $22 \cdot 0$ & 100 & 22 & $28 \cdot 2$ & $1 \cdot 7$ & 0.19 & $216 \cdot 0$ \\
\hline CU DSS 7 & $66 \cdot 0$ & 6.07 & 65 & $86 \cdot 7$ & 300 & $2 \cdot 2$ & 121 & 0.22 & $22 \cdot 0$ & 100 & 22 & $47 \cdot 8$ & $1 \cdot 3$ & $0 \cdot 16$ & $221 \cdot 0$ \\
\hline
\end{tabular}

\section{Triaxial and DSS testing}

\section{PHYSICAL PROPERTIES OF THE TEST SPECIMENS}

The physical properties of the test specimens for the different stages of the triaxial and DSS tests, along with the effective-stress levels achieved at the end of the consolidation stage and the strain rate and mobilised strength values for the shearing stage, are summarised in Tables 1 and 2.

From Figure 3, the initial degree of saturation of the triaxial and DSS test specimens increased from $60 \%$ to approximately $90 \%$ for increasing water content from 57 to $107 \%$, with the initial dry unit weight achieved showing a reducing trend over the same range of water contents (Figure 3(b)). For the triaxial tests, the initial dry unit weight and degree of saturation values of the three $36 \mathrm{~mm}$ dia. test specimens (i.e. CIUC triaxials 4-6) were found in good agreement with the corresponding correlations deduced for the $51 \mathrm{~mm}$ dia. test specimens, indicating no bias in the compaction procedure employed for the differently sized specimens.

\section{GENERAL PERFORMANCE OF THE TRIAXIAL TESTS}

The following observations are made from Table 1 for the CIUC, CIDC and CIUE triaxial tests.

- A pore pressure coefficient $B$ value of $\geq 0.94$ was achieved at the end of the saturation stage, and for the purposes of performing the calculations, these test specimens were assumed fully saturated at the end of the consolidation stage. Note that $u_{\mathrm{b}}$ values ranging $455-1040 \mathrm{kPa}$ were required to achieve these necessarily high $B$ values, with the $u_{\mathrm{b}}$ values employed for six of the eight test specimens (i.e. CIUC triaxials 1-6, CIDC triaxial 1 and CIUE triaxial 1) ranging $895-1040 \mathrm{kPa}$, as documented in Table 1.

- Despite consolidation stage durations of up to $198 \mathrm{~h}$, the measured volumetric strains were very small $\left(\varepsilon_{\mathrm{v}}=0 \cdot 5-4 \cdot 1 \%\right)$ considering the very high specimen water contents and high effective cell pressures $\left(\sigma_{\mathrm{ci}}^{\prime}=73-300 \mathrm{kPa}\right)$ induced.

As expected, the volumetric strain was greater for higher effective confinement pressure (Figure 4). Further, apart

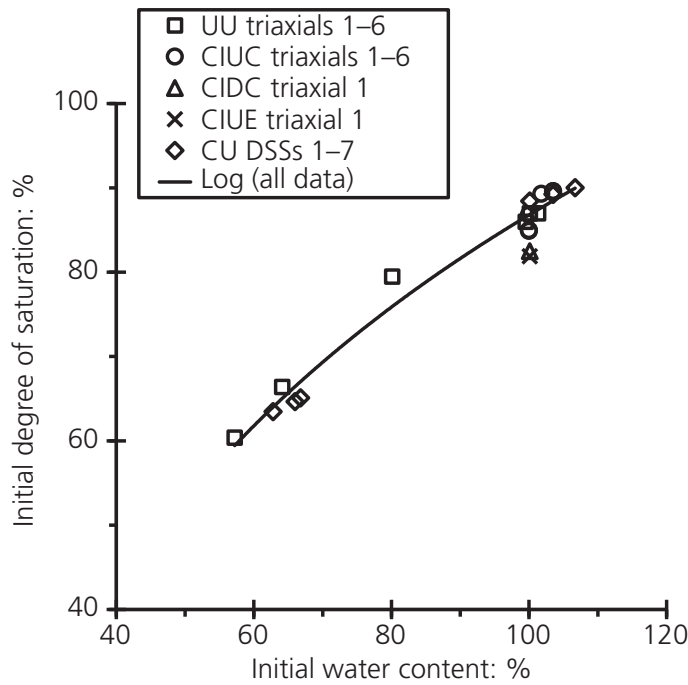

(a)

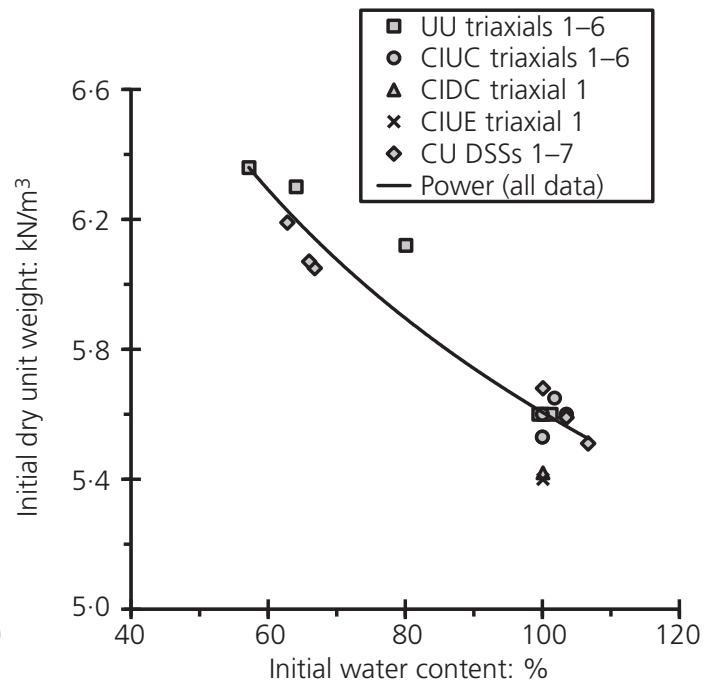

(b)

Figure 3. Initial state of the strength test specimens: (a) degree of saturation; (b) compacted dry unit weight 
Geotechnical properties of compacted biosolids for monofill design, As-Samra,

Jordan

'Kelly, Oettle and Ramos

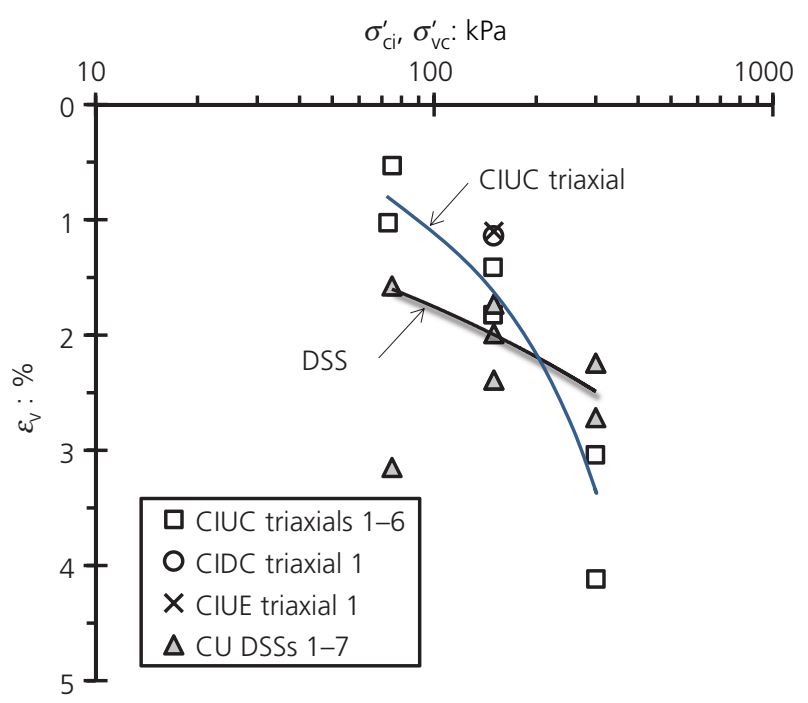

Figure 4. Volumetric strain achieved at the end of the consolidation stage for triaxial and DSS tests

from CIUC triaxials 5 and 6 , the water content of the triaxial specimens at the end of the consolidation stage had increased by as much as 14.3 percentage points from their initial values (Figure 5(a)).

- The terminal axial strain for the compression stage was defined by apparatus limitations as $15 \%$ (i.e. shear strain of $30 \%$ ), although the mobilised shear stress was typically continuing to increase marginally at this strain value
(Figure 6), with all of the TC specimens undergoing general bulging deformation for the water content range investigated $(w=57 \cdot 2-114 \cdot 3 \%)$. The reported shear strength values are corrected for the restraining effect of the latex membranes enclosing the triaxial test specimens.

\section{GENERAL PERFORMANCE OF THE CU DSS TESTS}

The following observations are made from Table 2 for the $\mathrm{CU}$ DSS tests and are generally similar to the observations reported in the previous section for the triaxial tests.

- Despite consolidation stage durations of up to $175 \mathrm{~h}$, the measured volumetric strains were very small, with $\varepsilon_{\mathrm{v}}$ ranging $1 \cdot 6-3 \cdot 1 \%$ for $\sigma_{\mathrm{vc}}^{\prime}=75-300 \mathrm{kPa}$. Compared to the CIUC, CIDC and CIUE triaxial specimens, however, the volumetric strains for the DSS specimens tested increased only marginally with increasing pre-shear vertical consolidation stress (Figure 4). Further, despite contractive volumetric strains, the water content values of the three DSS specimens compacted at $w=62 \cdot 8-66 \cdot 8 \%$ had significantly increased at the end of the consolidation stage by between $20 \cdot 7$ and $41 \cdot 8$ percentage points (Figure 5(b)).

- The terminal shear strain was defined by apparatus limitations as $22 \%$, with the mobilised shear stress continuing to increase marginally at this strain value.

A notable feature, therefore, is that the triaxial and DSS test specimens did not compress significantly by the end of the consolidation stage $\left(\varepsilon_{\mathrm{v}}=0 \cdot 5-4 \cdot 1 \%\right.$ for the targeted $\sigma_{\mathrm{ci}}^{\prime}\left(\sigma_{\mathrm{vc}}^{\prime}\right)=$

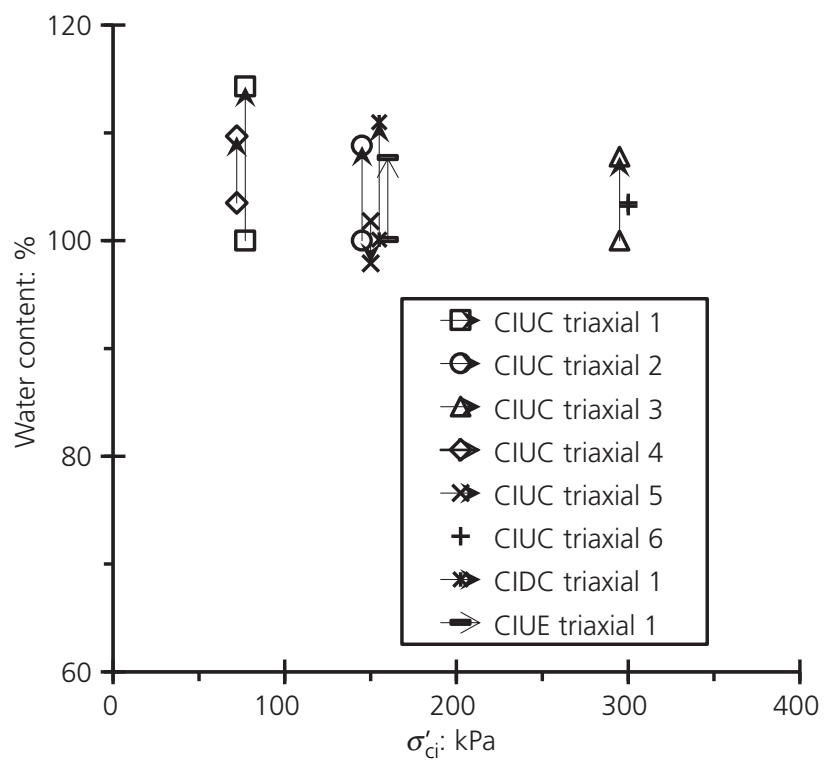

(a)

\begin{tabular}{|c|c|c|}
\hline E CU DSS 1 & - CUDSS 2 & $\Delta$ CUDSS 3 \\
\hline$\diamond$ CU DSS 4 & - CUDSS 5 & $\rightarrow$ CU DSS 6 \\
\hline
\end{tabular}

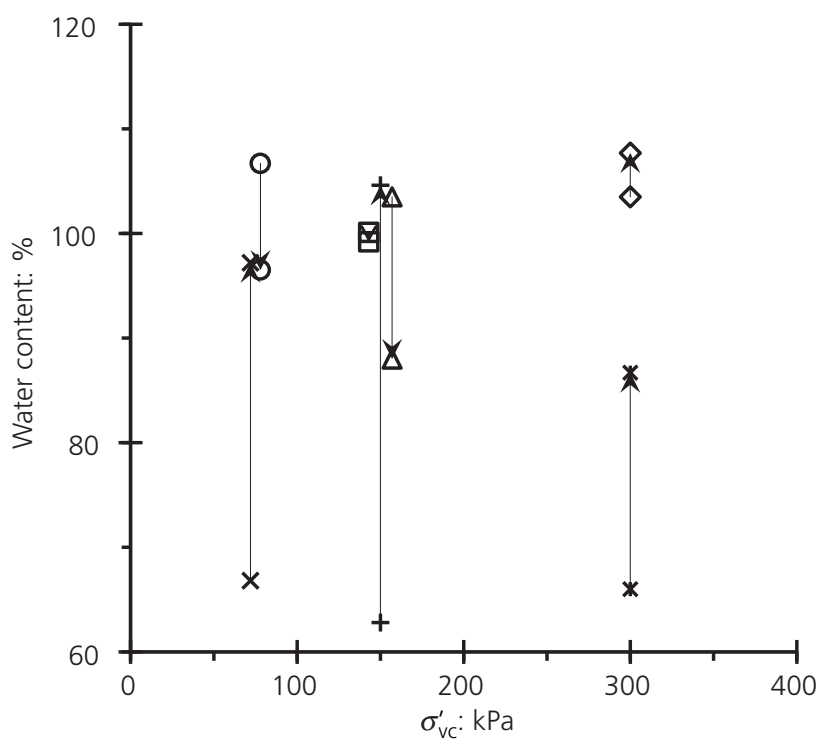

(b)

Figure 5. Initial and final water contents of the strength test specimens: (a) triaxial; (b) DSS 
Geotechnical properties of compacted biosolids for monofill design, As-Samra, Jordan

'Kelly, Oettle and Ramos

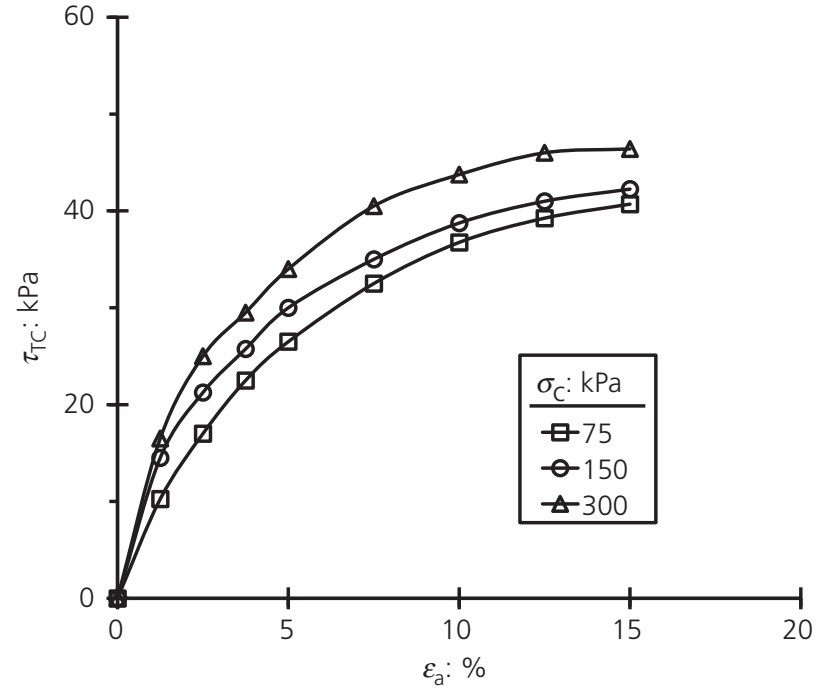

Figure 6. UU TC of compacted As-Samra biosolid material for different cell pressures $\left(w \approx 100 \% ; \dot{\varepsilon}_{\mathrm{a}}=60 \% / \mathrm{h}\right)$

73-300 $\mathrm{kPa}$ and stage duration of 6.4-198 h), which is indicative of the heavily over-consolidated (OC) state of these compacted test specimens. There appeared to be no bias shown in the geomechanical data related to the different effective drainage lengths of the 36 and $51 \mathrm{~mm}$ dia. triaxial specimens and the $25.4 \mathrm{~mm}$ high DSS specimens. In other words, the consolidation stage of these tests was generally of sufficiently long duration and, furthermore, the test specimens were subsequently sheared at sufficiently slow rates.

\section{Shear strength and water content}

Figure 7 shows all of the LV, triaxial and DSS strength data plotted against the water content of the test specimens for their shearing stage. As expected, a general trend of the shear strength increasing exponentially with reducing water content is evident.

The scatter in the data (strength variation for a given water content value) arises from a number of factors, including the following.

- The strength values mobilised for the partially saturated biosolid specimens increase with increasing confinement pressure (Kayser et al., 2011; O'Kelly, 2013a, 2013b) - that is, the LV specimens were tested for the condition of $\sigma_{\mathrm{v}}=$ $0 \mathrm{kPa}$ (i.e. approximately zero confinement pressure (O'Kelly, 2013a, 2013b)) compared to $\sigma_{\mathrm{c}}=75-300 \mathrm{kPa}$ applied for the UU triaxial tests.

- The specimen preparation method by compaction produced an OC state (O'Kelly, 2016b). Hence, during the saturation and consolidation stages of the CIUC, CIDC and CIUE triaxial tests and the consolidation stage of the DSS tests, the partially saturated compacted specimens absorbed significant amounts of water, with only marginal volumetric strains occurring

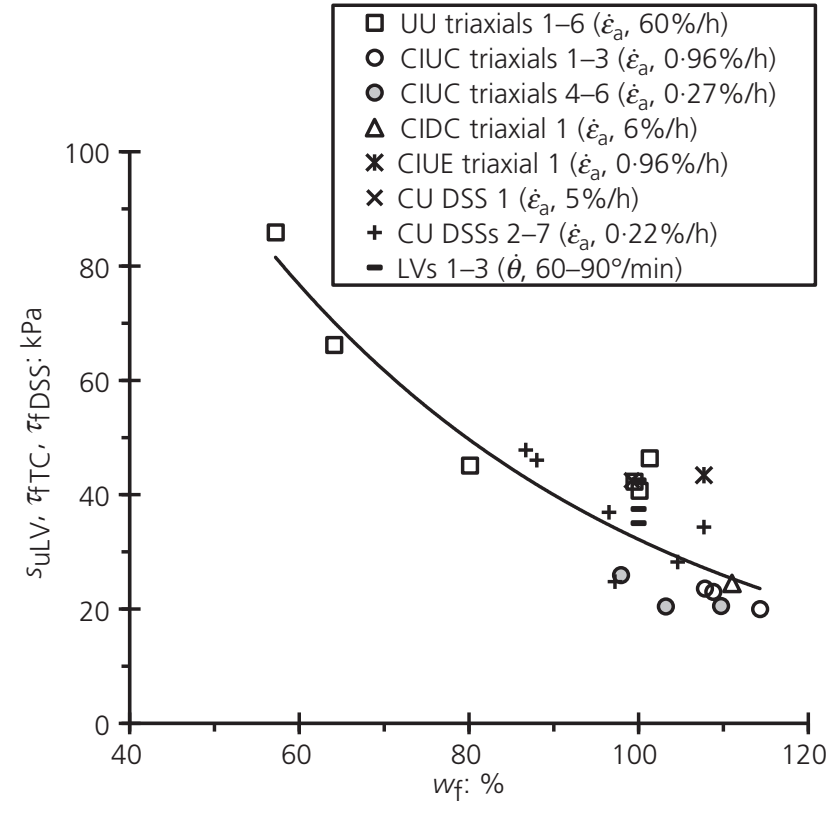

Figure 7. Mobilised shear strength against water content for As-Samra WWTP biosolid material under different shearing conditions

during the consolidation stage for significant effective confinement pressure. Consequently, the water content value for the shearing stage of these tests was generally appreciably greater than the initial water content value of the compacted test specimen. This was most evident for the DSS specimens compacted at between $62 \cdot 8$ and $66 \cdot 8 \%$ water content (i.e. compacted near the MP $w_{\text {opt }}$ value) (see Figure 5(b)).

- Most of the test specimens were sheared in an OC state, with the degree of overconsolidation present for the CIUC, CIDC and CIUE triaxial and CU DSS specimens reducing with increasing effective confinement pressure achieved at the end of the consolidation stage.

- Test specimens in an OC state have a strength anisotropy (O'Kelly, 2016b), such that even with all other factors being equal, the different shearing modes applied in the different test apparatus result in different mobilised shear strength values (O'Kelly, 2013a, 2013b, 2016b).

- Although the pore water pressure (suction) response was not monitored for the UU triaxial 1-6 specimens, positive pore pressure development was not expected during the compression stage because of their unsaturated condition. However, positive pore pressure development occurred for the practically fully saturated CIUC triaxial and CU DSS specimens when sheared in normally consolidated (NC) and lightly and marginally OC states, which resulted in lower mobilised strength values compared with identically prepared UU triaxial specimens.

- Since the strain rate dependence of strength for biosolid materials is substantially greater than that of inorganic soil (O'Kelly, 2013a, 2016a, 2016b, 2018b), the almost 
three-order-of-magnitude differences in the shear strain rates employed for the various strength tests performed in this investigation had a significant effect on the mobilised strength values.

- Different terminal shear strain values of 30 and $22 \%$ were imposed by limitations of the triaxial and DSS apparatuses, respectively. Hence, with the shear resistance of the biosolid material typically showing a marginal increase at the terminal strain value (Kayser et al., 2011; O'Kelly, 2006a, 2013b, 2016b), greater shear resistance is generally mobilised for larger terminal shear strain values.

All of the preceding points are investigated further in the section headed 'Discussion'. Other possible factors, which were deemed not significant in the present investigation for the reasons given below, include the following.

- Ongoing generation of biogas internally could inhibit the specimen consolidation process, particularly for the longerduration triaxial tests. Further, the associated increase in the pore fluid pressure for slow undrained shearing would produce a consequential reduction in the effective confinement pressure acting on the test specimen, resulting in a lower mobilised strength value (according to the effective Mohr-Coulomb failure criterion) for the same water content value (O'Kelly, 2006a, 2013a, 2013b, 2016b). However, the measured pore water pressure responses for the compression stage of the CIUC and CIDC triaxial tests presented in the present investigation indicated that the rate of ongoing biodegradation was such that it did not significantly influence the strength test results for the compacted As-Samra WWTP biosolid specimens.

- A potential scale effect related to the sizes of the larger solid particles compared to the 36 and $51 \mathrm{~mm}$ dia. triaxial and $25.4 \mathrm{~mm}$ high DSS test specimens and the $12.7 \mathrm{~mm}$ wide shear vane device employed in the investigations. For instance, this effect can be significant for testing of fibrous peat and paper mill sludge materials (Moo-Young and Zimmie, 1996; O'Kelly, 2015, 2017; O'Kelly and Orr, 2014). However, the thorough mixing of the bulk sample of biosolid material prior to the specimen preparation procedure and its negligible fibrosity (O'Kelly, 2013b) meant that the strength test specimens of the As-Samra WWTP biosolid material were homogeneous, with no significant fibre reinforcement present in the soil matrix, such that this scale effect had a negligible impact on its mobilised strength values.

\section{Triaxial effective-stress strength testing}

The experimental results for the CIUC, CIDC and CIUE triaxial tests are presented in Figures 8 and 9, namely, deviatoric stress $q^{\prime}$ (i.e. $\sigma_{\mathrm{v}}^{\prime}-\sigma_{\mathrm{c}}^{\prime}$ ), excess pore water pressure $\left(u_{\mathrm{e}}\right)$ and the pore pressure coefficient $A$ (i.e. $u_{\mathrm{e}} / q^{\prime}$ ) plotted against the axial strain, the values of $A$ corresponding to the peak deviatoric stress $\left(q_{\mathrm{f}}^{\prime}\right)$ values (i.e. $A_{\mathrm{f}}$ ) plotted against the initial effective confinement pressure $\left(\sigma_{\mathrm{ci}}^{\prime}\right), p^{\prime}-q^{\prime}$ traces and the inferred failure envelope, where $p^{\prime}$ is the mean effective stress (i.e. $\left.\left(\sigma_{\mathrm{v}}^{\prime}+2 \sigma_{\mathrm{c}}^{\prime}\right) / 3\right)$.
In Figure 8(a), the trace for the CIUC triaxial 5 specimen is distinctly different from those of the other specimens presented. Referring to Table 1; all six of the CIUC triaxial specimens were compacted at water contents in the range of $100 \cdot 0-103 \cdot 5 \%$. Despite undergoing positive volumetric strains of between 0.5 and $4 \cdot 1 \%$ by the end of the consolidation stage, the specimen water content range had increased to $103 \cdot 2-114 \cdot 3 \%$ - that is, except for the CIUC triaxial 5 specimen, which experienced a slight reduction in its water content value to $97.9 \%$. For comparison, the water content value of the CIUC triaxial 2 specimen, which was consolidated under the same $\sigma_{\mathrm{ci}}^{\prime}$ value of $149 \mathrm{kPa}$, increased to $108.8 \%$ by the end of the consolidation stage. Although the authors do not have an explanation for this apparent anomaly, the results for the compression stage are consistent in that the lower water content CIUC triaxial 5 specimen mobilised the highest $q_{\mathrm{f}}^{\prime}\left(\tau_{\mathrm{fTC}}\right)$ value among these six test specimens.

As summarised in Table 3, based on the observed characteristic shapes of the data plots in Figures 8 and 9, the CIUC triaxial 3 and 6 specimens $\left(\sigma_{\mathrm{ci}}^{\prime}=300 \mathrm{kPa}\right)$ and the CIUE triaxial 1 specimen were sheared in an NC state, the CIUC triaxial 1 and 2 specimens were both marginally $\mathrm{OC}$, the CIUC triaxial 4 specimen was moderately $\mathrm{OC}$ and the CIUC triaxial 5 and CIDC triaxial 1 specimens were both sheared in a heavily OC state. In other words, with $q^{\prime}$ continuing to increase for increasing axial strain in undrained TC mode (Figure 8(a)), the $u_{\mathrm{e}}$ values generated continued to increase or approached steady elevated values or decreased marginally from a moderately elevated value or decreased to approach a steady negative value, respectively, (Figure 8(b)). These conclusions are confirmed by the values of $A_{\mathrm{f}}$ (i.e. corresponding to the terminal axial strain) presented in Figure $8(\mathrm{~d})$. In general, the value of $A_{\mathrm{f}}$ for fine-grained soil depends on the stress path followed and the stress history, with $A_{\mathrm{f}}$ values of -0.5 to 0 typically measured for heavily OC clay, $0-0 \cdot 5$ for lightly OC clay and $>0 \cdot 5$ for NC clay. For the present investigation, an $A_{\mathrm{f}}$ value of -0.2 was calculated for the heavily OC CIUC-triaxial 5 specimen, 1.0 and 0.7 for the marginally OC CIUC-triaxial 1 and 2 specimens and finally 2.7 and 2.9 for the NC CIUC-triaxial 3 and 6 specimens. In other words, the $A_{\mathrm{f}}$ coefficient reduces in value for lower $\sigma_{\mathrm{ci}}^{\prime}$ values (Figure $8(\mathrm{~d})$ ) - that is, it is indicative of an increasing level of overconsolidation for the compacted biosolid specimens. These results are consistent with reported $A_{\mathrm{f}}$ values, ranging $1 \cdot 0$ to $2 \cdot 1$ for CIUC triaxial testing of five saturated $36 \mathrm{~mm}$ dia. NC pasteurised specimens of Tullamore WWTP biosolid material $(N=70 \%)$ (O'Kelly, 1994). Further, the CIDC triaxial 1 specimen continued to dilate during the compression stage (see the second $y$-axis in Figure 8(c)), consistent with its deduced heavily OC state.

From the TC $p^{\prime}-q^{\prime}$ traces and the inferred failure envelope shown in Figures 8(e) and 8(f), the effective angle of shearing resistance $\left(\phi_{\mathrm{TC}}^{\prime}\right)$ and cohesion intercept $\left(c_{\mathrm{TC}}^{\prime}\right)$ values were determined for the different stress histories (i.e. NC or different levels of OC state) based on the gradient of the failure line $M_{\mathrm{TC}}$ (i.e. $q_{\mathrm{f}}^{\prime} / p^{\prime}$ ) and its intercept with the $q^{\prime}$ axis, respectively, with the findings of this analysis presented in Table 3. Referring to Figure 8(f), saturated compacted biosolid specimens tested in the NC state had $c_{\mathrm{TC}}^{\prime}$ and 
Environmental Geotechnics

Volume 7 Issue 6
Geotechnical properties of compacted biosolids for monofill design, As-Samra,

Jordan

'Kelly, Oettle and Ramos

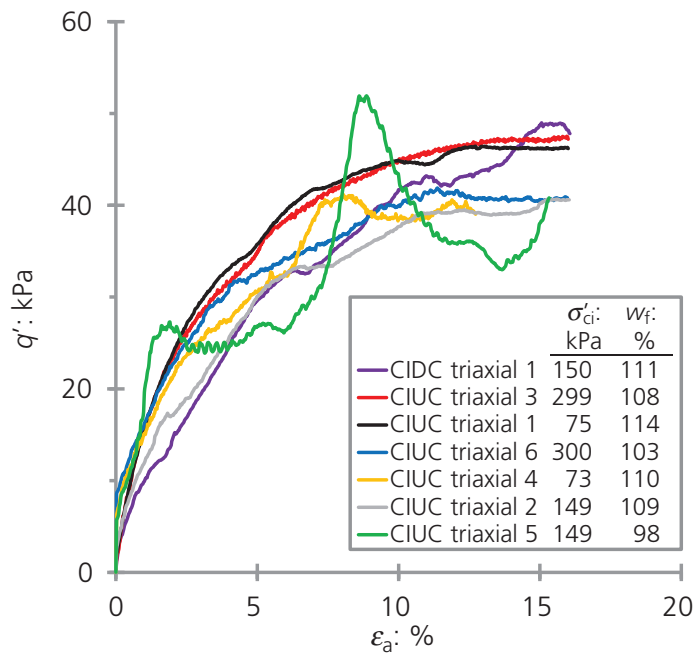

(a)

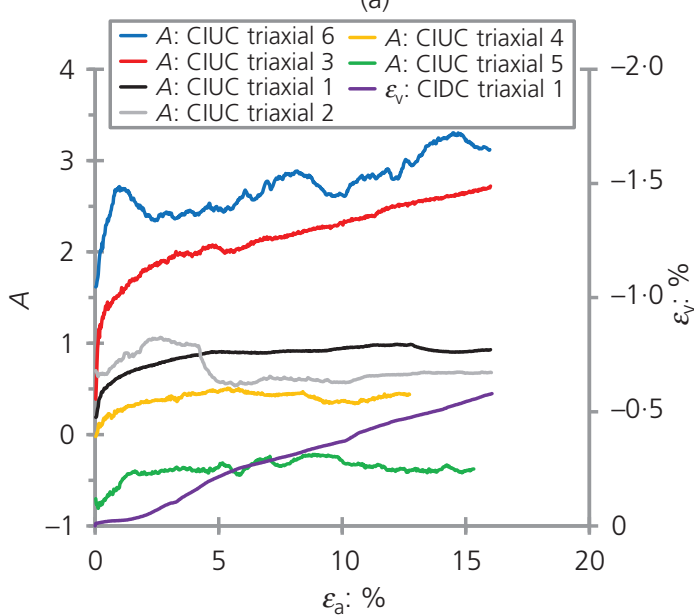

(c)

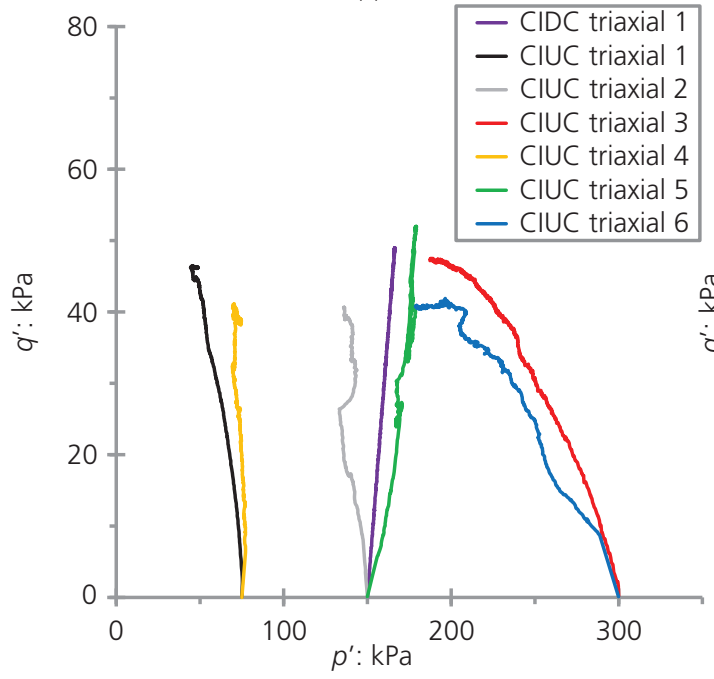

(e)

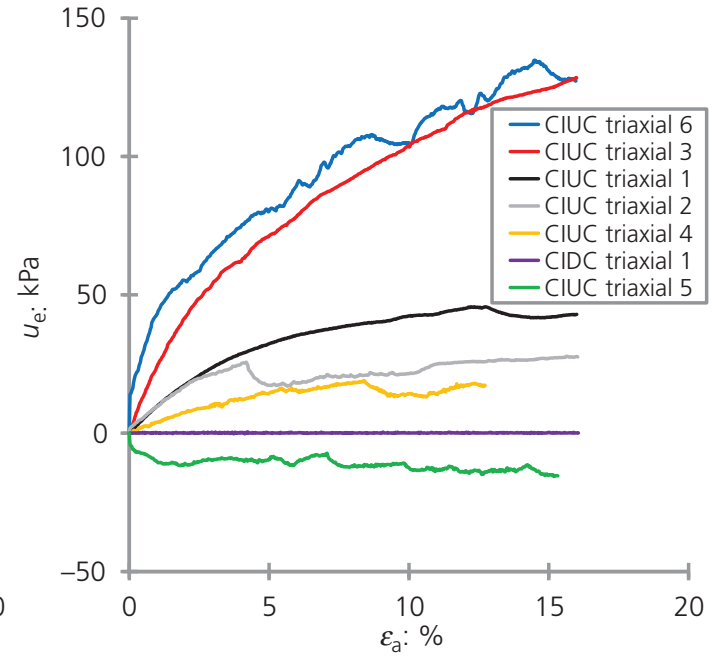

(b)

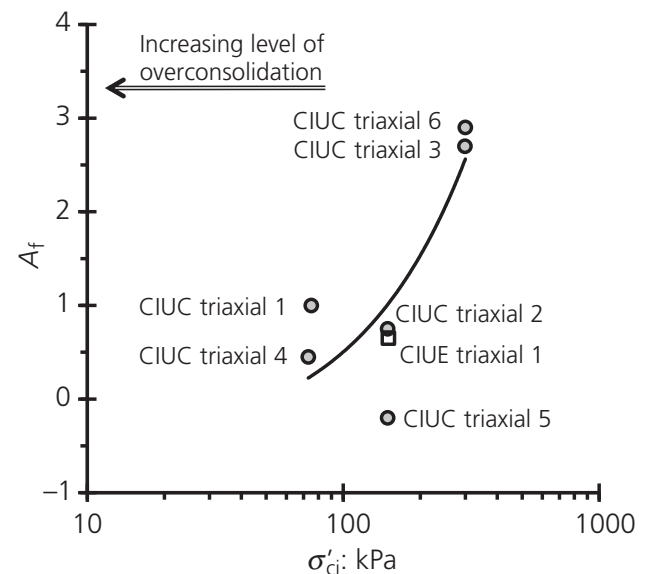

(d)

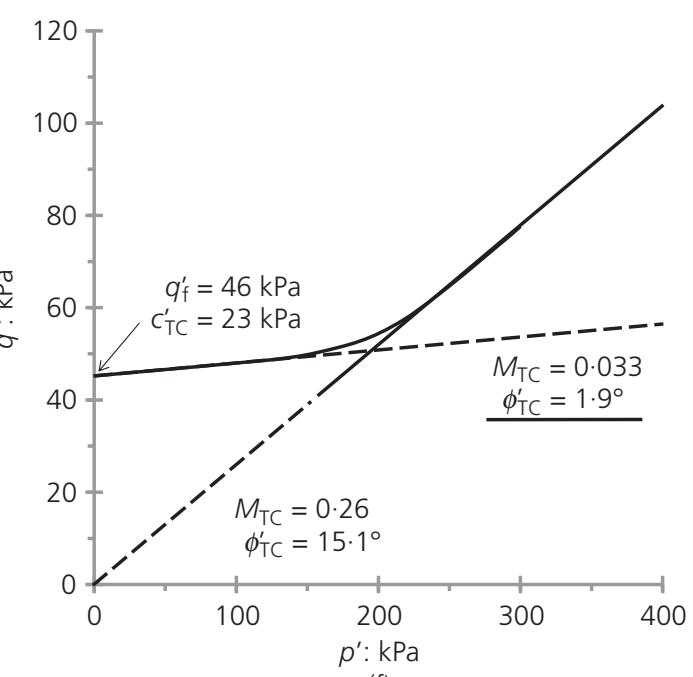

(f)

Figure 8. Compression stage of CIUC and CIDC triaxial tests on saturated compacted As-Samra WWTP biosolid material: (a) deviatoric stress against axial strain; (b) excess pore water pressure against axial strain; (c) pore pressure coefficient $A$ and volumetric strain against axial strain; (d) pore pressure coefficient $A$ at failure; (e) $p^{\prime}-q^{\prime}$ traces; (f) inferred failure envelope 


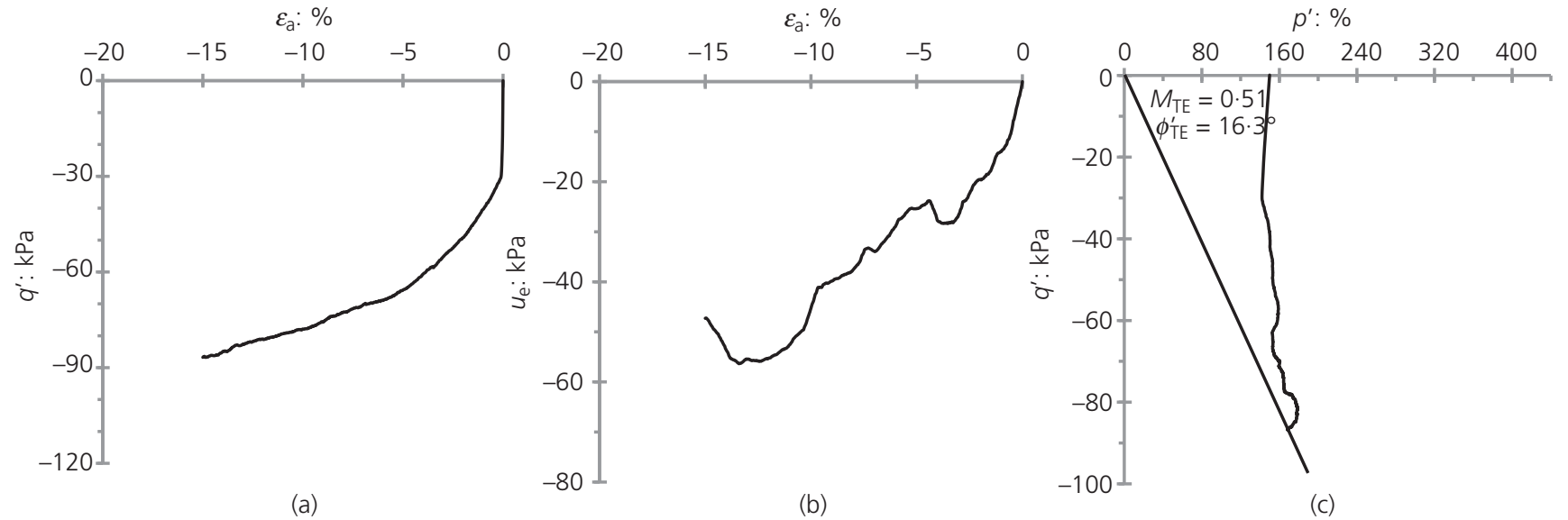

Figure 9. Compression stage of CIUE triaxial test on saturated compacted As-Samra WWTP biosolid material $\left(W_{\mathrm{f}}=107 \cdot 7 \%, \sigma_{\mathrm{ci}}^{\prime}=\right.$ $150 \mathrm{kPa}$ ): (a) deviatoric stress against axial strain; (b) excess pore water pressure against axial strain; (c) $p^{\prime}-q^{\prime}$ trace

Table 3. Effective-stress strength parameter values derived for saturated compacted As-Samra WWTP biosolid material from TC testing

\begin{tabular}{|c|c|c|c|c|c|c|c|}
\hline Test & $w_{\mathrm{i}}: \%$ & Compaction effort & $\sigma_{\mathrm{ci}}^{\prime}: \mathrm{kPa}$ & $c_{\mathrm{TC}}^{\prime}\left(C_{\mathrm{TE}}^{\prime}\right): \mathrm{kPa}$ & $\phi_{\mathrm{TC}}^{\prime}\left(\phi_{\mathrm{TE}}^{\prime}\right):^{\circ}$ & $A_{\mathrm{f}}$ & State \\
\hline CIUC triaxial 6 & $103 \cdot 5$ & Midway between SP and MP & 300 & 0 & $15 \cdot 1$ & $2 \cdot 90$ & NC \\
\hline CIUC triaxial 3 & $100 \cdot 0$ & Midway between SP and MP & 299 & 0 & $13 \cdot 6$ & $2 \cdot 70$ & NC \\
\hline CIUC triaxial 2 & $100 \cdot 0$ & Midway between SP and MP & 149 & 6 & 8.9 & 0.70 & Marginally $\mathrm{OC}$ \\
\hline CIUC triaxial 1 & $100 \cdot 0$ & Midway between SP and MP & 75 & 23 & 1.9 & 1.00 & Marginally $\mathrm{OC}$ \\
\hline CIUC triaxial 4 & $103 \cdot 5$ & Midway between SP and MP & 73 & 17 & $5 \cdot 7$ & 0.45 & Moderately OC \\
\hline CIUC triaxial 5 & $101 \cdot 8$ & Midway between SP and MP & 149 & 17 & $5 \cdot 7$ & -0.20 & Heavily OC \\
\hline CIDC triaxial 1 & $100 \cdot 1$ & Midway between SP and MP & 150 & 17 & $5 \cdot 7$ & NA & Heavily OC \\
\hline CIUE triaxial 1 & $100 \cdot 1$ & Midway between SP and MP & 150 & (0) & $(16 \cdot 3)$ & 0.70 & NC \\
\hline
\end{tabular}

NA, not applicable; NC, normally consolidated; OC, overconsolidated

$\phi_{\mathrm{TC}}^{\prime}$ values of $0 \mathrm{kPa}$ and $15 \cdot 1^{\circ}$, respectively. As expected, for an increasing level of overconsolidation, these parameter values increased and decreased respectively, such that $c_{\mathrm{TC}}^{\prime}$ of $23 \mathrm{kPa}$ and $\phi_{\mathrm{TC}}^{\prime}$ of $1.9^{\circ}$ were inferred for $p^{\prime}=0$. In a similar way, a $\phi_{\mathrm{TE}}^{\prime}$ value of $16 \cdot 3^{\circ}$ (with $c_{\mathrm{TE}}^{\prime}=0 \mathrm{kPa}$ ) was derived from the gradient of the triaxial extension failure line (i.e. $M_{\mathrm{TE}}$ value of 0.51 ) measured for the NC CIUE-triaxial 1 specimen (Figure 9(c)).

There is no indication from the $q^{\prime}-\varepsilon_{\mathrm{a}}$ traces presented in Figure 8(a) whether strain softening would occur (and its extent) for $\varepsilon_{\mathrm{a}} \gg$ $15 \%$. Further, the heavily OC CIDC-triaxial 1 specimen continued to dilate during the compression stage (Figure 8(c)) without ever showing signs of approaching a constant-volume condition for the terminal axial strain value of $15 \%$. In other words, with the critical state condition yet to be reached for significantly greater axial strain, the $\phi_{\mathrm{TC}}^{\prime}$ values reported in Table 3 for the NC state are greater than the biosolid material's critical state (constant-volume) angle of shearing resistance $\left(\phi_{\mathrm{cv}}^{\prime}\right)$ value, but the extent of these differences cannot be determined from the presented experimental results, such that the material's actual $\phi_{\mathrm{cv}}$ value remains unknown.

\section{DSS effective-stress strength testing}

The experimental results for the shearing stage of the CU DSS 1-7 tests are presented in Figure 10. Compared to the CIUC, CIDC
(Figure 8(b)) and CIUE (Figure 9(b)) triaxial results, the measured $u_{\mathrm{e}}$ responses for the CU DSS test specimens presented in Figure 10(b) exhibited much greater fluctuation. The authors suspect that the pore water pressure transducer used for the CU DSS tests was particularly sensitive to relatively minor changes occurring in the ambient laboratory temperature. For instance, compared to the $u_{\mathrm{e}}-\gamma$ trace for the CU DSS 1 specimen sheared at $\dot{\gamma}=5 \% / \mathrm{h}$ over a $4.4 \mathrm{~h}$ period, substantial diurnal cycling is eventful for the CU DSS 2-6 specimens, which were sheared significantly slower at $\dot{\gamma}=0.22 \% / \mathrm{h}$ over a $4.2 \mathrm{~d}$ period in order to achieve the same terminal shear strain value of $22 \%$. From Figure 10(b), it is also observed that the least diurnal cycling effect was for the CU DSS 2 and 5 specimens, which had the lowest $\sigma_{\mathrm{vc}}^{\prime}$ value of $75 \mathrm{kPa}$ investigated, suggesting that the $\sigma_{\mathrm{vc}}^{\prime}$ magnitude was another determining factor. Similarly, the $\tau_{\mathrm{DSS}}-\sigma_{\mathrm{v}}^{\prime}$ traces for the CU DSS 2-7 specimens also experience much greater fluctuations compared to the CU DSS 1 specimen (Figure 10(d)) since the measured $u_{\mathrm{e}}$ values are used in computing the $\sigma_{\mathrm{v}}^{\prime}$ values.

Based on the observed characteristic shapes of the data plots, the CU DSS 4 specimen $\left(\sigma_{\mathrm{vc}}^{\prime}=300 \mathrm{kPa}\right)$ was sheared in an NC state, the CU DSS 7 specimen was marginally OC, the CU DSS 6 specimen was lightly OC, the CU DSS 5 specimen was moderately $\mathrm{OC}$ and the CU DSS 2 and 3 specimens were both sheared in a 


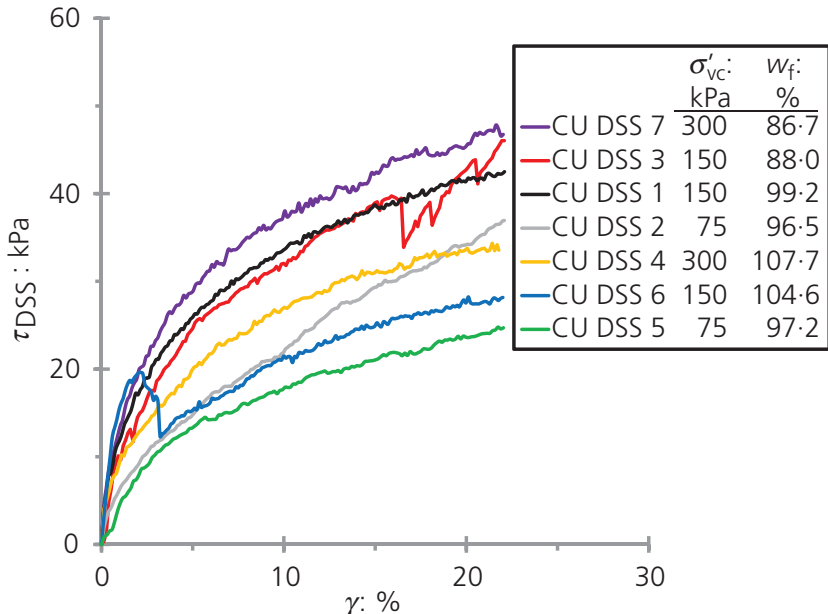

(a)

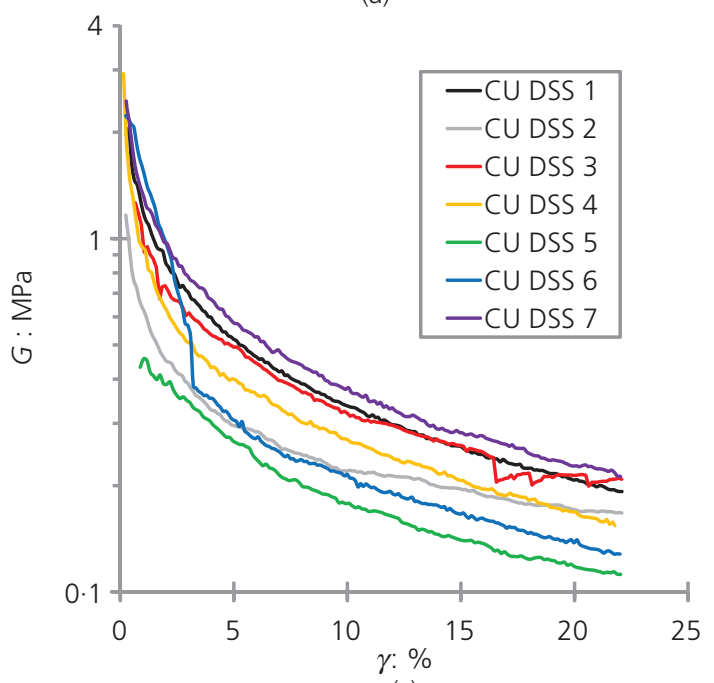

(c)

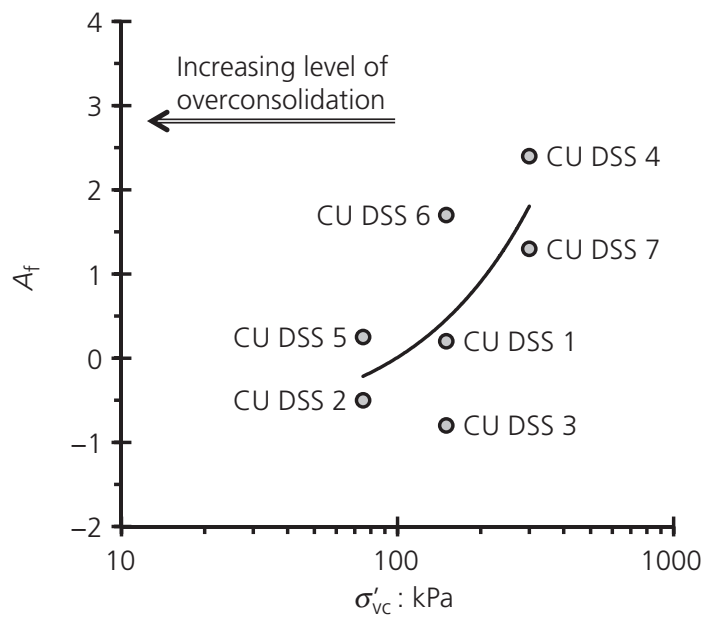

(e)

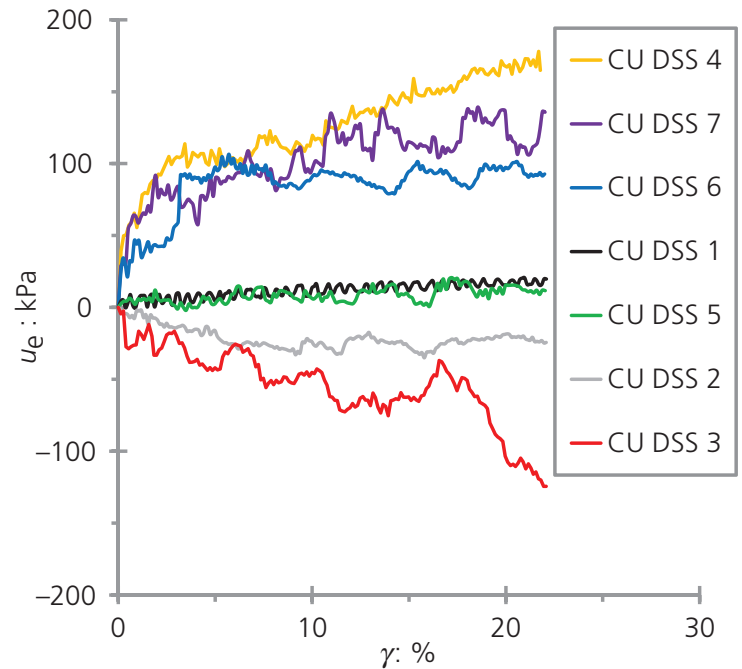

(b)

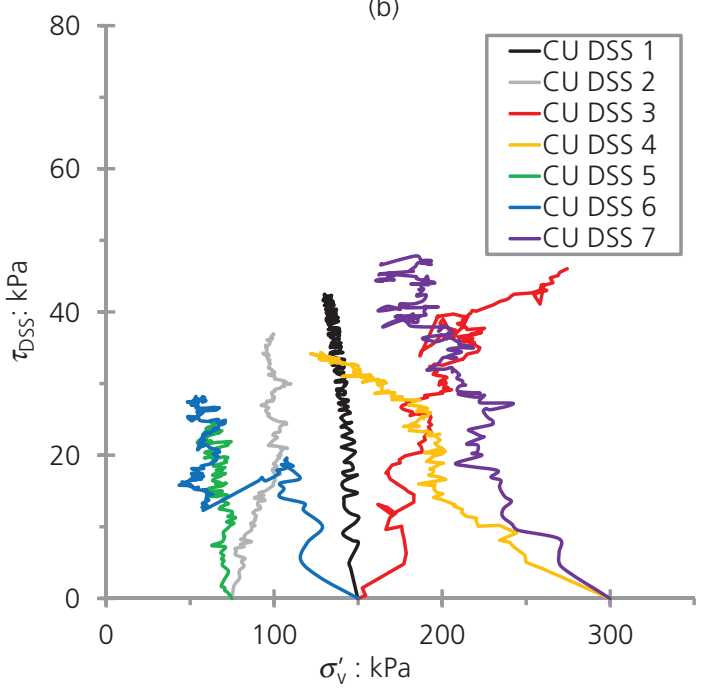

(d)

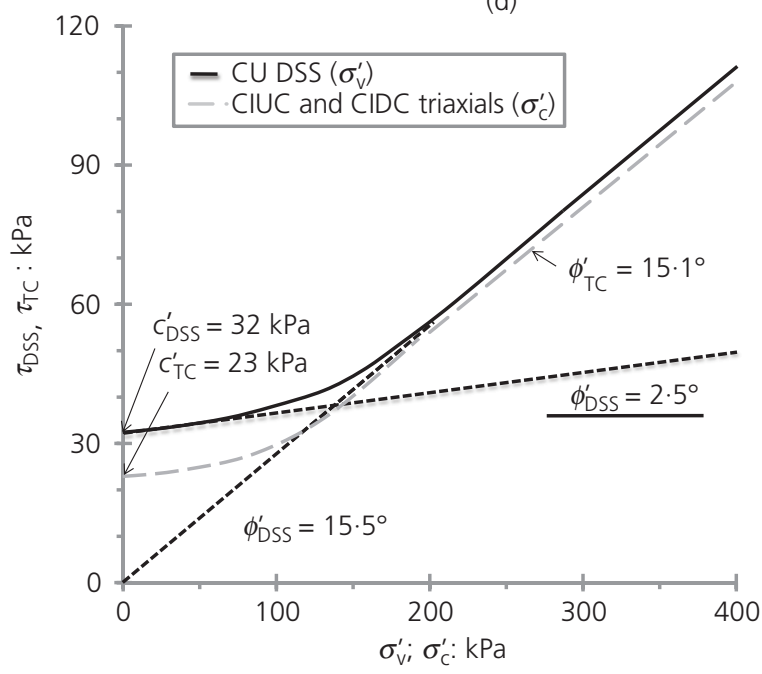

(f)

Figure 10. Shearing stage of DSS tests on saturated compacted As-Samra WWTP biosolid material: (a) shear stress against shear strain; (b) excess pore water pressure against shear strain; (c) shear modulus against shear strain; (d) shear stress against effective normal stress; (e) pore pressure coefficient $A$ at failure; (f) inferred failure envelopes 
heavily OC state. In other words, with $\tau_{\mathrm{DSS}}$ continuing to increase in value with increasing shear strain (Figure 10(a)), the $u_{\mathrm{e}}$ values generated continued to increase or approached a steady elevated value or decreased marginally from an elevated value or reached a steady low value or continued to decrease, thereby generating significant negative $u_{\mathrm{e}}$ values, respectively, as evident in Figure 10(b). These conclusions are confirmed by the values of the $A_{\mathrm{f}}$ coefficient presented in Figure $10(\mathrm{e})$, with the $A_{\mathrm{f}}$ value of $2 \cdot 4$ calculated for the NC CU-DSS 4 specimen consistent with the $A_{\mathrm{f}}$ values determined for the NC CIUC-triaxial 3 and 6 specimens (Figure 8(d)). Figure 10(c) presents the shear modulus $G$ (i.e. $\tau_{\mathrm{DSS}} / \gamma$ ) against shear strain responses for the CU DSS 1-7 specimens, with the small-strain $G$ value of these saturated compacted biosolid specimens dependent on the initial $\sigma_{\mathrm{vc}}^{\prime}$ value, but typically ranging between approximately 1 and $3 \mathrm{MPa}$.

The shearing rate used for the CU DSS 1 test (and also for the initial portion of the shearing stage for the CU DSS 6 test) was too fast, such that significantly non-uniform $u_{\mathrm{e}}$ distributions would have developed within these test specimens. Hence, only the experimental results for the CU DSS 2-5 and 7 specimens were considered in performing the effective-stress strength parameter analysis, whose findings are presented in Table 4.

Referring to Figure 10(f), the saturated compacted DSS specimen tested in the NC state had $c_{\mathrm{DSS}}^{\prime}$ and $\phi_{\mathrm{DSS}}^{\prime}$ values of $0 \mathrm{kPa}$ and $15 \cdot 5^{\circ}$, respectively. As expected, for an increasing level of overconsolidation, the values of these parameters increased and decreased, respectively, such that $c_{\mathrm{DSS}}^{\prime}$ of $32 \mathrm{kPa}$ and $\phi_{\mathrm{DSS}}^{\prime}$ of $2.5^{\circ}$ were inferred for the heavily $\mathrm{OC}$ specimens tested. The failure envelope determined for the saturated compacted As-Samra WWTP biosolid material from the CU DSS tests is shown in Figure 10(f). Comparing this with the failure envelope inferred from the CIUC triaxial tests (also included in Figure 10(f)) indicates that the saturated compacted material had isotropic strength properties when tested in the NC state $\left(\phi_{\mathrm{TC}}^{\prime} \approx \phi_{\mathrm{DSS}}^{\prime}\right.$, with $c^{\prime}=0$ ), whereas it exhibited cross-anisotropic strength behaviour (i.e. $\tau_{\mathrm{fDSS}}>\tau_{\mathrm{fTC}}$ ) when tested in the OC state, with the degree of cross-anisotropy progressively increasing for reducing $\sigma_{\mathrm{vc}}^{\prime}\left(\sigma_{\mathrm{ci}}^{\prime}\right)$ values below a threshold of approximately $190 \mathrm{kPa}$.

\section{Oedometer tests}

PHYSICAL PROPERTIES OF THE TEST SPECIMENS

The initial and final properties of the oedometer test specimens are presented in Table 5 .

\section{GENERAL 1D COMPRESSION BEHAVIOUR AND DATA ANALYSIS}

From Figure 11, the compacted As-Samra WWTP biosolid specimens tested were moderately compressible (e.g. $\varepsilon_{\mathrm{a}} \approx 12 \%$ for $\left.\sigma_{\mathrm{v}}^{\prime}=150 \mathrm{kPa}\right)$ and they had significant swelling pressure $\left(\sigma_{\mathrm{s}}\right)$ and apparent pre-consolidation pressure $\left(\sigma_{\max }^{\prime}\right)$ values, indicative of their compaction-induced OC state.

These material characteristics are consistent with the values reported for other compacted biosolid materials (Arulrajah et al., 2011, 2013; Aydilek et al., 2000; Chen et al., 2014; Klein and Sarsby, 2000; Lo et al., 2002; O'Kelly, 2004, 2005c, 2006a, 2016b, 2016c; Sarsby, 2005). For instance, the compressibility characteristics of the inundated oedometer 3 specimen of compacted As-Samra WWTP biosolid material with $w_{\mathrm{i}}=107 \%$ are consistent with those reported by O'Kelly (2005c, 2006a) for SPcompacted Tullamore WWTP biosolid specimens with $w_{\mathrm{i}}=100$ and $130 \%$. The oedometer derived properties and behaviour for both of these materials are presented in Table 6 and Figure 11(a). Table 6 was assembled following a comprehensive review of the pertinent literature, and it documents all biosolid and sewage sludge materials from different WWTPs for which at least their $w_{\mathrm{i}}$ and $e_{\mathrm{i}}$ values and either their $\varepsilon_{\mathrm{a}}-\log \sigma_{\mathrm{v}}^{\prime}$ data curves or deduced $C_{\mathrm{c}}$ values

Table 4. Effective-stress strength parameter values derived for saturated compacted As-Samra WWTP biosolid material from CU DSS testing

\begin{tabular}{|c|c|c|c|c|c|c|c|}
\hline Test & $w_{\mathrm{i}}: \%$ & Compaction effort & $\sigma_{\mathrm{vc}}^{\prime}: \mathrm{kPa}$ & $c_{\mathrm{DSS}}^{\prime}: \mathrm{kPa}$ & $\phi_{D S S}^{\prime}:^{\circ}$ & $A_{\mathrm{f}}$ & State \\
\hline CU DSS 4 & $103 \cdot 5$ & Midway between SP and MP & 300 & 0 & $15 \cdot 5$ & $2 \cdot 4$ & NC \\
\hline CU DSS 7 & $66 \cdot 0$ & $95 \% \mathrm{MP}$ & 300 & 2 & $15 \cdot 2$ & $1 \cdot 3$ & Marginally $O C$ \\
\hline CU DSS 5 & $66 \cdot 8$ & $95 \% \mathrm{MP}$ & 75 & 11 & $12 \cdot 2$ & $0 \cdot 25$ & Moderately OC \\
\hline CU DSS 2 & $106 \cdot 7$ & Midway between SP and MP & 75 & 32 & $2 \cdot 5$ & -0.5 & Heavily OC \\
\hline CU DSS 3 & $103 \cdot 5$ & Midway between SP and MP & 150 & 32 & $2 \cdot 5$ & $-0 \cdot 8$ & Heavily OC \\
\hline
\end{tabular}

Table 5. Initial and final physical properties of oedometer specimens tested

\begin{tabular}{|c|c|c|c|c|c|c|c|c|c|c|c|c|}
\hline \multirow[b]{2}{*}{ Test } & \multirow[b]{2}{*}{$\begin{array}{l}\text { Specimen } \\
\text { inundated }\end{array}$} & \multirow[b]{2}{*}{$\sigma_{v}^{\prime}$ range: $\mathrm{kPa}$} & \multicolumn{4}{|c|}{ Initial state } & \multicolumn{5}{|c|}{ End of test } & \multirow[b]{2}{*}{$\begin{array}{l}\text { Total test } \\
\text { duration: } \mathbf{d}\end{array}$} \\
\hline & & & $\begin{array}{l}W_{\mathrm{i}}: \\
\%\end{array}$ & $e_{i}$ & $\begin{array}{c}\gamma_{\mathrm{d}}: \\
\mathrm{kN} / \mathrm{m}^{3}\end{array}$ & $\begin{array}{l}S_{r}: \\
\%\end{array}$ & $\begin{array}{l}\varepsilon_{\mathrm{a}}: \\
\%\end{array}$ & $\begin{array}{c}W_{f}: \\
\%\end{array}$ & $e_{f}$ & $\begin{array}{c}\gamma_{\mathrm{d}}: \\
\mathrm{kN} / \mathrm{m}^{3}\end{array}$ & $\begin{array}{l}S_{\mathrm{r}}: \\
\%\end{array}$ & \\
\hline Oedometer 1 & No & $11-1200$ & 74 & 1.84 & $5 \cdot 81$ & 68 & $30 \cdot 8$ & 54 & 0.96 & $8 \cdot 40$ & 95 & 14 \\
\hline Oedometer 2 & No & $5-1200$ & 106 & 1.95 & $5 \cdot 59$ & 91 & $31 \cdot 1$ & 72 & $1 \cdot 31$ & $7 \cdot 14$ & 92 & 13 \\
\hline Oedometer 3 & Yes & $27-1200$ & 107 & 1.98 & $5 \cdot 53$ & 91 & $25 \cdot 3$ & 87 & $1 \cdot 53$ & $6 \cdot 50$ & 96 & 13 \\
\hline Oedometer 4 & Yes & 50-150 & 110 & $2 \cdot 16$ & $5 \cdot 21$ & 86 & $14 \cdot 1$ & 110 & $1 \cdot 71$ & $6 \cdot 07$ & 100 & 42 \\
\hline
\end{tabular}




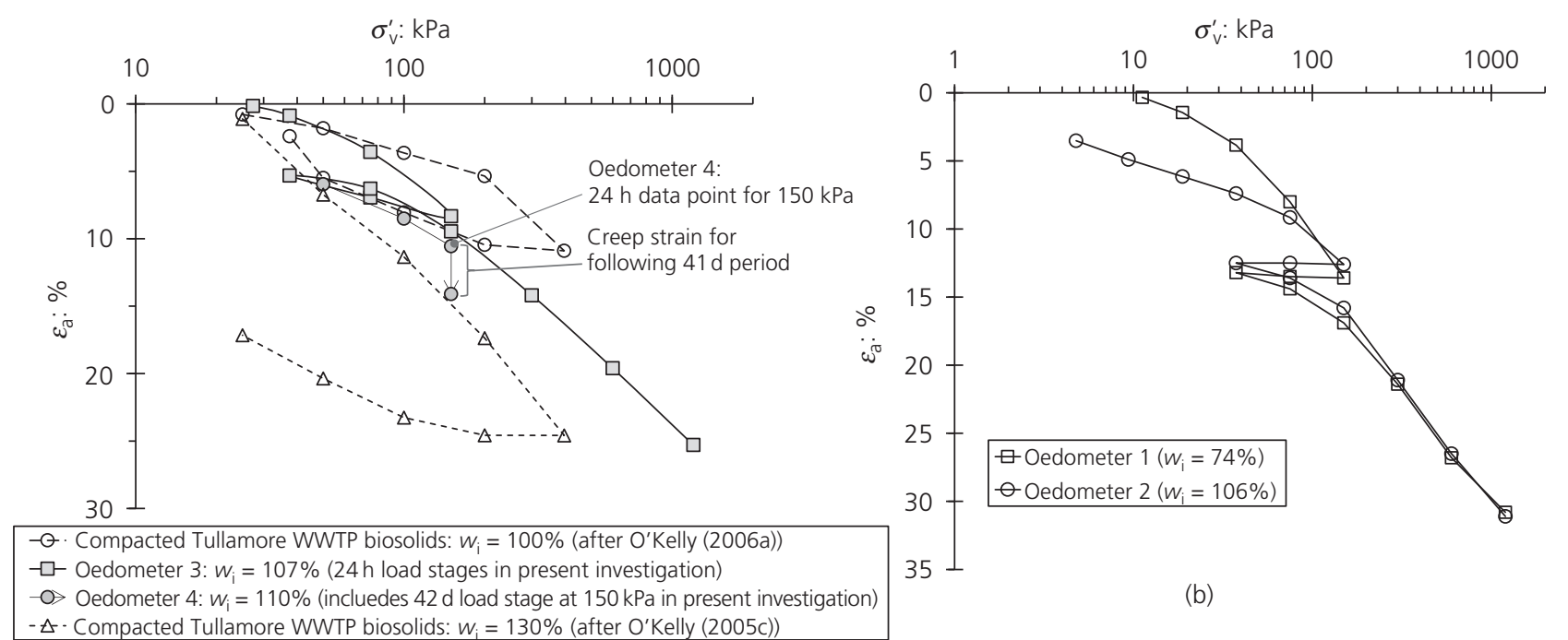

(a)

Figure 11. Oedometer results presented as axial strain against $\log \sigma_{v}^{\prime}$ : (a) inundated specimens; (b) non-inundated specimens

for oedometer testing of compacted specimens are reported. Using this database, correlations between $C_{\mathrm{c}}$ and $w_{\mathrm{i}}$ or $e_{\mathrm{i}}$ for compacted biosolid and sewage sludge materials are investigated later in the paper (in the section headed 'Compression index correlations').

The compression, consolidation and creep parameter values for the compacted As-Samra WWTP biosolid specimens are reported in Tables 7 and 8. The compression index $\left(C_{\mathrm{c}}\right)$ and recompression index $\left(C_{\mathrm{r}}\right)$ values were derived from the $\varepsilon_{\mathrm{a}}-\log \sigma_{\mathrm{v}}^{\prime}$ data curves in the usual manner, with the $C_{\mathrm{r}}$ values corresponding to the gradient of the initial loading (recompression) to the compaction-induced $\sigma_{\max }^{\prime}$ value. The latter was determined as the $\sigma_{\mathrm{v}}^{\prime}$ value corresponding to the intersection of the initial recompression and idealised linear NC segments of the experimental $\varepsilon_{\mathrm{a}}-\log \sigma_{\mathrm{v}}^{\prime}$ curve. The compression ratio $\left(C_{\mathrm{R}}\right)$, recompression ratio $\left(R_{\mathrm{R}}\right)$ and at-rest rebound parameter $(m)$ values were computed according to the following equations

1. $C_{\mathrm{R}}=C_{\mathrm{c}} /\left(1+e_{\mathrm{i}}\right)$

2. $R_{\mathrm{R}}=C_{\mathrm{r}} /\left(1+e_{\mathrm{i}}\right)$

3. $m=\left(C_{\mathrm{R}}-R_{\mathrm{R}}\right) / C_{\mathrm{R}}$

When presented on an $\varepsilon_{\mathrm{a}}-\log t$ plot, the points of inflection of the experimental loading (unloading) curves were not evident (rather the curves were shaped convex upwards), such that the end-ofprimary-consolidation condition was not readily discernible from standard curve fitting. Note $t$ is the elapsed time from application of the load increment for a given load stage. Further, rather than exhibiting loading curves shaped concave upwards when presented on an $\varepsilon_{\mathrm{a}}-t^{1 / 2}$ plot, many of the experimental curves appeared as approximately straight lines, particularly for the noninundated specimens, in which case their $t_{90}$ values (i.e. the time period corresponding to $90 \%$ of the consolidation strain associated with the load step) could not be determined by standard curve fitting. Such behaviour was previously reported for Tullamore WWTP biosolid specimens SP-compacted at $w_{\mathrm{i}}=100$ and $130 \%$ (O'Kelly, 2005c, 2006a). The linear nature of the final portions of the $24 \mathrm{~h} \varepsilon_{\mathrm{a}}-\log t$ curves for the As-Samra WWTP biosolid specimens indicated that large secondary compression strain was occurring for the latter part of each load stage and was significantly greater than any remaining primary consolidation component. The secondary compression coefficient $\left(C_{\alpha}\right)$ values were computed from the linear final portion of the $\varepsilon_{\mathrm{a}}-\log t$ curves in the normal manner and are reported in Table 8 .

Two approaches were used in determining the coefficient of the consolidation $\left(c_{\mathrm{v}}\right)$ value for a given load step. The end of the primary consolidation phase was assumed as the specimen strain corresponding to the initial data point on the linear final portion of the experimental $\varepsilon_{\mathrm{a}}-\log t$ curve (Hobbs, 1986; O'Kelly, 2005c, 2006a, 2008a; 2018c). Apart from $\sigma_{\mathrm{v}}^{\prime} \geq 300 \mathrm{kPa}$, it was also possible to determine for each load stage of the inundated oedometer 3 test the specimen strain corresponding to $90 \%$ of the primary consolidation strain using the $t^{1 / 2}$ curve-fitting method (this was generally not the case for the non-inundated oedometer 1 and 2 tests). The specimen strain corresponding to the start of the primary consolidation phase was determined using the $t^{1 / 2}$ curve-fitting method (Taylor, 1942). In this manner, the $t_{50}$ (i.e. the time period corresponding to $50 \%$ of the consolidation strain associated with the load step) and $t_{90}$ values for each load step were determined and used to calculate the corresponding $c_{\mathrm{V}}$ 


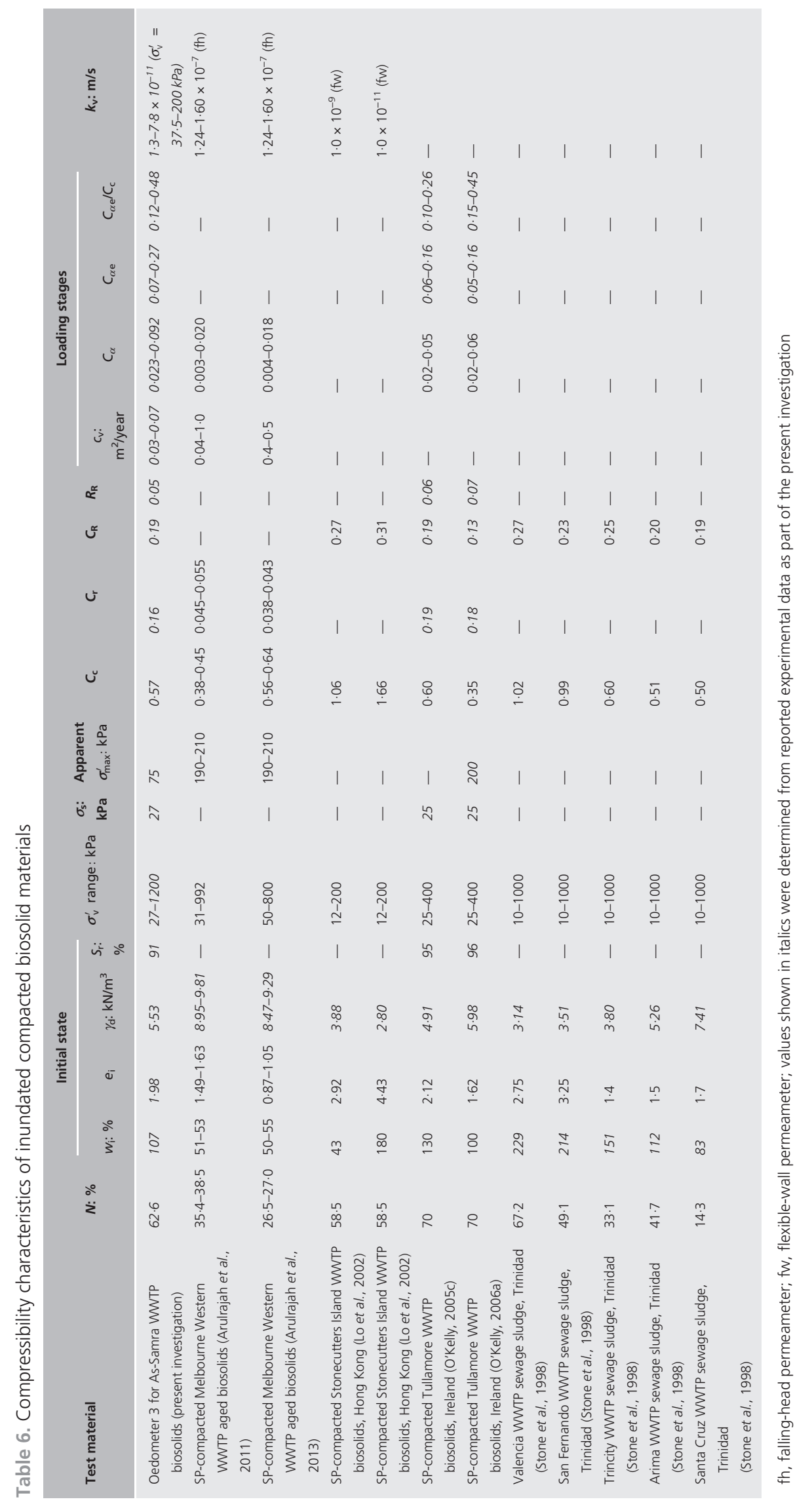


Table 7. Compressibility properties of compacted As-Samra WWTP biosolid material

\begin{tabular}{|c|c|c|c|c|c|c|c|c|c|}
\hline Test & Specimen inundated & $\sigma_{\mathrm{v}}^{\prime}$ range: $\mathrm{kPa}$ & $\sigma_{\mathrm{s}}: \mathrm{kPa}$ & Apparent $\sigma_{\max }^{\prime}: \mathrm{kPa}$ & $C_{\mathrm{c}}$ & $C_{r}$ & $C_{R}$ & $R_{\mathrm{R}}$ & $m$ \\
\hline Oedometer 1 & No & $11-1200$ & 11 & 45 & 0.52 & $0 \cdot 16$ & 0.19 & 0.05 & $0 \cdot 70$ \\
\hline Oedometer 2 & No & $5-1200$ & 5 & 105 & 0.59 & 0.12 & 0.20 & 0.04 & 0.80 \\
\hline Oedometer 3 & Yes & $27-1200$ & 27 & 75 & 0.57 & 0.16 & 0.19 & 0.05 & 0.72 \\
\hline Oedometer 4 & Yes & 50-150 & - & - & - & - & - & - & - \\
\hline
\end{tabular}

Table 8. Consolidation and creep properties of compacted As-Samra WWTP biosolid material

\begin{tabular}{|c|c|c|c|c|c|c|c|}
\hline \multirow{2}{*}{ Test number } & \multirow{2}{*}{ Specimen inundated } & \multicolumn{2}{|c|}{$c_{\mathrm{v}}: \mathrm{m}^{2} /$ year } & \multicolumn{2}{|c|}{$\mathrm{C}_{\alpha}$} & \multicolumn{2}{|c|}{$\mathrm{C}_{\alpha \mathrm{e}} / \mathrm{C}_{\mathrm{c}}$} \\
\hline & & OC region & NC region & OC region & NC region & OC region & NC region \\
\hline Oedo & No & $07(3)$ & $0.07-$ & 0.00 & 0.024 & $12(3)$ & $0 \cdot 14$ \\
\hline Oedometer 2 & No & $0 \cdot 07-0 \cdot 13(5)$ & $0.06 \rightarrow 0.03(5)$ & $0.006-0.021(6)$ & $0.023-0.034(5)$ & $0.03-0 \cdot 10(6)$ & $0 \cdot 12-0.17(5)$ \\
\hline Oedometer 3 & Yes & $0 \cdot 16-0.39(4)$ & $0.07 \rightarrow 0.03(4)$ & $0.004-0.012(3)$ & $0.023-0.092(5)$ & $0.02-0.06(3)$ & $0.12-0.48(5)$ \\
\hline Oedometer 4 & Yes & - & $0.04(1)$ & - & $0.041(1)$ & - & - \\
\hline
\end{tabular}

Bracketed values indicate numbers of experimental results available, $\rightarrow$ indicates a reduction

values in the usual way. However, the characteristic shapes of the experimental $\varepsilon_{\mathrm{a}}$ against $t^{1 / 2}$ and $\log t$ curves determined whether it was possible to calculate one, a pair or no $c_{\mathrm{v}}$ values for a given load stage. The $\varepsilon_{\mathrm{a}}-\log t$ approach described had the advantage that it could be applied for all of the load stages and allowed a more definitive interpretation of the primary consolidation and secondary compression components for each data curve. There was good agreement overall in the deduced parameter values for a given load stage when it was possible to apply both the $\log t$ and $t^{1 / 2}$ approaches with confidence. Compared to the inundated specimens, the initial axial strain of the non-inundated oedometer specimens was significantly greater on account of the associated compression of the pore gas voids present.

\section{COMPRESSIBILITY}

Swelling pressure Referring to Table 7, the swelling pressure $\left(\sigma_{\mathrm{s}}\right)$ value was significantly greater for the inundated condition (i.e. $27 \mathrm{kPa}$ as compared to $5 \mathrm{kPa}$ for the non-inundated condition with $w_{\mathrm{i}} \approx 106 \%$ : oedometer specimens 3 and 2, respectively) and also for lower compaction water content (11 and $5 \mathrm{kPa}$ for $w_{\mathrm{i}} \approx 74$ and 106\%: oedometer specimens 1 and 2, respectively). Greater swelling pressure correlated with reduced compressibility for the OC state - for example, for $\sigma_{\mathrm{v}}^{\prime}=37.5 \mathrm{kPa}, \varepsilon_{\mathrm{a}} \approx 0.9,3.9$ and $7 \cdot 4 \%$ for the inundated oedometer specimen 3 and non-inundated oedometer specimens 1 and 2, respectively. Further, based on the limited data available, the degree of overconsolidation (assessed here in terms of the $\sigma_{\mathrm{s}}$ value) present for the non-inundated specimens was greater for the lower compaction water content. Refer to oedometer specimens 1 and $2\left(w_{\mathrm{i}}=74\right.$ and $106 \%$, respectively) in Table 7 .

Compression and recompression indices For compaction water contents of between 74 and 107\%, the non-inundated and inundated As-Samra WWTP biosolid specimens had broadly similar compression and recompression index values, with mean $C_{\mathrm{c}}=0.56$ and mean $C_{\mathrm{r}}$ (for loading to the compaction-induced $\sigma_{\max }^{\prime}$ value) of $0 \cdot 15$, based on the data presented in Table 7. A distinctive feature of the non-inundated specimens was that they underwent no swelling for subsequent unloading (as evident from the unload-reload loops for oedometer specimens 1 and 2 presented in Figure 11(b)), since they had no access to free water during the testing.

Coefficient of consolidation A near full suite of $c_{\mathrm{v}}$ values was calculated based on the $t_{50}$ values deduced from the experimental $\varepsilon_{\mathrm{a}}-\log t$ curves using the modified curve-fitting approach described in the section headed 'General 1D compression behaviour and data analysis'. However, the shapes of the $\varepsilon_{\mathrm{a}}-t^{1 / 2}$ curves often did not match the characteristic curves given by Terzaghi's 1D consolidation theory (typical of other biosolid materials (O'Kelly, 2018c)), such that fewer $c_{\mathrm{v}}$ values were deduced for the As-Samra WWTP biosolid specimens based on the $t_{50}$ values determined using the $t^{1 / 2}$ curve-fitting approach.

All of the computable $c_{\mathrm{V}}$ values for the load-unload-reload stages of the oedometer tests on the inundated and non-inundated compacted biosolid specimens are presented in Figures 12 and 13, respectively. For instance, the oedometer 3 test was composed of 11 load stages for $\sigma_{\mathrm{v}}$ ranging $27-1200 \mathrm{kPa}$, with a measured $\sigma_{\mathrm{s}}$ value of $27 \mathrm{kPa}$ and $\sigma_{\max }^{\prime}$ value of $75 \mathrm{kPa}$ deduced from curve fitting of the experimental $\varepsilon_{\mathrm{a}}-\log \sigma_{\mathrm{v}}^{\prime}$ curve, as described in the section headed 'General 1D compression behaviour and data analysis'. In other words, for the first load stage at $\sigma_{\mathrm{v}}=27 \mathrm{kPa}$, this inundated test specimen swelled back to its original volume after initially consolidating, with the OC specimen then consolidating for the next two load stages at $\sigma_{\mathrm{v}}=37.5$ and $75 \mathrm{kPa}$. This specimen was in an NC state for the following load stage at $150 \mathrm{kPa}$ and then in an $\mathrm{OC}$ state for the subsequent unload-reload loop (i.e. with $\sigma_{\mathrm{v}}$ reducing to $75 \mathrm{kPa}$ and then to $37 \cdot 5 \mathrm{kPa}$, before increasing again to $75 \mathrm{kPa}$ and then to $150 \mathrm{kPa}$ ). This specimen was in an NC state for the final three load stages that is, $\sigma_{\mathrm{v}}=300,600$ and $1200 \mathrm{kPa}$. In summary, of the total 11 load stages; this test specimen was in $\mathrm{NC}$ and $\mathrm{OC}$ states for 


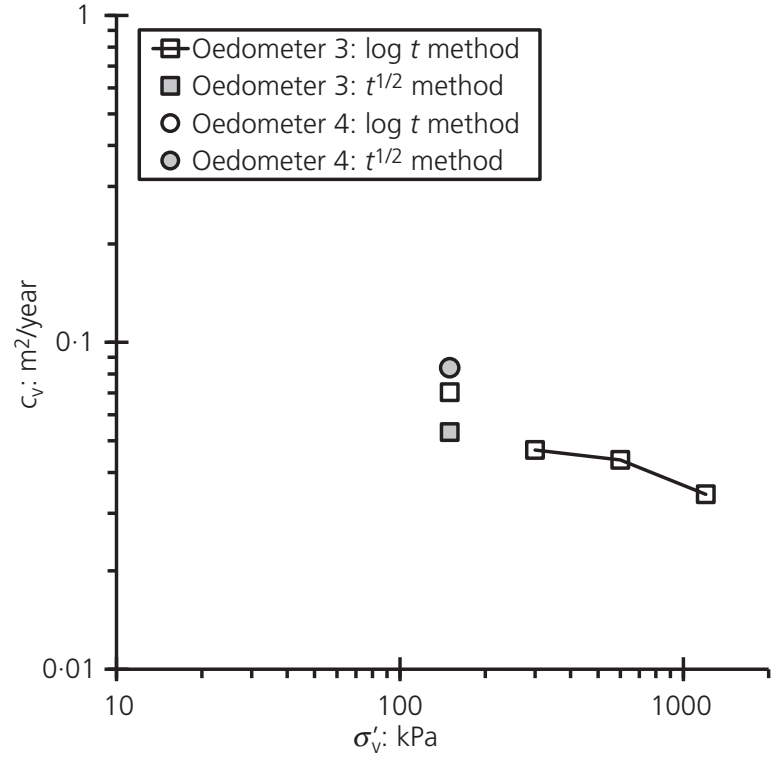

(a)

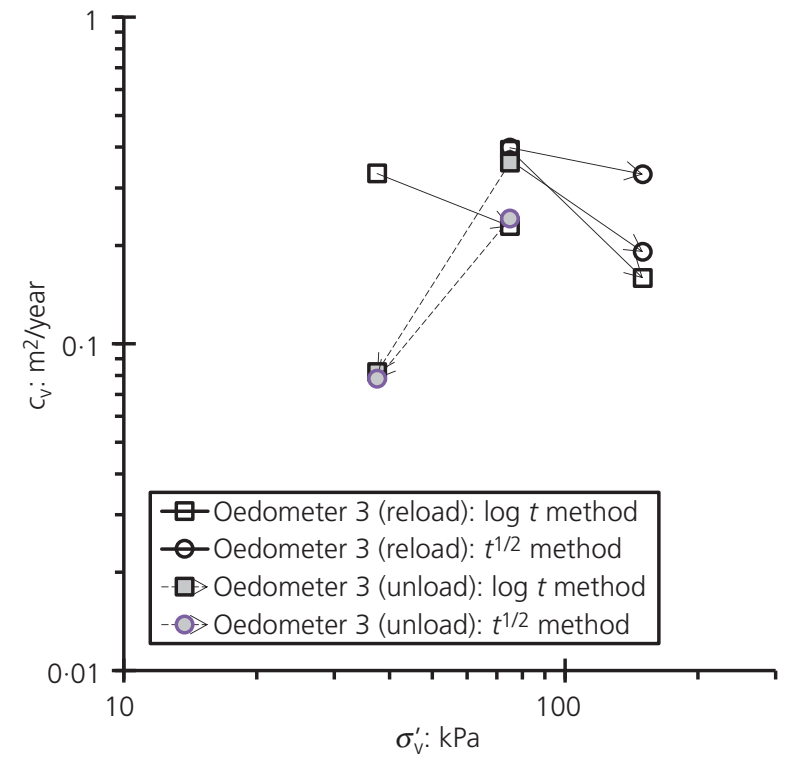

(b)

Figure 12. Coefficient of consolidation values for inundated oedometer specimens: (a) loading in the NC region; (b) unloading and reloading

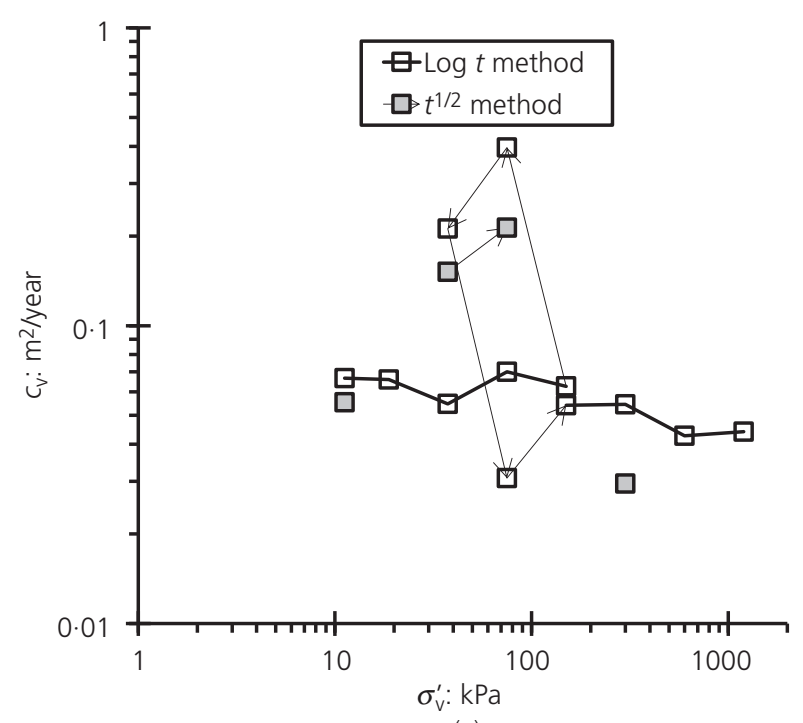

(a)

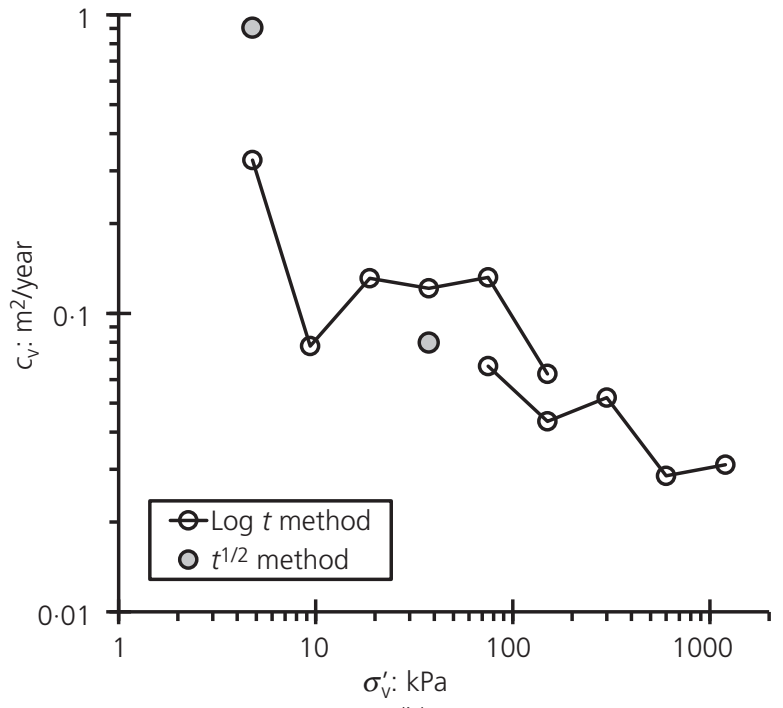

(b)

Figure 13. Coefficient of consolidation values for non-inundated biosolid material: (a) oedometer 1 specimen $\left(w_{i}=74 \%\right)$; (b) oedometer 2 specimen $\left(w_{i}=106 \%\right)$

four and seven of them, respectively, with all of its computable $c_{\mathrm{V}}$ values presented in Figures 12(a) and 12(b), respectively.

For loading of the inundated oedometer 3 specimen in its NC state, the deduced $c_{\mathrm{v}}$ values were approximately inversely proportional to $\sigma_{\mathrm{v}}^{\prime}$ when presented on a double-logarithmic plot (Figure 12(a)), reducing from approximately 0.07 to $0.03 \mathrm{~m}^{2} /$ year for $\sigma_{\mathrm{v}}^{\prime}$ increasing from 150 to $1200 \mathrm{kPa}$. The $c_{\mathrm{v}}$ values derived for loading to the compaction-induced $\sigma_{\max }^{\prime}$ value were approximately one order of magnitude greater (see oedometer 3 (reload) data in Figure 12(b)).

For loading of the non-inundated oedometer specimens 1 and 2 within the investigated $\sigma_{\mathrm{v}}^{\prime}$ range of $5-1200 \mathrm{kPa}$, the deduced $c_{\mathrm{v}}$ values also typically ranged $0.03-0.07 \mathrm{~m}^{2} /$ year, again reducing approximately linearly in value with increasing $\sigma_{\mathrm{v}}^{\prime}$ when presented on a double-logarithmic plot (Figure 13). This $c_{\mathrm{v}}$ value range is 
Geotechnical properties of compacted

biosolids for monofill design, As-Samra,

Jordan

'Kelly, Oettle and Ramos reasonably consistent with the $c_{\mathrm{v}}$ range of $0.01-0.03 \mathrm{~m}^{2} /$ year determined from oedometer testing of saturated, very soft Tullamore WWTP biosolid material $(N=70 \%)$ over the $\sigma_{\mathrm{v}}^{\prime}$ range of 6-100 kPa (O’Kelly, 2008a).

Secondary compression The $C_{\alpha}$ and $C_{\alpha \mathrm{e}} / C_{\mathrm{c}}$ ratio (where $\left.C_{\alpha \mathrm{e}}=\partial e / \partial \log t\right)$ values deduced for the inundated and noninundated oedometer specimens are presented in Figures 14 and 15 , respectively. Overall, the values of $C_{\alpha}$ and $C_{\alpha \mathrm{e}} / C_{\mathrm{c}}$ generally increased with increasing $\sigma_{\mathrm{v}}^{\prime}$ (and vice versa), typical of soil behaviour (O'Kelly, 2006b). In other words, the secondary compression strain component of a given load stage became increasingly dominant over its primary consolidation strain component with increasing $\sigma_{\mathrm{v}}^{\prime}$ for the As-Samra WWTP biosolid specimens, similar to that of Tullamore WWTP biosolid material reported by O'Kelly (2005c, 2006a, 2008a).

From the loading of oedometer 3 and 4 specimens in the $\mathrm{NC}$ state (i.e. $\sigma_{\mathrm{v}}^{\prime}=150-1200 \mathrm{kPa}$ in Figure $14(\mathrm{a})$ ), the $C_{\alpha}$ and $C_{\alpha \mathrm{e}} / C_{\mathrm{c}}$ values for the inundated compacted As-Samra WWTP biosolid material ranged $0.023-0.092$ (mean of 0.048 for $n=6$ ) and $0 \cdot 12-0 \cdot 48$ (mean of 0.26 for $n=5$ ), respectively. This $C_{\alpha \mathrm{e}} / C_{\mathrm{c}}$ range is consistent with the values reported for SP-compacted Tullamore WWTP biosolid material (O'Kelly, 2005c, 2006a), which are summarised in Table 6. However, the experimental $C_{\alpha \mathrm{e}} / C_{\mathrm{c}}$ ranges for both of these biosolid materials are significantly greater than the ranges of $0 \cdot 02-0 \cdot 10$ and $0 \cdot 04-0 \cdot 06$ reported by Mesri and Castro (1987) for peats and highly organic plastic clays, respectively. For loading in the OC state, the deduced $C_{\alpha}$ and $C_{\alpha e} / C_{\mathrm{c}}$ values for the oedometer 3 specimen were approximately one order of magnitude lower than those deduced for its NC state (Figure 14(b)).
For loading of the oedometer 1 and 2 specimens in the NC state (i.e. $\sigma_{\mathrm{v}}^{\prime}=75-1200 \mathrm{kPa}$ in Figure $15(\mathrm{a})$ ), the $C_{\alpha}$ and $C_{\alpha \mathrm{e}} / C_{\mathrm{c}}$ values for the non-inundated compacted As-Samra WWTP biosolid material ranged $0.023-0.035$ (mean of 0.028 for $n=11$ ) and $0 \cdot 12$ to $0 \cdot 20$ (mean of $0 \cdot 15$ for $n=11$ ), respectively. In other words, the inundated specimens underwent significantly greater creep strain (axial deformation) than the non-inundated specimens for maintained loading in the $\mathrm{NC}$ state, particularly at higher $\sigma_{\mathrm{v}}^{\prime}$ levels. For loading in the OC state, the creep strain levels deduced for the non-inundated specimens, with $C_{\alpha}$ and $C_{\alpha \mathrm{e}} / C_{\mathrm{c}}$ values ranging $0 \cdot 005-0 \cdot 021$ (mean of $0 \cdot 013$ for $n=9$ ) and $0 \cdot 03-0 \cdot 12$ (mean of 0.07 for $n=9$ ), respectively (Figure 15(c)), were marginally greater than those determined for the inundated oedometer 3 specimen.

Tertiary compression The $C_{\alpha}$ values determined for the inundated oedometer 3 and 4 specimens at $\sigma_{\mathrm{v}}=150 \mathrm{kPa}$ (load stage durations of $24 \mathrm{~h}$ and $42 \mathrm{~d}$, respectively) were in excellent agreement - that is, $C_{\alpha} \approx 0 \cdot 04$ : see Figure 14(a)). Further, there was no increase in the gradient of the secondary compression portion (appeared as a straight line segment) of the $\varepsilon_{\mathrm{a}}-\log t$ data curve evident for the $42 \mathrm{~d}$ duration load stage of the oedometer 4 test. These observations would indicate that negligible tertiary compression (i.e. axial strain arising from loss of susceptible organic matter in the test specimen due to the effect of ongoing biodegradation under the laboratory test conditions) had occurred over the course of the inundated oedometer tests. This is consistent with the earlier observation in the section headed 'Shear strength and water content' for the measured pore water pressure responses during the compression stage of the CIUC and CIDC triaxial tests, which indicated that biodegradation did not have a significant impact on the test results.

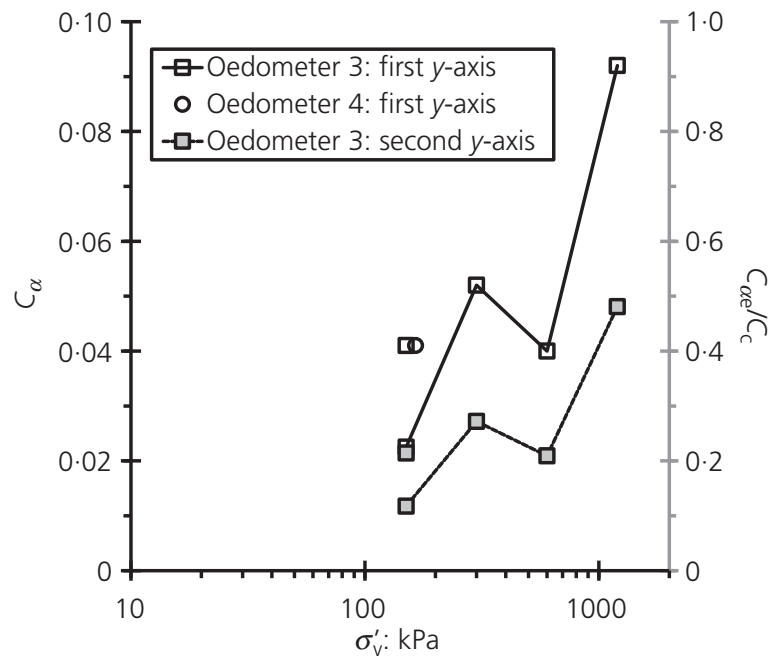

(a)

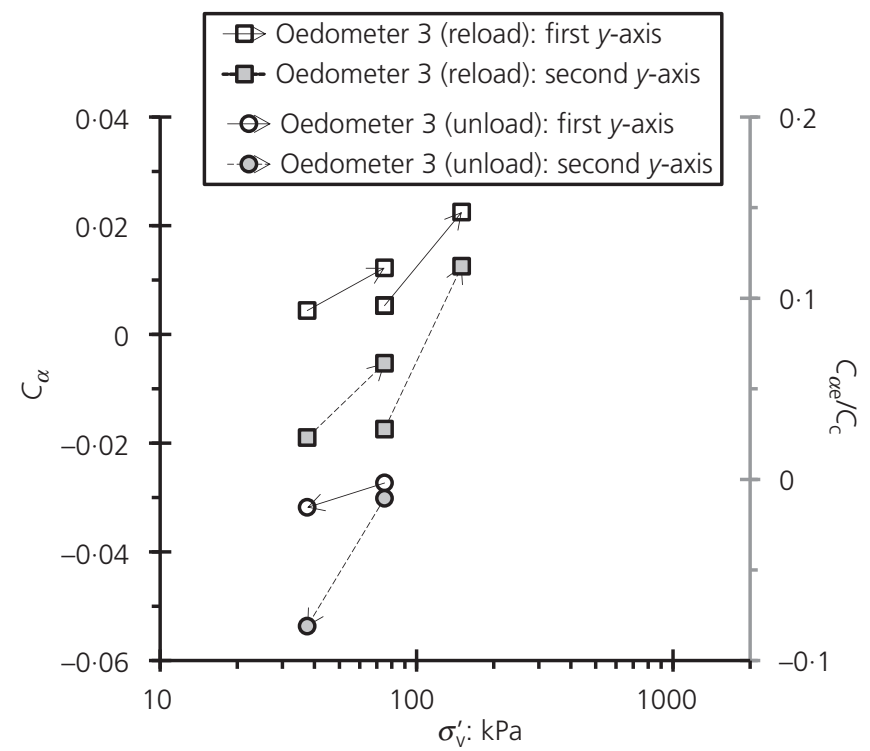

(b)

Figure 14. Secondary compression coefficient values for inundated biosolid specimens: (a) loading in the NC region; (b) unloading and reloading 


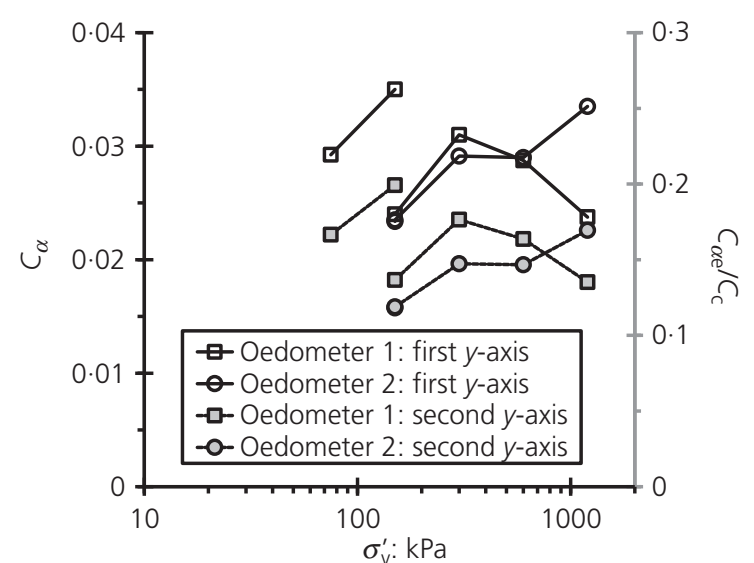

(a)

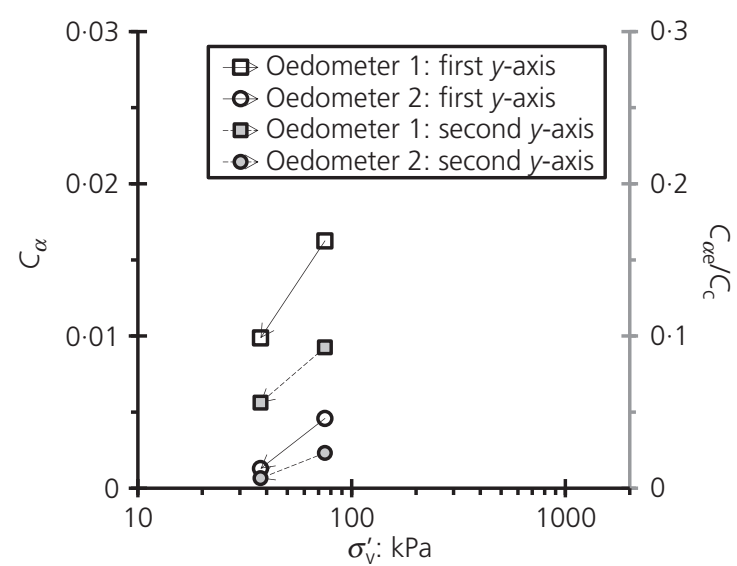

(b)

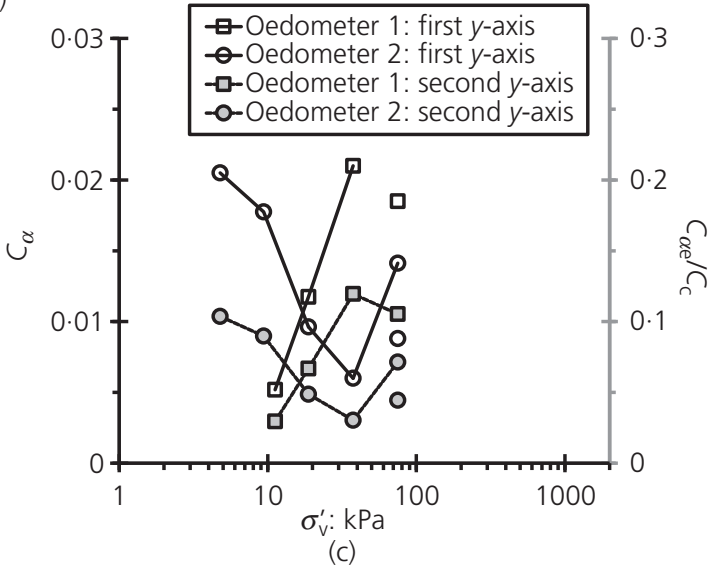

Figure 15. Secondary compression coefficient values for non-inundated biosolid specimens: (a) loading in the NC region; (b) unloading; (c) reloading

\section{Permeability coefficient}

The permeability coefficient $\left(k_{\mathrm{v}}\right)$ value for the saturated As-Samra WWTP biosolid specimen compacted at $110 \%$ water content $\left(e_{\mathrm{i}}=\right.$ $2 \cdot 05)$ was extremely low, as demonstrated by the very small flow volume of approximately $10 \%$ of the pore void volume measured at the end of the 2.5 month testing period in the flexible-wall permeameter device. From the experimental results, the $k_{\mathrm{v}}$ value of this specimen was determined as $2.9 \times 10^{-12} \mathrm{~m} / \mathrm{s}$ for the controlled level of effective stress of $75 \mathrm{kPa}$ and ambient laboratory temperature of $20^{\circ} \mathrm{C}$. This $k_{\mathrm{v}}$ value is in excellent agreement with the value of $2.7 \times 10^{-12} \mathrm{~m} / \mathrm{s}$ deduced from extrapolation to $e=2.05$ of the linear experimental $e-\log k_{\mathrm{v}}$ relationship presented for the Nine Springs WWTP (Madison, Wisconsin, USA) biosolid material $(N=25 \%)$ as Figure 3 of the publication by Aydilek et al. (2000). This relationship was established using hydraulic conductivity tests performed with flow moving from top to bottom of a $203 \mathrm{~mm}$ dia. specimen at the end of each load stage of a slurry consolidometer test on very soft Nine Springs WWTP biosolid material. Further, the measured $k_{\mathrm{v}}$ value for the saturated compacted As-Samra WWTP biosolid specimen is in good agreement with the flexible-wall permeameter derived $k_{\mathrm{v}}$ value of $1.0 \times 10^{-11} \mathrm{~m} / \mathrm{s}$ reported by Lo et al. (2002) for SP-compacted Stonecutters Island WWTP biosolid material $\left(w_{\mathrm{i}}=180 \%, N=58 \cdot 5 \%\right)$.

In Figure 16, the flexible-wall permeameter $k_{\mathrm{v}}$ value measured for the As-Samra WWTP biosolid specimen is compared with the $k_{\mathrm{v}}$ values calculated for each load increment of the oedometer 3 test (i.e. inundated specimen) using 1D consolidation theory, according to the equation
4. $k_{\mathrm{v}}=c_{\mathrm{v}} m_{\mathrm{v}} \times 3 \cdot 1 \times 10^{-10}(\mathrm{~m} / \mathrm{s})$

where $c_{\mathrm{v}}$ is the coefficient of consolidation $\left(\mathrm{m}^{2} /\right.$ year) and $m_{\mathrm{v}}$ is the coefficient of volume compressibility $\left(\mathrm{m}^{2} / \mathrm{MN}\right)$ determined for the particular load increment under consideration.

For $\sigma_{\mathrm{v}}^{\prime}=37 \cdot 5-150 \mathrm{kPa}$, the oedometer-derived $k_{\mathrm{v}}$ values for the inundated As-Samra WWTP biosolid specimens reduced from approximately $7 \cdot 8 \times 10^{-11}$ to $1.3 \times 10^{-11} \mathrm{~m} / \mathrm{s}$, exhibiting the characteristic inverse relationship when presented on a doublelogarithmic $k_{\mathrm{v}}-\sigma_{\mathrm{v}}^{\prime}$ plot (Figure 16). This range of $k_{\mathrm{v}}$ values is consistent with the reported ranges of $1.3 \times 10^{-10}$ to $6.8 \times$ 
Geotechnical properties of compacted

biosolids for monofill design, As-Samra,

Jordan

'Kelly, Oettle and Ramos

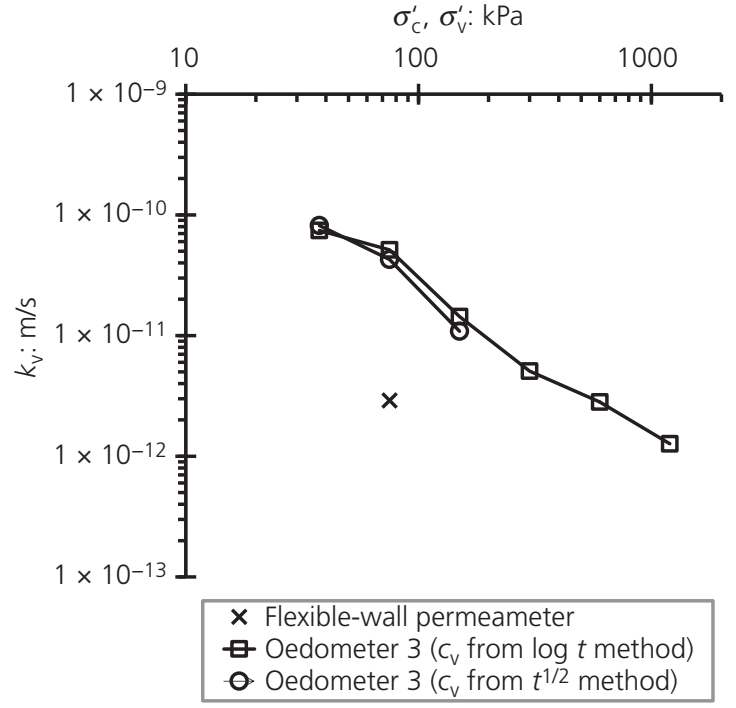

Figure 16. Permeability coefficient values for saturated compacted As-Samra WWTP biosolid materia

$10^{-11} \mathrm{~m} / \mathrm{s}$ (Chen et al., 2014), $10^{-10}$ to $10^{-11} \mathrm{~m} / \mathrm{s}$ (Koenig et al., 1996), $1 \times 10^{-11} \mathrm{~m} / \mathrm{s}$ for $w=180 \%$ (Lo et al., 2002), $<10^{-9} \mathrm{~m} / \mathrm{s}$ (O'Kelly, 2005c, 2008a) and $10^{-9}$ to $10^{-12} \mathrm{~m} / \mathrm{s}$ (Zhan et al., 2014), which were derived from $1 \mathrm{D}$ compression test results for various saturated very soft biosolid specimens. Inverse $\log k_{\mathrm{v}}-\log \sigma_{\mathrm{v}}^{\prime}$ relationships were also deduced from oedometer testing of three alum water-treatment residue (WTR) materials (classified as highly organic silt: $N=45-57 \%$ ) in the papers by O'Kelly (2008b, 2010) and O'Kelly and Quille (2009). However, the calculated $k_{\mathrm{v}}$ values for these WTR materials were approximately one order of magnitude greater than those determined from the oedometer data for the As-Samra WWTP biosolid specimens at comparable $\sigma_{\mathrm{v}}^{\prime}$ levels.

Referring to Figure 16, the mean $k_{\mathrm{v}}$ value of $4.7 \times 10^{-11} \mathrm{~m} / \mathrm{s}$ calculated using 1D consolidation theory and curve-fitting analysis of the oedometer $\varepsilon_{\mathrm{a}-t}$ data for $\sigma_{\mathrm{v}}^{\prime}=75 \mathrm{kPa}$ was approximately one order of magnitude greater than the $k_{\mathrm{v}}$ value of $2.9 \times 10^{-12} \mathrm{~m} / \mathrm{s}$ measured in the permeameter test for $\sigma_{\mathrm{c}}^{\prime}=$ $75 \mathrm{kPa}$. As described by O'Kelly (2016c, 2018c), there are various complicating issues regarding the application of data interpretation and analysis techniques developed for inorganic soil to biosolid and sewage sludge materials, since they do not adequately satisfy several essential assumptions underlying the 1D consolidation theory. For instance, Darcy's law is not valid for these materials since their pore liquid phase has a gel-like nature (Klein and Sarsby, 2000; O'Kelly, 2013b), and as pointed out in the paper by O'Kelly (2016c), the viscosity of the pore liquid artificially increases during the course of oedometer and consolidometer testing on account of the filtering action caused by the porous medium in contact with the specimen drainage boundaries. In other words, the experimental results reflect the sample drainage response (rather than the materials' true behaviour) which becomes adversely and increasingly affected by the measurement technique. The viscous nature of the liquid phase of biosolid and sewage sludge materials is caused by the high concentration of dissolved solids, high bonding or adsorption of the liquid phase within and around the aggregate flocs and some form of biological coagulation between the pore fluid and the organic solids (Klein and Sarsby, 2000; O'Kelly, 2008a, 2013b; Sarsby, 2005). Further, as described in the section headed 'General 1D compression behaviour and data analysis' and reported for other biosolid and sewage sludge materials in the papers by O'Kelly (2005c, 2006a, 2008a), the shapes of the oedometer $\varepsilon_{\mathrm{a}}$ against $\log t$ and $t^{1 / 2}$ data curves for the As-Samra WWTP biosolid material are not characteristic of the theoretical forms given by the 1D consolidation theory. This makes the data interpretation using standard curve-fitting techniques difficult and sometimes not possible for biosolid and sewage sludge materials. Overall, the approximate one order of magnitude difference between the permeameter-measured and oedometer-derived $k_{\mathrm{v}}$ values for the As-Samra WWTP biosolid specimens is considered reasonable, given the various issues described and also the difference in the isotropic and 1D confinement stress states applied in the respective test apparatus.

\section{Discussion}

\section{Strength dependence on confinement pressure for} partially saturated specimens

For the UU triaxial $1-3$ specimens $\left(w \approx 100 \%, \gamma_{\mathrm{d}}=5 \cdot 6 \mathrm{kN} / \mathrm{m}^{3}\right)$, the mobilised undrained strength $\left(s_{\mathrm{uTC}}\right)$ values were $40 \cdot 7,42 \cdot 3$ and $46.4 \mathrm{kPa}$ (mean $s_{\mathrm{uTC}}$ of $43.1 \mathrm{kPa} ; \sigma=2.9 \mathrm{kPa}$ ) for the applied $\sigma_{\mathrm{c}}$ values of 75,150 and $300 \mathrm{kPa}$, respectively. As evident from Figure 17, the mobilised strength increased in value with increasing confinement pressure on account of the partially saturated state $\left(S_{\mathrm{r}} \approx 87 \%\right)$ of these test specimens. In other words,

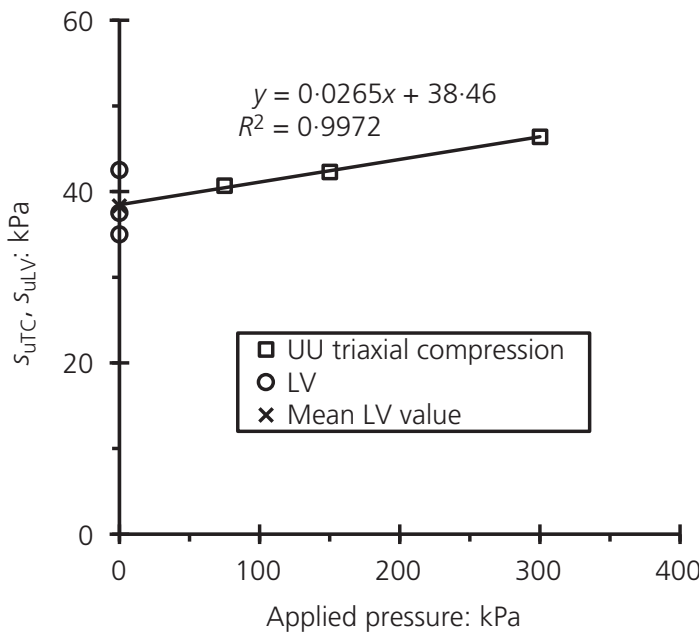

Figure 17. Undrained shear strength mobilised for As-Samra WWTP biosolid material compacted at $W \approx 100 \%\left(S_{\mathrm{r}} \approx 87 \% ; \gamma_{\mathrm{d}}=\right.$ $5.60 \mathrm{kN} / \mathrm{m}^{3}$ ) 
typical of unsaturated geomaterials, the partially saturated biosolid test specimens did not behave as a $\phi_{\mathrm{u}}=0$ material (Kayser et al., 2011; O'Kelly, 2013a, 2013b, 2016b). Hence, the mean $s_{\mathrm{uLV}}$ value of $38.3 \mathrm{kPa}(n=3 ; \sigma=3.8 \mathrm{kPa})$ was lower than the $s_{\text {uTC }}$ values mobilised for $\sigma_{\mathrm{c}}=75-300 \mathrm{kPa}$ (see Figure 17).

\section{Strength dependence on compaction water content}

Referring to Table 2, for the same shear strain rate of $0 \cdot 22 \% / \mathrm{h}$, the MP-compacted CU DSS 5-7 specimens $\left(w_{\mathrm{i}}=62 \cdot 8-66 \cdot 8 \%\right)$ mobilised a considerably lower mean $\tau_{\mathrm{fDSS}}$ value of $33.6 \mathrm{kPa}$, compared to $39 \cdot 1 \mathrm{kPa}$ developed for the CU DSS 2-4 specimens $\left(w_{\mathrm{i}}=103 \cdot 5-106 \cdot 7 \%\right)$, which were prepared using a lower compaction energy level to achieve a dry unit weight value midway between the SP and MP $\gamma_{\mathrm{d}}$ values. The higher compaction energy used in preparing the CU DSS 5-7 specimens for the lower compaction water content range investigated had the effect of producing a more OC state. As such, these specimens absorbed significant amounts of water during the 'consolidation' stage of the CU DSS tests - that is, $w_{\mathrm{f}}=$ $86 \cdot 7-104 \cdot 6 \%$, compared to some consolidation to $w_{\mathrm{f}}=$ $88 \cdot 0-107 \cdot 7 \%$ for the CU DSS 2-4 specimens (Figure 5(b)). Usually higher shear strengths are mobilised for lower water contents - for instance, see the UU triaxial 1-6 data presented in Figure 7 for the as-compacted state. The behaviour of lower saturated shear strengths for the biosolid specimens compacted at lower water contents is, however, consistent with the results presented by Mitchell and Soga (2005) for compacted clayey fills and occurs on account of changes in the soil fabric arising from dry side against wet side compaction.

\section{Normalised undrained strength ratio}

Figure 18 presents the normalised undrained strength ratio (i.e. $\tau_{\mathrm{fDSS}} / \sigma_{\mathrm{vc}}^{\prime}, \tau_{\mathrm{fTC}} / \sigma_{\mathrm{ci}}^{\prime}$ and $\left.\tau_{\mathrm{fTE}} / \sigma_{\mathrm{ci}}^{\prime}\right)$ values for the saturated compacted As-Samra WWTP biosolid specimens determined from DSS, TC and triaxial extension testing, respectively.

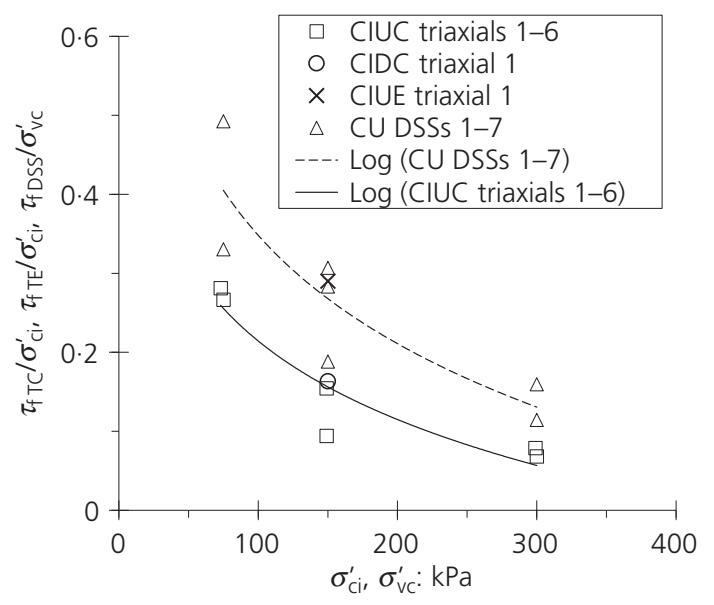

Figure 18. Normalised undrained strength ratio against effective consolidation pressure for As-Samra WWTP biosolid material
To give some context, the normalised undrained strength ratio values for NC clay and silt materials typically range $0 \cdot 20-0 \cdot 27$ and $0 \cdot 30-0 \cdot 35$, respectively (Mesri and Ajlouni, 2007) although as described by Casey and Germaine (2013), there is strong indication given in recent research that some fine-grained soils exhibit considerable variation in the normalised undrained strength value with effective-stress level when viewed over a wide effective-stress range. In Figure 18, the normalised undrained strength ratio for the saturated compacted As-Samra WWTP biosolid material shows a general trend of reducing in value with increasing effective consolidation stress, which is most likely explained by the test specimens' compaction-induced stress history. In other words, for $\sigma_{\mathrm{ci}}^{\prime}\left(\sigma_{\mathrm{vc}}^{\prime}\right)$ values of 300 and $75 \mathrm{kPa}$, the test specimens were typically in NC and moderately or heavily OC states, respectively. The lowest normalised undrained strength ratio values for the As-Samra WWTP biosolid material were determined for the highest effective consolidation stress values investigated (i.e. $\sigma_{\mathrm{ci}}^{\prime}=\sigma_{\mathrm{vc}}^{\prime}=300 \mathrm{kPa}$ ) and they are consistent with the lowerbound $\tau_{\mathrm{fTC}} / \sigma_{\mathrm{ci}}^{\prime}$ value of 0.07 reported for artificially sedimented specimens of Wyoming bentonite (sodium montmorillonite) (Mesri and Olson, 1970). The Wyoming bentonite material investigated had broadly similar plasticity properties (i.e. $w_{\mathrm{P}}$ and $I_{\mathrm{P}}$ ranges of $40-90$ and $300-600 \%$, respectively, compared to $w_{\mathrm{P}}=68 \%$ and $I_{\mathrm{P}}=390 \%$ measured for the biosolid material under investigation). Further, its $k_{\mathrm{v}}$ value was as low as $2 \times 10^{-14} \mathrm{~m} / \mathrm{s}$ (Mesri and Olson, 1971 ), which is reasonably consistent with the $k_{\mathrm{v}}$ value of $2.9 \times$ $10^{-12} \mathrm{~m} / \mathrm{s}$ measured for the saturated compacted As-Samra WWTP biosolid specimen.

Another notable aspect of the data presented in Figure 18 is that $\tau_{\mathrm{fDSS}} / \sigma_{\mathrm{vc}}^{\prime}>\tau_{\mathrm{fTC}} / \sigma_{\mathrm{ci}}^{\prime}$ for comparable test specimens of the saturated compacted As-Samra WWTP biosolid material. It is postulated that this occurred on account of the compactioninduced anisotropy (O'Kelly, 2015, 2017) in addition to the different consolidation stress and boundary conditions imposed in the triaxial and DSS tests. Another reason may be related to the different procedures employed for the first stage of these strength tests, in that the triaxial specimens were back-pressure saturated, whereas the DSS specimens were inundated with water but were not back-pressure saturated.

Acknowledging the significant scatter in the available data, mean values for $\tau_{\mathrm{fTC}} / \sigma_{\mathrm{ci}}^{\prime}$ of $0 \cdot 15$ (based on the CIUC triaxial $1-3$ and 6 data in Table 1) and $\tau_{\mathrm{fDSS}} / \sigma_{\mathrm{vc}}^{\prime}$ of $0 \cdot 135$ (based on the CU DSS 4 and 7 data in Table 2) were deduced for NC and marginally OC saturated compacted As-Samra WWTP biosolid material. Taken together, these TC and DSS data sets indicate a normalised undrained strength ratio value of $0 \cdot 14(n=6)$, which is significantly lower than the normalised undrained strength ratio ranges of $0 \cdot 47-0 \cdot 78$ and $0 \cdot 38-0.55$ reported for natural fibrous peats from TC and DSS testing, respectively (O'Kelly, 2017). Hence, as described in the papers by O'Kelly (2013b, 2016b), a degree of caution is needed in drawing analogies between the strength behaviour of biosolids (sewage sludge) and fibrous peat, since there are significant physical differences between these 
Geotechnical properties of compacted

biosolids for monofill design, As-Samra,

Jordan

'Kelly, Oettle and Ramos

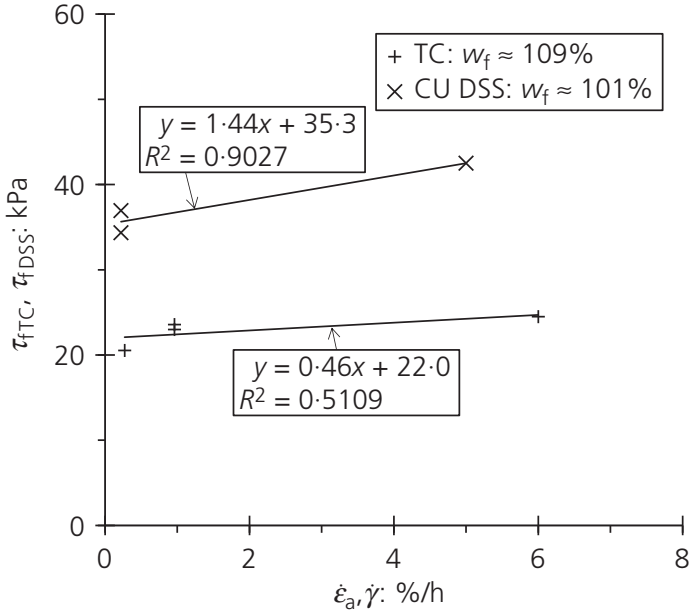

Figure 19. Strain rate dependence of strength for As-Samra WWTP biosolid material

materials, including higher organic matter and fibre contents and significantly slower biodegradation rates of fibrous peats (O'Kelly and Pichan, 2014; Pichan and O'Kelly, 2012, 2013).

\section{Strain rate dependence of strength}

Compared to the strain rate dependency of strength $(\mu)$ value of $0 \cdot 1 \pm 0 \cdot 05$ typically associated with inorganic soils (Kulhawy and Mayne, 1990; Ladd and Foott, 1974), $\mu$ values of 0.38, 0.28 and $0 \cdot 20$ have been reported in the papers by O'Kelly (2016b, 2018b) for biosolid ( $w=355 \% ; N=66-70 \%$ ), blended Clara Bog peat $(w=610 \% ; N=98 \cdot 8 \%)$ and alum WTR $(w=222 \% ; N=57 \%)$ materials, respectively.

Comparisons of the strengths mobilised for physically identical specimen sets of the saturated compacted As-Samra WWTP biosolid material sheared at different strain rates allowed appraisals of its strain rate dependency (see Figure 19), with $\mu$ values of $0 \cdot 21\left(w_{\mathrm{f}} \approx 109 \%\right)$ and $0 \cdot 41\left(w_{\mathrm{f}} \approx 101 \%\right)$ deduced for CIUC triaxial and CU DSS testing, respectively. In other words, similar to other highly organic soils, the saturated compacted AsSamra WWTP biosolid material has a much higher strain rate dependence of strength compared to inorganic soils, with a tenfold increase in the strain rate producing 21 and $41 \%$ increases in its mobilised $\tau_{\mathrm{f} \mathrm{TC}}$ and $\tau_{\mathrm{f} \text { DSs }}$ values, respectively.

\section{Effective-stress strength parameter values}

This section discusses the values of the effective-stress strength parameters measured for the saturated compacted As-Samra WWTP biosolid specimens in the context of those values reported for other biosolid materials. As explained earlier, the OC biosolid test specimens were cross-anisotropic on account of the compactioninduced fabric with the degree of cross-anisotropy increasing with reducing $\sigma_{\mathrm{ci}}^{\prime}\left(\sigma_{\mathrm{vc}}^{\prime}\right)$ value - for example, $\tau_{\mathrm{fTC}}$ and $\tau_{\mathrm{fDSs}}$ values of 23 and $32 \mathrm{kPa}$, respectively, were inferred for the unconfined specimen condition (Figure 10(f)). In contrast, the measured $\phi_{\mathrm{TC}}^{\prime}, \phi_{\mathrm{TE}}^{\prime}$ and $\phi_{\text {DSS }}^{\prime}$ values for the NC state (i.e. $c^{\prime}=0$ ) of $15 \cdot 1,16 \cdot 3$ and $15 \cdot 5^{\circ}$, respectively, were in excellent agreement, essentially indicating isotropic behaviour. These $\phi_{\mathrm{NC}}^{\prime}$ values are in good agreement with the $\phi_{\mathrm{DS}}^{\prime}$ values of 10 and $15^{\circ}$ deduced from consolidated-drained direct shear (DS) testing of pre-consolidated biosolid materials $\left(w_{\mathrm{L}}=353 \%, w_{\mathrm{P}}=106 \%, N=32 \cdot 3-51 \cdot 0 \%\right)$ sampled rom the Chengdu Changan landfill for $\sigma_{\mathrm{vc}}^{\prime}=0-100$ and $100-400 \mathrm{kPa}$, respectively (Zhan et al., 2014). Encouragingly, the $\phi_{\mathrm{NC}}^{\prime}$ values measured for the As-Samra WWTP biosolid material are also in reasonable agreement with the $\phi_{\mathrm{NC}}^{\prime}$ values of $17 \cdot 1$ and $19 \cdot 1^{\circ}$ predicted using Equation 5 for the As-Samra WWTP and Chengdu Changan landfilled biosolid materials $\left(I_{\mathrm{P}}=390\right.$ and 247\%, respectively). The following equation was derived by Sorensen and Okkels (2013) for inorganic reconstituted and undisturbed NC clays using a database combining previously published data

\section{5. $\phi_{\mathrm{NC}}^{\prime}=43-10 \log _{10}\left(I_{\mathrm{P}}\right) \quad\left(R^{2}=0 \cdot 41, n=233\right)$}

where $I_{\mathrm{P}}$ (as \%) is the plasticity index and the unit of $\phi_{\mathrm{NC}}^{\prime}$ is degree.

However, the measured $\phi_{\mathrm{NC}}^{\prime}$ and $\phi_{\mathrm{DS}}^{\prime}$ values for the As-Samra WWTP and Chengdu Changan landfilled biosolid materials and also the values predicted for these materials using Equation 5 are significantly lower than those computed by the authors as part of the present investigation for other saturated $\mathrm{NC}$ biosolid test specimens, including

- the $\phi_{\mathrm{DS}}^{\prime}$ value of $25^{\circ}$ deduced from consolidated drained DS test results presented for saturated compacted Hangzhou WWTP biosolid test specimens $\left(w_{\mathrm{L}}=115 \%, w_{\mathrm{P}}=75 \%, N=\right.$ $66 \% ; \sigma_{\mathrm{vc}}^{\prime}=400 \mathrm{kPa}$ ) in Figure 8 of the paper by Chen et al. (2014)

- the $\phi_{\mathrm{TC}}^{\prime}$ value of $26.5^{\circ}$ deduced from CIUC triaxial test results for saturated aged SP-compacted Melbourne Western WWTP biosolid test specimens $\left(N=35-38 \% ; \sigma_{\mathrm{ci}}^{\prime}=430 \mathrm{kPa}\right)$ presented in Figure 4 of the paper by Disfani et al. (2015); these specimens were prepared by static compaction for $\sigma_{\mathrm{v}}=400 \mathrm{kPa}$

- the values of $\phi_{\mathrm{DS}}^{\prime} \approx 42^{\circ}$ and $\phi_{\mathrm{TC}}^{\prime} \approx 36^{\circ}$ deduced from consolidated drained DS and CIUC triaxial test results presented for saturated, aged, SP-compacted Melbourne Western WWTP biosolid test specimens $(N=26 \cdot 5-27 \cdot 0 \%$; $\left.\sigma_{\mathrm{vc}}^{\prime}\left(\sigma_{\mathrm{ci}}^{\prime}\right)=480 \mathrm{kPa}\right)$ in Figures 5(a) and 7, respectively, of the paper by Arulrajah et al. (2013)

- the $\phi_{\mathrm{TC}}^{\prime}$ values of 32 and $37^{\circ}$ reported for saturated, pasteurised Tullamore WWTP biosolid test specimens ( $N=70$ and $55 \%$, respectively) in the paper by O'Kelly (2006a); these specimens were prepared from a pressed cake that had been consolidated from a slurry condition in a consolidometer apparatus set-up described by O'Kelly (2005c, 2006a).

The reasons for the considerable differences in these measured $\phi_{\mathrm{NC}}^{\prime}$ values for the various biosolid materials are not understood, but these merit urgent investigation given the potentially 
significant implications for geotechnical design. Possible reasons may include (a) the effects of biogas produced internally, particularly for undrained strength tests of longer duration (O'Kelly, 2006a, 2013a, 2016b) and (b) inherent differences in the specimen preparation and strength test methods adopted by different researchers - for instance, differences in the compacted water content, compaction effort and the strain rate employed for the specimen shearing stage and inadequate levels of specimen saturation and (or) consolidation achieved.

\section{Permeability coefficient}

The permeameter-measured $k_{\mathrm{v}}$ value of $2.9 \times 10^{-12} \mathrm{~m} / \mathrm{s}$ $\left(\sigma_{\mathrm{c}}^{\prime}=75 \mathrm{kPa}\right)$ and oedometer-derived $k_{\mathrm{v}}$ range of $1.3 \times 10^{-11}$ to $7 \cdot 8 \times 10^{-11} \mathrm{~m} / \mathrm{s}\left(\sigma_{\mathrm{v}}^{\prime}=37 \cdot 5-150 \mathrm{kPa}\right)$ for the saturated and inundated conditions, respectively, indicate that when compacted at approximately $110 \%$ water content (i.e. on the wet side of the $w_{\text {opt }}$ value), the As-Samra WWTP biosolid material has extremely low permeability. However, as described in the papers by O'Kelly (2016b, 2016c), significantly larger $k_{\mathrm{v}}$ values can be expected for biosolid materials compacted near to and below their $w_{\text {opt }}$ values on account of the network of larger pore voids present between the peds and which facilitate preferential flow of the pore fluid. For instance, falling-head permeability tests and flexible-wall permeameter constant-head tests indicated saturated $k_{\mathrm{v}}$ values of $1.24 \times 10^{-7}$ to $1.60 \times 10^{-7}$ and $1.49 \times 10^{-7} \mathrm{~m} / \mathrm{s}$, respectively, for Melbourne Western WWTP SP-compacted aged biosolid material ( $N=35 \cdot 4-38 \cdot 5 \%)$ (Arulrajah et al., 2011; Disfani et al., 2015). Stone et al. (1998) reported measured $k_{\mathrm{v}}$ values ranging from $1 \cdot 3$ $\times 10^{-7}$ to $6.4 \times 10^{-7} \mathrm{~m} / \mathrm{s}$ for four different sewage sludge materials $\left(N=14 \cdot 3-49 \cdot 1 \%\right.$ and $\left.w_{\mathrm{opt}}=34-79 \%\right)$ and $\mathrm{a}$ significantly greater $k_{\mathrm{v}}$ value of $1.9 \times 10^{-5} \mathrm{~m} / \mathrm{s}$ for a higher organic content sewage sludge material $\left(N=67 \cdot 2 \%\right.$ and $w_{\text {opt }}=$ $88 \%$ ), all of which had been SP-compacted at their $w_{\text {opt }}$ values. In the present research, saturated $k_{\mathrm{v}}$ values were not measured (or could not be derived from curve fitting of the experimental oedometer $\varepsilon_{\mathrm{a}-t}$ data) for As-Samra WWTP biosolid specimens prepared at significantly lower compaction water contents (i.e. $w<w_{\text {opt }} \ll 110 \%$ ). Based on the limited experimental data reported for other compacted biosolid and sewage sludge materials (summarised above), it is postulated that the saturated $k_{\mathrm{v}}$ values for As-Samra WWTP biosolids compacted at the lower end of the typical water content range of $60-100 \%$ targeted for placement of this material in the proposed biosolid monofill facility could be approximately on the order of $10^{-7} \mathrm{~m} / \mathrm{s}$.

\section{Effect of ongoing biodegradation}

Based on the absence of a discernible tertiary compression phase in the $\varepsilon_{\mathrm{a}}-\log t$ curve for the $42 \mathrm{~d}$ duration load stage at $\sigma_{\mathrm{v}}=$ $150 \mathrm{kPa}$ of the oedometer 4 test and also the measured pore water pressure responses for the compression stage of the CIUC and CIDC triaxial tests, it was concluded that ongoing biodegradation had no significant effect on the geomechanical behaviour of the inundated (saturated) compacted As-Samra WWTP biosolid specimens for the test conditions and ambient laboratory temperature of $20^{\circ} \mathrm{C}$. In other words, negligible biogas generation and organic matter reduction occurred over the duration of these laboratory tests. However, this is generally not the case for slurry and very soft biosolid materials (O'Kelly, 2005c, 2006a, 2008a, 2013a, 2018a) and it would also not be the case in the longer term for biosolid material compacted in the proposed monofill facility (O’Kelly, 2004, 2005a, 2016b).

There is a dearth of knowledge regarding the effects of ongoing biodegradation on the geotechnical properties and behaviour of biosolid materials in general, with no documented studies reporting on its effects for compacted biosolid material in particular. Geotechnical research on the effects of biodegradation for dewatered biosolids is limited to those presented in the papers by O'Kelly (2005c, 2006a, 2008a). In these investigations, the changes in some physical properties of bulk dewatered Tullamore WWTP biosolid samples stored at ambient outdoor temperatures of $5-15^{\circ} \mathrm{C}$ were monitored over a 13-year period. The effects of accelerated biodegradation rates achieved in the laboratory environment at the optimum temperature for mesophilic digestion of $35^{\circ} \mathrm{C}$ were also investigated over a $21 \mathrm{~d}$ period. The $N$ value for this dewatered biosolid material was reduced from initially 70 to $55 \%$ for both of these scenarios (corresponding to a 33\% reduction in the solids dry mass), with copious amounts of biogas evolving at an approximately steady rate (e.g. up to $0.33 \mathrm{~m}^{3}$ of biogas per day per ton of this the moderately degraded slurry material under the laboratory conditions described (O'Kelly, 2005c, 2006a)).

As explained in the paper by O'Kelly (2016b), greater levels of biodegradation for biosolid materials are associated with (a) reductions in their plasticity and organic contents (the latter correlating with reductions in their natural water contents); (b) increases in their particle density values and hence their bulk and dry unit weights (assuming that the biogas produced internally can escape); (c) reductions in their $w_{\text {opt }}$ values for compaction and increases in their associated maximum dry unit weight values; and (d) modest increases in their rates of primary consolidation and its relative proportion of the overall strain response for maintained loading. For landfilled biosolid and sewage sludge materials, however, the described changes in the geotechnical properties may not occur uniformly throughout the entire deposit.

\section{Compression index correlations}

Numerous empirical correlations exist for many geomaterials between $C_{\mathrm{c}}$ and other properties (e.g. $w_{\mathrm{i}}$ and $e_{\mathrm{i}}$ ) that are more straightforward to determine accurately and at significantly less expense than standard oedometer and consolidometer testing. For instance, Mesri and Ajlouni (2007) reported $C_{\mathrm{c}}=0.01 \times w_{\mathrm{i}}$ for fibrous peats. Such correlations have not been explicitly derived or proposed for biosolid and sewage sludge materials, although they would provide a useful starting point for performing preliminary assessments of, for instance, the anticipated compression strains for inundated (waterlogged) compacted biosolid monofill deposits.

Using the experimental data presented in Tables 5-7, the authors investigated $C_{\mathrm{c}}$ and $C_{\mathrm{R}}$ correlations with $w_{\mathrm{i}}$ and $e_{\mathrm{i}}$ for compacted 


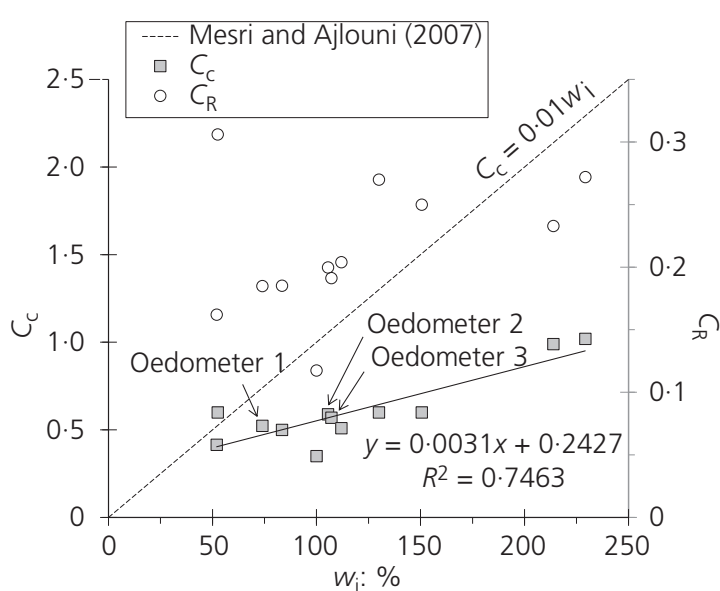

(a)

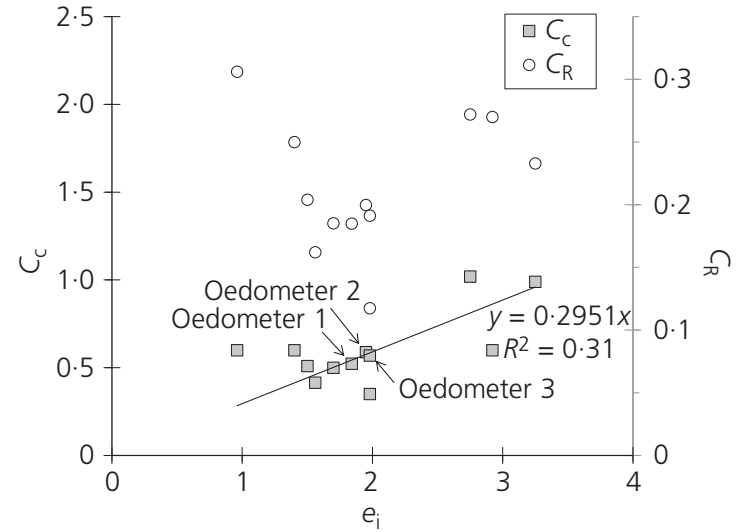

(b)

Figure 20. Compressibility index correlations for compacted biosolid materials derived using the data reported in Tables 5-7: (a) with initial water content; (b) with initial void ratio. Note: oedometer 1 and 2 (non-inundated) and oedometer 3 (inundated) specimens relate to As-Samra WWTP biosolid material

biosolid and sewage sludge materials (see Figure 20). As mentioned earlier, Table 6 documents all previously reported biosolid and sewage sludge materials for which at least their $w_{\mathrm{i}}$ and $e_{\mathrm{i}}$ values and either their $\varepsilon_{\mathrm{a}}-\log \sigma_{\mathrm{v}}^{\prime}$ data curves or deduced $C_{\mathrm{c}}$ values for oedometer testing of compacted specimens are presented. Similar to peats and other highly organic soils, the proposed correlations for biosolid and sewage sludge materials are essentially based on the premise that their $C_{\mathrm{c}}$ values correlate strongly with their organic content $(N)$ values which, in turn, strongly influence their $w_{\mathrm{i}}$ and $e_{\mathrm{i}}$ values for different $\sigma_{\mathrm{v}}^{\prime}$ levels.

The value of $e_{\mathrm{i}}$ can be calculated from measured $w_{\mathrm{i}}$ and $N$ values and the estimated $\rho_{\mathrm{s}}$ value from the correlation given by Equation 6, which was derived from an extensive database for biosolid and sewage sludge materials presented in the paper by O'Kelly (2018d) - that is, for $S_{\mathrm{r}}=1, e_{\mathrm{i}}=w_{\mathrm{i}} \times \rho_{\mathrm{s}} / \rho_{\mathrm{w}}$ where $\rho_{\mathrm{w}}$ is the density of water.

$$
\begin{aligned}
\rho_{\mathrm{s}}= & 1 \cdot 12 \times 10^{-4} N^{2}-0 \cdot 02636 N \\
& +2 \cdot 65\left(\mathrm{Mg} / \mathrm{m}^{3}\right)(10 \%<N<80 \%)\left(R^{2}=0.9792\right) \\
& (\text { after O'Kelly }(2018 \mathrm{~d}))
\end{aligned}
$$

6.

From Figure 20, correlations between $C_{\mathrm{c}}$ and $w_{\mathrm{i}}$ or $e_{\mathrm{i}}$ appear more promising, exhibiting considerably less scatter than the equivalent $C_{\mathrm{R}}$ relationships. This is rational since $C_{\mathrm{c}}, w_{\mathrm{i}}$ and $e_{\mathrm{i}}$ are influenced by the soil composition and structure, whereas a linear variation between $C_{\mathrm{c}}$ and $e_{\mathrm{i}}$ is implicit for the $C_{\mathrm{R}}-w_{\mathrm{i}}$ relationship. From regression analysis, the best-fit $C_{\mathrm{c}}-w_{\mathrm{i}}$ correlation given by Equation 7 indicates that although highly compressible, inundated compacted biosolid and sewage sludge materials have significantly lower compressibility than predicted by the Mesri and Ajlouni (2007) correlation for fibrous peats (see Figure 20(a)). This can be explained by their lower organic and fibre content values compared to fibrous peats (e.g. see the paper of O'Kelly and Pichan (2013)).

$$
\text { 7. } C_{\mathrm{c}}=0.0031 w_{\mathrm{i}}+0.2427 \quad\left(50 \%<w_{\mathrm{i}}<230 \%\right)
$$

\section{Field applicability}

This section presents recommendations on the appropriate water content range for the placement and compaction of the As-Samra WWTP biosolid material in the proposed monofill facility, as well as appropriate design shear strength values (with due consideration of how biogas production, creep etc. play a role in their selection) for associated geotechnical stability assessments. Various aspects of the geotechnical design of biosolid and WTR monofills are described in the papers by O'Kelly (2004, 2005a, 2006a, 2010, 2016b). At the As-Samra WWTP facility, the solar-dried biosolid material taken from the evaporation lagoons after approximately 2-3 months has a water content range of typically $60-100 \%$. Inundation of the biosolid material compacted at the lower end of this water content range in the monofill environment would cause considerable water absorption, which would cause significant strength reductions and potentially also swelling of the deposit to occur. Hence, the As-Samra WWTP biosolid material should be placed and compacted in the proposed monofill facility near the higher end of its solar-dried water content range (i.e. $100 \%$ water content).

With good drainage and biogas-extraction systems in place, the unconfined $s_{\mathrm{uTC}}$ value of $38.5 \mathrm{kPa}$ deduced for As-Samra WWTP biosolid specimens compacted at $100 \%$ water content is likely to represent a modestly conservative shear strength value for the shortterm non-inundated field condition. This strength value was 
determined as the $y$-axis intercept (i.e. $\sigma_{\mathrm{c}}=0 \mathrm{kPa}$ ) of the extrapolated best-fit line to the UU triaxial 1-3 strength data (see Figure 17). Higher short-term shear strength values can be adopted when the biosolid material is placed and compacted at lower water contents (refer to Figure 7). Any consolidation and resulting improvement in the shear strength would occur over a very long time period, such that the $s_{\mathrm{uTC}}$ value of $38.5 \mathrm{kPa}$ is appropriate for performing short-term stability analyses, employing an appropriate safety factor in establishing the achievable gradient of the monofill slopes. From Figure 10(f), 32 and $23 \mathrm{kPa}$ represent lower-bound values for the long-term shear strength of the saturated compacted As-Samra WWTP biosolid material determined from DSS and TC testing, respectively, with $\sigma_{\mathrm{v}}^{\prime}\left(\sigma_{\mathrm{c}}^{\prime}\right)=0 \mathrm{kPa}$. The long-term shear strength increases in value with increasing effective overburden pressure provided that the biogas generated internally can readily escape from the monofill body through a managed gas extraction system. Further, the monofill drainage systems must be designed to control surface water (limiting rainwater infiltration to the monofill body, thereby mitigating against wetting of the compacted biosolid material in order to maintain its in-situ shear strength) and to collect biogas and leachate generated within the landfill body for their safe disposal. Excessive build-up of pore fluid pressure due to ongoing biogas generation within biosolid lagoons has been identified as a trigger of slope instability (Claydon et al., 1997). Hence, the authors recommend the installation of ground instrumentation and its regular monitoring to prove the effectiveness of the biogas and leachate extraction and surface water control systems. The authors also recommend that in-situ strength testing be performed as the proposed monofill buildout continues in order to understand better the shear strength properties and behaviour of the biosolid material for the as-built field conditions.

When tested in its NC state, the saturated compacted As-Samra WWTP biosolid material $(N=62 \cdot 6 \%)$ has isotropic strength properties, with a normalised undrained strength ratio value of $0 \cdot 14$ and effective-stress strength parameter values of $c^{\prime}=0$ and $\phi_{\mathrm{TC}}^{\prime} \approx \phi_{\mathrm{DSS}}^{\prime} \approx 15^{\circ}$. The latter value is significantly lower than the $\phi_{\mathrm{NC}}^{\prime}$ values of 42 and $36^{\circ}\left(\phi_{\mathrm{DS}}^{\prime}\right.$ and $\phi_{\mathrm{TC}}^{\prime}$, respectively; $N=$ $26 \cdot 5-27 \cdot 0 \%), 26 \cdot 5^{\circ}\left(\phi_{\mathrm{TC}}^{\prime} ; N=35-38 \%\right), 25^{\circ}\left(\phi_{\mathrm{DS}}^{\prime} ; N=66 \%\right)$ and 32 and $37^{\circ}\left(\phi_{\mathrm{TC}}^{\prime} ; N=70\right.$ and $55 \%$, respectively) determined for other saturated compacted biosolid materials tested in their $\mathrm{NC}$ state (refer to the section headed 'Effective-stress strength parameter values'). As described in the paper by O'Kelly (2016b), these $\phi^{\prime}$ values are unrealistically high for use in design and hence could potentially produce unconservative geotechnical designs. Given the significance of this finding, further research is urgently required in order to understand better the differences in the material characteristics and (or) testing conditions that produced these excessively high laboratory-derived $\phi_{\mathrm{NC}}^{\prime}$ values. Possible contributing factors may include their significantly different organic contents and associated levels of bioactivity, differences in the specimen saturation procedures employed, inadequate degree of consolidation values achieved for the consolidation stage and inappropriate strain rates used for the shearing stage of the strength tests.
As described in the paper by O'Kelly (2016b), the anticipated overall settlement of biosolid monofills can be predicted as the summation of the immediate, primary consolidation, secondary compression and biodegradation-induced (tertiary compression) settlement components. The primary consolidation and secondary compression settlement rates for the proposed As-Samra WWTP biosolid monofill facility can be predicted from knowledge of the $c_{\mathrm{V}}$, and $C_{\alpha}$ or $C_{\alpha e} / C_{\mathrm{c}}$ ratio values and their $\sigma_{\mathrm{v}}^{\prime}$ dependence, which were described earlier in the section headed 'Compressibility'. The biodegradation-induced settlement rate can be predicted using the analytical method presented in the paper by Disfani et al. (2013) and requires knowledge of the water content, $\mathrm{pH}$ value, magnitude of the biodegradable fraction, temperature and biodegradation rate (dependent on its age) of the in-situ biosolid material.

Only a relatively small amount of settlement is anticipated for placement and compaction of up to approximately $7 \mathrm{~m}$ depth of the As-Samra WWTP biosolid material at $60-100 \%$ water content followed by the construction of a capping layer (non-inundated condition) at the proposed monofill facility on account of its compaction-induced OC state (i.e. mean $C_{\mathrm{r}}=0.15$ for $\sigma_{\mathrm{v}}^{\prime}<$ $\sigma_{\max }^{\prime} \approx 75 \mathrm{kPa}$ ). Further, with $c_{\mathrm{v}}=0.05-0.13 \mathrm{~m}^{2} /$ year and $C_{\alpha}=$ $0.005-0.021$, this settlement is anticipated to occur at an extremely slow rate. Greater monofill depths are anticipated to produce significant primary consolidation and secondary compression settlements (i.e. mean $C_{\mathrm{c}}=0.56, C_{\alpha}=0.023-0.035$ and $C_{\alpha \mathrm{e}} / C_{\mathrm{c}}=0 \cdot 12-0 \cdot 20$ ) although, again, these settlements would occur over an extremely long period. The consolidation rate could be controlled (increased) somewhat by incorporating an effective drainage system within the monofill body.

Based on the compacted bulk unit weight values of up to $11 \cdot 2 \mathrm{kN} / \mathrm{m}^{3}, \quad \sigma_{\mathrm{v}}^{\prime} \ll \sigma_{\max }^{\prime}$ for waterlogged anticipated maximum final monofill depths of up to approximately $30 \mathrm{~m}$. Hence, with laboratory-derived $C_{\mathrm{r}}, C_{\alpha}$ and $C_{\alpha \mathrm{e}} / C_{\mathrm{c}}$ values broadly similar to those determined for the non-inundated condition, it is anticipated that the amounts and rates of the primary consolidation and secondary compression settlements for the inundated (waterlogged) conditions would not be significantly different from those determined for the non-inundated conditions. In other words, the waterlogged compacted As-Samra WWTP biosolid material would remain in an OC state for the anticipated maximum effective overburden pressure value. Waterlogged compacted As-Samra WWTP biosolid material may experience some swelling for low confinement stress levels.

It was found that the biodegradation-induced settlement component was not significant for the compacted biosolid specimens at an ambient laboratory temperature of $20^{\circ} \mathrm{C}$. However, significantly higher temperatures are anticipated within the core of the proposed As-Samra WWTP biosolid monofill facility, particularly given the high ambient temperatures at its geographic location. Hence, it is probable that appreciable biodegradation-induced settlements would occur for the biosolid monofill environment, particularly for higher material saturation 
levels, assuming that the biogas and leachate extraction systems are functioning efficiently (O’Kelly, 2004, 2005a, 2016b).

Finally, biosolid materials compacted on the wet side of their $w_{\mathrm{opt}}$ values typically have $k_{\mathrm{v}}$ values on the order of $10^{-10}$ to $10^{-12} \mathrm{~m} / \mathrm{s}$. However, with $w_{\mathrm{i}} \approx 100 \%$ and $w_{\mathrm{S}}=5 \%$, compacted biosolid material left without a capping layer for a significant period of time would desiccate and crack in the arid environment, such that a closure cap system is strongly recommended as part of the AsSamra WWTP biosolid monofill design.

\section{Summary and conclusions}

Typical of previously investigated biosolid materials, the AsSamra WWTP biosolid material has very high organic content but negligible fibrosity; extremely high SP and MP $w_{\text {opt }}$ for compaction values of 83 and $59 \%$, respectively; and very large compression, swelling and shrinkage potentials, with secondary compression increasingly dominant over primary consolidation for increasing $\sigma_{\mathrm{v}}^{\prime}$ levels. Typical of other highly organic soils, the AsSamra WWTP biosolids have a very high strain rate dependency of strength, with respective $\mu$ values of approximately 0.21 and 0.41 deduced for TC and DSS testing of the saturated material compacted on the wet side of the $w_{\text {opt }}$ value (i.e. $w_{\mathrm{f}}=109 \%$ and $101 \%$, respectively).

As-Samra WWTP biosolid material compacted at approximately $100 \%$ water content was in an OC state for $\sigma_{\mathrm{vc}}^{\prime}\left(\sigma_{\mathrm{ci}}^{\prime}\right)<\sim 300 \mathrm{kPa}$, exhibiting cross-anisotropic strength properties (i.e. $\tau_{\mathrm{fDSS}}>\tau_{\mathrm{fTC}}$ ). A very low $\phi_{\mathrm{TC}}^{\prime}$ value of $1.9^{\circ}$ and a high $c_{\mathrm{TC}}^{\prime}$ value of approximately $23 \mathrm{kPa}$ were measured for $p^{\prime}<\sim 150 \mathrm{kPa}$ ( $\phi_{\mathrm{DSS}}^{\prime}$ of $2 \cdot 5^{\circ}$ and $c_{\text {DSS }}^{\prime}$ of approximately $32 \mathrm{kPa}$ for $\sigma_{\mathrm{v}}^{\prime}<\sim 100 \mathrm{kPa}$ ). The compaction-induced anisotropy reduced in significance for higher effective confinement pressure levels, such that the saturated compacted biosolid material had isotropic strength properties for $\sigma_{\mathrm{vc}}^{\prime}\left(\sigma_{\mathrm{ci}}^{\prime}\right)>\sim 300 \mathrm{kPa}$, with values of $c^{\prime}=0 \mathrm{kPa}, \phi_{\mathrm{NC}}^{\prime} \approx 15^{\circ}$ and a mean normalised undrained strength ratio of $\sim 0 \cdot 14$. The $\phi_{\mathrm{NC}}^{\prime}$ value deduced for the As-Samra WWTP biosolid test specimens was significantly lower than those values reported previously for other saturated, consolidated or compacted biosolid materials (i.e. $\phi_{\mathrm{NC}}^{\prime} \gg 20^{\circ}$ ), although the authors consider them unrealistically high for use in geotechnical design. The experimental results presented above for the As-Samra WWTP biosolid material relate to the laboratory conditions and an ambient temperature of $20^{\circ} \mathrm{C}$. Significantly higher temperatures and hence greater biodegradation rates are expected to occur within the monofill body, such that further research investigating their effects on the geotechnical properties and behaviour of the in-situ biosolid material and hence the longer-term stability of the proposed biosolid monofill are necessary.

Solar drying of the dewatered biosolid material in on-site evaporation lagoons for a 2-3-month period reduced its water content within the range of typically $60-100 \%$. It was found that compared to the $100 \%$ water content value, laboratory compaction of the biosolid material near the lower end of this water content range produced a more OC state, such that considerable swelling accompanied by a reduction in strength subsequently occurred for the inundated (waterlogged) condition. Hence, it is recommended that once the water content has reduced to approximately $100 \%$, the biosolid material should be removed from the evaporation lagoons and SP-compacted within the proposed monofill facility before sealing with a capping layer to prevent desiccation cracking and periodic rainwater infiltration. The laboratory test results indicated that the non-inundated As-Samra biosolid material compacted at approximately $100 \%$ water content had a lower-bound undrained TC shear strength value of approximately $38 \mathrm{kPa}$, which is adequate for on-site compaction activities and the short-term geotechnical stability of the monofill deposit. Appropriate $c^{\prime}$ and $\phi^{\prime}$ values selected from the Mohr-Coulomb failure envelopes presented in the paper for the TC and DSS modes, taking into consideration the in-situ effective-stress levels, can be used in performing long-term geotechnical stability assessments. Relatively small in-situ settlements are anticipated on account of the compacted material's low bulk unit weight values and OC state. New correlations were presented to allow assessments of the compressibility of this and other waterlogged compacted biosolid (and sewage sludge) materials based on their initial water content or void ratio values. The settlements are expected to occur at an extremely slow rate for both the non-inundated and waterlogged conditions due to the extremely low $k_{\mathrm{v}}\left(10^{-10}\right.$ to $\left.10^{-12} \mathrm{~m} / \mathrm{s}\right)$, and hence $c_{\mathrm{v}} \quad\left(0.03-0.13 \mathrm{~m}^{2} /\right.$ year $)$ values for biosolid material compacted at approximately $100 \%$ water content.

With its very high organic content, the As-Samra WWTP biosolid material likely experiences substantial variation in performance as suction changes. The associated shear strength variation was evaluated to some extent using UU, CIUC, CIUE and CIDC triaxial and CU DSS testing, with these approaches allowing different amounts of water to be absorbed or not absorbed depending on the specimen stress and boundary conditions. In other words, these tests were used to evaluate different potential conditions after compaction in the monofill facility and their associated shear strength values. In-situ drying of the compacted biosolid material due to the As-Samra desert climate would produce an increase in its shear strength, although its effect may not be significant in reality on account of the expected fast material placement rate. Further research regarding the evaluation of moisture sensitiveness after compaction (i.e. wetting and drying), particularly in terms of swelling and shrinkage properties, is recommended, especially for other proposed monofill facilities where compacted biosolid layers close to the ground surface may experience significant seasonal moisture variation due to climatic action. Finally, the authors recommend regular long-term monitoring of ground instrumentation at the proposed As-Samra biosolid monofill facility to prove the effectiveness of biogas and leachate extraction and surface water control systems, in addition to the measurement of in-situ geomechanical properties, the rate of biogas generation and the pore fluid pressure response in order to understand better the shear strength and deformation responses for the as-built field conditions. 


\section{Acknowledgements}

The subject matter presented in this paper was based on work performed by AECOM on behalf of the US Agency for International Development (USAID). Any opinions, findings and conclusions or recommendations expressed herein are those of the authors and do not necessarily reflect the views of AECOM or USAID. GeoTesting Express of Acton, Massachusetts, USA, is acknowledged for performing the various geotechnical laboratory testing reported in the paper.

\section{REFERENCES}

Arulrajah A, Disfani MM, Suthagaran V and Imteaz M (2011) Select chemical and engineering properties of wastewater biosolids. Waste Management 31(12): 2522-2526, https://doi.org/10.1016/j.wasman. 2011.07.014.

Arulrajah A, Disfani MM, Suthagaran V and Bo MW (2013) Laboratory evaluation of the geotechnical characteristics of wastewater biosolids in road embankments. Journal of Materials in Civil Engineering 25(11): 1682-1691, https://doi.org/10.1061/(ASCE)MT.1943-5533. 0000739 .

ASTM (2003) D 2850-03a: Standard test method for unconsolidatedundrained triaxial compression test on cohesive soils. ASTM International, West Conshohocken, PA, USA.

ASTM (2007a) D 422-63(2007)e2: Standard test method for particle-size analysis of soils. ASTM International, West Conshohocken, PA, USA.

ASTM (2007b) D 6528-07: Standard test method for consolidated undrained direct simple shear testing of fine grain soils. ASTM International, West Conshohocken, PA, USA.

ASTM (2008) D 4943-08: Standard test method for shrinkage factors of soils by the wax method. ASTM International, West Conshohocken, PA, USA.

ASTM (2010a) D 4318-10: Standard test methods for liquid limit, plastic limit, and plasticity index of soils. ASTM International, West Conshohocken, PA, USA.

ASTM (2010b) D 2216-10: Standard test methods for laboratory determination of water (moisture) content of soil and rock by mass. ASTM International, West Conshohocken, PA, USA.

ASTM (2010c) D 5084-10: Standard test methods for measurement of hydraulic conductivity of saturated porous materials using a flexible wall permeameter. ASTM International, West Conshohocken, PA, USA.

ASTM (2011a) D 4767-11: Standard test method for consolidated undrained triaxial compression test for cohesive soils. ASTM International, West Conshohocken, PA, USA.

ASTM (2011b) D 7181-11: Method for consolidated drained triaxial compression test for soils. ASTM International, West Conshohocken, PA, USA.

ASTM (2011c) D 2435-11: Standard test methods for one-dimensional consolidation properties of soils using incremental loading. ASTM International, West Conshohocken, PA, USA.

ASTM (2012a) D 698-12e2: Standard test methods for laboratory compaction characteristics of soil using standard effort $\left(12400 \mathrm{ft}-1 \mathrm{bf} / \mathrm{ft}^{3}\left(600 \mathrm{kN}-\mathrm{m} / \mathrm{m}^{3}\right)\right)$. ASTM International, West Conshohocken, PA, USA.

ASTM (2012b) D 1557-12e1: Standard test methods for laboratory compaction characteristics of soil using modified effort $\left(56,000 \mathrm{ft}-\mathrm{lbf} / \mathrm{ft}^{3}\left(2,700 \mathrm{kN}-\mathrm{m} / \mathrm{m}^{3}\right)\right)$. ASTM International, West Conshohocken, PA, USA.

ASTM (2013a) D 4972-13: Standard test method for $\mathrm{pH}$ of soils. ASTM International, West Conshohocken, PA, USA.

ASTM (2013b) D 4648-13: Standard test methods for laboratory miniature vane shear test for saturated fine-grained clayey soil. ASTM International, West Conshohocken, PA, USA.
ASTM (2014a) D 854-14: Standard test methods for specific gravity of soil solids by water pycnometer. ASTM International, West Conshohocken, PA, USA.

ASTM (2014b) D 2974-14: Standard test methods for moisture, ash, and organic matter of peat and other organic soils. ASTM International, West Conshohocken, PA, USA.

Aydilek AH, Edil TB and Fox PJ (2000) Consolidation characteristics of wastewater sludge. In Geotechnics of High Water Content Materials (Edil TB and Fox PJ (eds)). ASTM, West Conshohocken, PA, USA, ASTM STP1374, pp. 309-323.

Bray JD, Zekkos D, Kavazanjian E Jr, Athanasopoulos GA and Riemer MF (2009) Shear strength of municipal solid waste. Geotechnical and Geoenvironmental Engineering 135(6): 709-722, https://oi.org/10. 1061/(ASCE)GT.1943-5606.0000063.

Casey B and Germaine JT (2013) Variation of cohesive sediment strength with stress level. In Multiphysical Testing of Soils and Shales (Laloui L and Ferrari A (eds)). Springer, Berlin, Germany, pp. 261-266.

Chen P, Zhan L and Wilson W (2014) Experimental investigation on shear strength and permeability of a deeply dewatered sewage sludge for use in landfill covers. Environmental Earth Sciences 71(10): 4593-4602, https://doi.org/10.1007/s12665-013-2851-8.

Claydon JR, Eadie HS and Harding C (1997) Deighton tip-failure, investigation and remedial works. In Proceedings of the 19th Congress of the International Commission on Large Dams (ICOLD), Florence, Italy. ICOLD Press, Paris, France, vol. 4, pp. 233-245.

Diliūnas J, Dundulis K, Gadeikis S, Jurevičius A and Kaminskas M (2010) Geotechnical and hydrochemical properties of sewage sludge. Bulletin of Engineering Geology and the Environment 69(4): 575-582, https:// doi.org/10.1007/s10064-010-0279-X.

Disfani MM, Arulrajah A, Suthagaran V and Bo MW (2013) Long-term settlement prediction for wastewater biosolids in road embankments. Resources, Conservation and Recycling 77: 69-77, https://doi.org/10. 1016/j.resconrec.2013.05.009.

Disfani MM, Arulrajah A, Maghoolpilehrood F, Bo MW and Narsilio GA (2015) Geotechnical characteristics of stabilised aged biosolids. Environmental Geotechnics 2(5): 269-279, https://doi.org/10.1680/ envgeo.13.00054.

Hobbs NB (1986) Mire morphology and the properties and behaviour of some British and foreign peats. Quarterly Journal of Engineering Geology 19(1): 7-80, https://doi.org/10.1144/GSL.QJEG.1986.019.01.02.

Kavazanjian E Jr, Matasović N, Bonaparte R and Schmertmann GR (1995) Evaluation of MSW properties for seismic analysis. In Proceedings Geoenvironment 2000: Characterization, Containment, Remediation, and Performance in Environmental Geotechnics, New Orleans, Louisiana, USA (Acar YB and Daniel DE (eds)). American Society of Civil Engineers, Reston, VA, USA, GSP 46, vol. 2, pp. 1126-1141.

Kayser C (2012) The Geotechnical and Environmental Properties of Amended Biosolids. PhD thesis, University of Auckland, Auckland, New Zealand. See http://hdl.handle.net/2292/18902 (accessed 30/05/ 2018).

Kayser C, Larkin T and Singhal N (2011) Enhancement of the shear strength of wastewater residuals using industrial waste by-products. Environmental Engineering 137(11): 1002-1011, https://doi.org/10. 1061/(ASCE)EE.1943-7870.0000426.

Klein A and Sarsby RW (2000) Problems in defining the geotechnical behaviour of wastewater sludges. In Geotechnics of High Water Content Materials (Edil TB and Fox PJ (eds)). ASTM, West Conshohocken, PA, USA, ASTM STP1374, pp. 74-87.

Koenig A and Bari QH (2001) Vane shear strength of dewatered sludge from Hong Kong. Water Science and Technology 44(2-3): 389-397, https://doi.org/10.2166/wst.2001.0794.

Koenig A and Kay JN (1995) Geotechnical stability of dewatered wastewater sludges for landfills. Proceedings of the 68th Annual Conference of the Water Environment Federation, Miami Beach, FL, USA, pp. 213-223. 
Koenig A, Kay JN and Wan IM (1996) Physical properties of dewatered wastewater sludge for landfilling. Water Science and Technology 34(3-4): 533-540, https://doi.org/10.1016/0273-1223(96)00621-X.

Kulhawy FH and Mayne PW (1990) Manual on Estimating Soil Properties for Foundation Design. Electric Power Research Institute, Palo Alto, CA, USA, Report No. EL-6800. See https://www.epri.com/\#/pages/ product/EL-6800/ (accessed 21/02/2018).

Ladd CC and Foott R (1974) New design procedure for stability of soft clays. Journal of the Geotechnical Engineering Division, ASCE 100(7): 763-786.

Lin C, Zhu W and Han J (2013) Strength and leachability of solidified sewage sludge with different additives. Journal of Materials in Civil Engineering 25(11): 1594-1601, https://doi.org/10.1061/(ASCE)MT. 1943-5533.0000738.

Lin W, Zhan X, Zhan TL et al. (2014) Effect of $\mathrm{FeCl}_{3}$-conditioning on consolidation property of sewage sludge and vacuum preloading test with integrated PVDs at the Changan landfill, China. Geotextiles and Geomembranes 42(3): 181-190, https://doi.org/10.1016/j.geotexmem. 2013.12.008

Lo IMC, Zhou WW and Lee KM (2002) Geotechnical characterization of dewatered sewage sludge for landfill disposal. Canadian Geotechnical Journal 39(5): 1139-1149, https://doi.org/10.1139/t02-058.

Loll U (1991) Measurement of laboratory vane shear strength as community standard or reference method for testing the suitability of de-watered sludges for use as landfill. In Proceedings of the Symposium on Treatment and Use of Sewage Sludge and Liquid Agricultural Wastes, Athens, Greece (L'Hermite P (ed.)). Elsevier, London, UK, pp. 310-315.

Mesri G and Ajlouni M (2007) Engineering properties of fibrous peats. Geotechnical and Geoenvironmental Engineering 133(7): 850-866, https://doi.org/10.1061/(ASCE)1090-0241(2007)133:7(850).

Mesri G and Castro A (1987) $C_{\alpha} / C_{\mathrm{c}}$ concept and $K_{0}$ during secondary compression. Journal of Geotechnical Engineering 113(3): 230-247, https://doi.org/10.1061/(ASCE)0733-9410(1987)113:3(230).

Mesri G and Olson RE (1970) Shear strength of montmorillonite Géotechnique 20(3): 261-270, https://doi.org/10.1680/geot.1970.20.3. 261.

Mesri G and Olson RE (1971) Consolidation characteristics of montmorillonite. Géotechnique 21(4): 341-353, https://doi.org/10. 1680/geot.1971.21.4.341.

Metcalf \& Eddy, Inc. (2004) Wastewater Engineering: Treatment and Reuse, 4th edn. (Tchobanoglous G, Burton FL and Stensel HD (eds)). McGraw-Hill, New York, NY, USA.

Mitchell JK and Soga K (2005) Fundamentals of Soil Behavior. Wiley, New York, NY, USA.

Moo-Young HK and Zimmie TF (1996) Geotechnical properties of paper mill sludges for use in landfill covers. Journal of Geotechnical Engineering, ASCE 122(9): 768-775, https://doi.org/10.1061/(ASCE) 0733-9410(1996)122:9(768).

O'Kelly BC (1994) Mechanical Properties and Slope Stability of Dewatered Digested Sewage Sludge. MEngSc thesis, University College Dublin, Dublin, Ireland. See http://hdl.handle.net/2262/67065 (accessed 21/02/2018).

O'Kelly BC (2004) Geotechnical aspects of sewage sludge monofills. Proceedings of the Institution of Civil Engineers - Municipal Engineer 157(3): 193-197, https://doi.org/10.1680/muen.2004.157.3.193.

O'Kelly BC (2005a) Sewage sludge to landfill: some pertinent engineering properties. Journal of the Air and Waste Management Association 55(6): 765-771, https://doi.org/10.1080/10473289.2005.10464670.

O'Kelly BC (2005b) Mechanical properties of dewatered sewage sludge. Waste Management 25(1): 47-52, https://doi.org/10.1016/j.wasman. 2004.08.003.

O'Kelly BC (2005c) Consolidation properties of a dewatered municipal sewage sludge. Canadian Geotechnical Journal 42(5): 1350-1358, https://doi.org/10.1139/t05-054.
O'Kelly BC (2005d) New method to determine the true water content of organic soils. Geotechnical Testing Journal 28(4): 365-369, https:// doi.org/10.1520/GTJ11963.

O'Kelly BC (2006a) Geotechnical properties of municipal sewage sludge. Geotechnical and Geological Engineering 24(4): 833-850, https://doi. org/10.1007/s10706-005-6611-8.

O'Kelly BC (2006b) Compression and consolidation anisotropy of some soft soils. Geotechnical and Geological Engineering 24(6): 1715-1728, https://doi.org/10.1007/s10706-005-5760-0.

O'Kelly BC (2008a) Effect of biodegradation on the consolidation properties of a dewatered municipal sewage sludge. Waste Management 28(8): 1395-1405, https://doi.org/10.1016/j.wasman. 2007.08 .004

O'Kelly BC (2008b) Geotechnical properties of a municipal water treatment sludge incorporating a coagulant. Canadian Geotechnical Journal 45(5): 715-725, https://doi.org/10.1139/T07-109.

O'Kelly BC (2010) Landfill disposal of alum water treatment residues: some pertinent geoengineering properties. Journal of Residuals Science and Technology 7(2): 95-113.

O'Kelly BC (2013a) Discussion of 'Enhancement of the shear strength of wastewater residuals using industrial waste by-products'. Environmental Engineering 139(2): 312-315, https://doi.org/10.1061/ (ASCE)EE.1943-7870.0000608.

O'Kelly BC (2013b) Undrained shear strength-water content relationship for sewage sludge. Proceedings of the Institution of Civil Engineers Geotechnical Engineering 166(6): 576-588, https://doi.org/10.1680/ geng. 11.00016

O'Kelly BC (2014) Drying temperature and water content-strength correlations. Environmental Geotechnics 1(2): 81-95, https://doi.org/ 10.1680 /envgeo. 13.00016 .

O'Kelly BC (2015) Effective stress strength testing of peat. Environmental Geotechnics 2(1): 33-44, https://doi.org/10.1680/envgeo.13.00112.

O'Kelly BC (2016a) Assessing the shear strength of municipal sludges and residues for landfill disposal. In Proceedings of the $3 \mathrm{rd}$ Symposium on Urban Mining and Circular Economy, Bergamo, Italy (Cossu R, Lavagnolo MC and Mudhoo A (eds)). CISA, Padova, Italy (CD-ROM).

O'Kelly BC (2016b) Geotechnics of municipal sludges and residues for landfilling. Geotechnical Research 3(4): 148-179, https://doi.org/10. 1680/jgere.16.00013.

O'Kelly BC (2016c) Laboratory permeability determinations for biosolids. Environmental Geotechnics 3(3): 132-139, https://doi.org/10.1680/ jenge. 15.00026.

O'Kelly BC (2017) Measurement, interpretation and recommended use of laboratory strength properties of fibrous peat. Geotechnical Research 4(3): 136-171, https://doi.org/10.1680/jgere.17.00006.

O'Kelly BC (2018a) Biodegradation of biosolids and specific gravity determination. Environmental Geotechnics, https://doi.org/10.1680/ jenge. 16.00014.

O'Kelly BC (2018b) Fall-cone strength testing of municipal sludges and residues. Environmental Geotechnics 5(1): 18-30, https://doi.org//10 1680/jenge. 15.00080 .

O'Kelly BC (2018c) Geotechnical laboratory testing and data interpretation for biosolids and sewage sludge. Geotechnical Research, https://doi. org/10.1680/jgere.18.00009.

O'Kelly BC (2018d) Corrigendum: Biodegradation of biosolids and specific gravity determination. Environmental Geotechnics 5(1): 63, https://doi.org/10.1680/jenge.2018.5.1.63.

O'Kelly BC and Li W (2018) Comparing water contents of organic soil determined on the basis of different oven-drying temperatures. In Proceedings of the China-Europe Conference on Geotechnical Engineering, Vienna, Austria (Wu W and Yu H-S (eds)). Springer, Cham, Switzerland, vol. 1, pp. 586-590.

O'Kelly BC and Orr TLL (2014) Effective-stress strength of peat in triaxial compression. Proceedings of the Institution of Civil Engineers - 
Geotechnical properties of compacted biosolids for monofill design, As-Samra,

Jordan

'Kelly, Oettle and Ramos
Geotechnical Engineering 167(5): 417-420, https://doi.org/10.1680/ geng.13.00143.

O'Kelly BC and Pichan SP (2013) Effects of decomposition on the compressibility of fibrous peat - a review. Geomechanics and Geoengineering 8(4): 286-296, https://doi.org/10.1080/17486025. 2013.804210 .

O'Kelly BC and Pichan SP (2014) Effect of decomposition on physical properties of fibrous peat. Environmental Geotechnics 1(1): 22-32, https://doi.org/10.1680/envgeo.13.00012.

O'Kelly BC and Quille ME (2009) Compressibility and consolidation of water treatment residues. Proceedings of the Institution of Civil Engineers - Waste and Resource Management 162(2): 85-97, https:// doi.org/10.1680/warm.2009.162.2.85.

O'Kelly BC and Sivakumar V (2014) Water content determinations for peat and other organic soils using the oven-drying method. Drying Technology 32(6): 631-643, https://doi.org/10.1080/07373937.2013. 849728.

Pichan SP and O'Kelly BC (2012) Effect of decomposition on the compressibility of fibrous peat. In Proceedings GeoCongress 2012: State of the Art and Practice in Geotechnical Engineering (Hryciw RD, Athanasopoulos-Zekkos A and Yesiller N (eds)). ASCE, Reston, VA, USA, GSP 225, pp. 4329-4338.

Pichan SP and O'Kelly BC (2013) Stimulated decomposition in peat for engineering applications. Proceedings of the Institution of Civil Engineers - Ground Improvement 166(3): 168-176, https://doi.org/10. 1680/grim.12.00003.

Sarsby RW (2005) Geotechnical properties of sewage sludge. In Proceedings of the 16th International Conference on Soil Mechanics and Geotechnical Engineering, Osaka, Japan (Organizing Committee of the 16th International Conference on Soil Mechanics and Geotechnical Engineering (ed.)). Millpress Science, vol. 4, pp. 2327-2329.

Sorensen KK and Okkels N (2013) Correlation between drained shear strength and plasticity index of undisturbed overconsolidated clays. In Proceedings of the 18th International Conference on Soil Mechanics and Geotechnical Engineering, Paris, France (Delage P, Desrues J, Frank R, Puech A and Schlosser F (eds)). Presses des Pont, Paris, France, vol. 1, pp. 423-428

Stone RJ, Ekwue El and Clarke RO (1998) Engineering properties of sewage sludge in Trinidad. Agricultural and Engineering Research 70(2): 221-230, https://doi.org/10.1006/jaer.1998.0266.

Taylor DW (1942) Research on Consolidation of Clays. Department of Civil and Sanitary Engineering, Massachusetts Institute of Technology, Cambridge, MA, USA, Serial 82.

Ukwatta A, Mohajerani A, Eshtiaghi N and Setunge S (2016) Variation in physical and mechanical properties of fired-clay bricks incorporating ETP biosolids. Journal of Cleaner Production 119: 76-85, https://doi. org/10.1016/j.jclepro.2016.01.094.

USEPA (US Environmental Protection Agency) (2001) Method 1684: Total, fixed, and volatile solids in water, solids, and biosolids. USEPA, Washington, DC, USA, EPA-821-R-01-015.

Wan LM (1998) Physical Characterization of Dewatered Sewage Sludge for Landfilling. MPhil thesis, University of Hong Kong, Hong Kong, China. See http://hdl.handle.net/10722/33429 (accessed 01/06/2018).

Zhan TL, Zhan Z, Lin W, Luo X and Chen Y (2014) Field and laboratory investigation on geotechnical properties of sewage sludge disposed in a pit at Changan landfill, Chengdu, China. Engineering Geology 170: 24-32, https://doi.org/10.1016/j.enggeo.2013.12.006.

\section{How can you contribute?}

To discuss this paper, please submit up to 500 words to the editor at journals@ice.org.uk. Your contribution will be forwarded to the author(s) for a reply and, if considered appropriate by the editorial board, it will be published as a discussion in a future issue of the journal. 